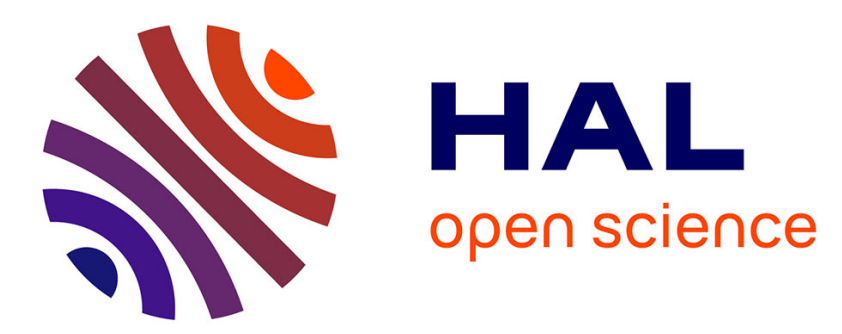

\title{
Bicyclic 5-6 Systems with One Bridgehead (Ring Junction) Nitrogen Atom: Four Extra Heteroatoms 2:2
}

\author{
Aurélie Claraz
}

\section{To cite this version:}

Aurélie Claraz. Bicyclic 5-6 Systems with One Bridgehead (Ring Junction) Nitrogen Atom: Four Extra Heteroatoms 2:2. Comprehensive Heterocyclic Chemistry IV, 11, Elsevier, pp.802-858, 2022, 10.1016/B978-0-12-818655-8.00086-X . hal-03452150

\section{HAL Id: hal-03452150 \\ https://hal.science/hal-03452150}

Submitted on 26 Nov 2021

HAL is a multi-disciplinary open access archive for the deposit and dissemination of scientific research documents, whether they are published or not. The documents may come from teaching and research institutions in France or abroad, or from public or private research centers.
L'archive ouverte pluridisciplinaire HAL, est destinée au dépôt et à la diffusion de documents scientifiques de niveau recherche, publiés ou non, émanant des établissements d'enseignement et de recherche français ou étrangers, des laboratoires publics ou privés. 


\section{Comprehensive Heterocyclic Chemistry IV}

Bicyclic 5-6 Systems with One Bridgehead (Ring Junction) Nitrogen Atom: Four Extra Heteroatoms 2:2

\section{Author Contact Information}

Aurélie Claraz

Institut de Chimie des Substances Naturelles, CNRS UPR 2301, Université Paris-Sud, Université ParisSaclay, 1, av. de la Terrasse, Gif-sur-Yvette 91198 Cedex, France.

aurelie.claraz@cnrs.fr

+33169823084

\section{Abstract}

Bicyclic 5-6 systems with one ring junction nitrogen atom and two extra heteroatoms (nitrogen, sulfur and oxygen) in both cycles are reviewed in this chapter. Literature data from 2007 to 2019 are considered. Among all the possible ring systems, 18 different structural backbones have been found in this period covering various triazolothiadiazines, oxadiazolotriazines, thiadiazolotriazines, and triazolotriazines derivatives. Fully as long as partially unsaturated regioisomers are examined. Most references deal with $[1,2,4]$ triazolo[3,4-b][1,3,4]thiadiazines. Theoretical methods, structural determinations and thermodynamic properties of the aforementioned ring systems are briefly discussed while their reactivity and syntheses are detailed. Notable applications of important compounds are also listed.

\section{Keywords}

triazolothiadiazine; oxadiazolotriazine; thiadiazolotriazine; triazolotriazine; cyclization; cyclocondensation; Dimroth rearrangement.

\section{Nomenclature}

$\begin{array}{ll}\mathrm{Ac} & \text { Acetyl group } \\ \mathrm{Ac}_{2} \mathrm{O} & \text { Acetic anhydride } \\ \mathrm{AcOH} & \text { Acetic acid } \\ \mathrm{AcONa} & \text { Sodium acetate } \\ \mathrm{Alk} & \text { Alkyl group } \\ \mathrm{Ar} & \text { Aryl group } \\ \mathrm{Bn} & \text { Benzyl group } \\ \mathrm{Bu} & \text { Butyl group } \\ \mathrm{BSA} & N, O \text {-bis-(trimethylsilyl)acetamide } \\ \mathrm{Boc} & \text { tert-butyloxycarbonyl } \\ \mathrm{CHEC} & \text { Comprehensive heterocyclic chemistry } \\ \mathrm{Cy} & \text { Cyclohexyl group } \\ \mathrm{D} & \text { Debye } \\ \mathrm{DABCO} & 1,4 \text {-diazabicyclo[2.2.2]octane } \\ \mathrm{DCC} & N, N \text {-Dicyclohexylcarbodiimide } \\ \mathrm{DCE} & 1,2 \text {-Dichloroethane } \\ \mathrm{DCM} & \text { Dichloromethane } \\ \mathrm{DDQ} & 2,3 \text {-dichloro-5,6-dicyano-1,4-benzoquinone }\end{array}$




\begin{tabular}{|c|c|}
\hline DFT & Density functional theory \\
\hline DIPEA & $N, N$-Diisopropylethylamine \\
\hline DMF & Dimethylformamide \\
\hline DMSO & Dimethyl sulfoxide \\
\hline DTG & Differential Thermogravimetric \\
\hline $\mathrm{EDCl}$ & 1-Ethyl-3-(3-dimethylaminopropyl)carbodiimide \\
\hline ESI & Electrospray ionization \\
\hline Et & Ethyl group \\
\hline $\mathrm{Et}_{3} \mathrm{~N}$ & Triethylamine \\
\hline EtOH & Ethanol \\
\hline eV & Electron Volt \\
\hline HMDSO & Hexamethyldisiloxane \\
\hline HOMO & Highest Occupied Molecular Orbital \\
\hline$i-\operatorname{Pr}$ & Iso-Propyl group \\
\hline LUMO & Lowest Unoccupied Molecular Orbital \\
\hline Me & Methyl group \\
\hline $\mathrm{MeOH}$ & Methanol \\
\hline MS & Mass spectra \\
\hline MW & Microwave \\
\hline NBS & $N$-Bromosuccinimide \\
\hline NMR & Nuclear Magnetic Resonance \\
\hline $\mathrm{Ph}$ & Phenyl group \\
\hline PIDA & Phenyliodine(III) diacetate \\
\hline $\mathrm{PivOH}$ & Pivalic acid \\
\hline PPA & Polyphosphoric acid \\
\hline $\operatorname{Pr}$ & Propyl group \\
\hline PTSA & para-Toluenesulfonic acid \\
\hline Py & Pyridine \\
\hline QSAR & Quantitative Structural Activity Relationship \\
\hline $\mathrm{S}_{\mathrm{N}} \mathrm{Ar}$ & Aromatic nucleophilic substitution \\
\hline STAT & Signal Transducer and Activator of Transcription \\
\hline$t-\mathrm{Bu}$ & tert-Butyl group \\
\hline TBAB & Tetrabutyl ammonium bromide \\
\hline TD-DFT & Time dependent density functional theory \\
\hline TFA & Trifluroroacetic acid \\
\hline THF & Tetrahydrofuran \\
\hline TMSOTf & Trimethylsilyl trifluoromethanesulfonate \\
\hline UDP & Uridine diphosphate \\
\hline
\end{tabular}




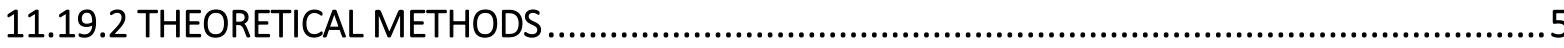

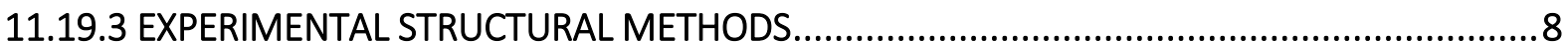

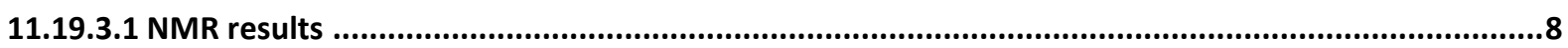

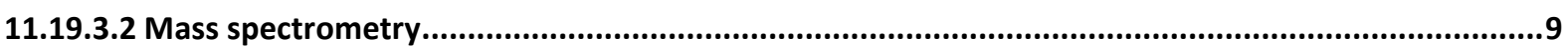

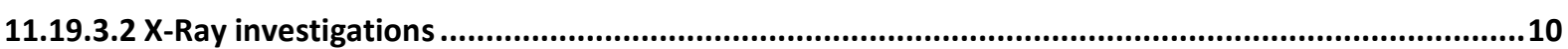

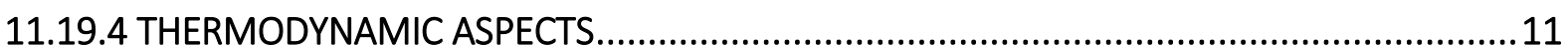

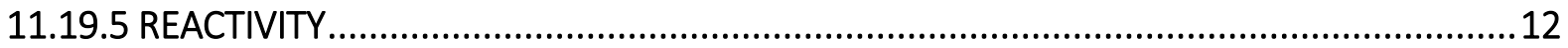

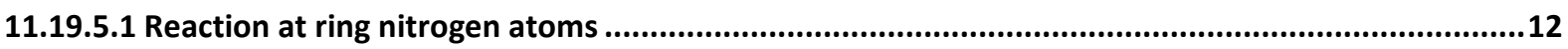

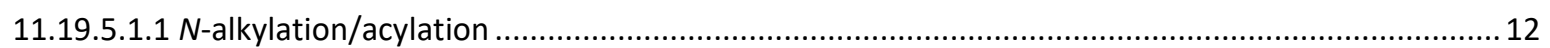

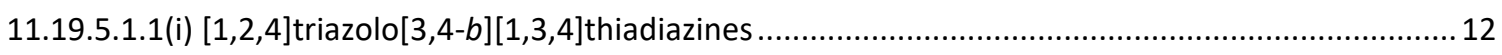

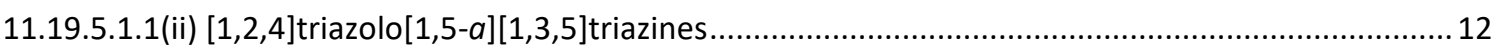

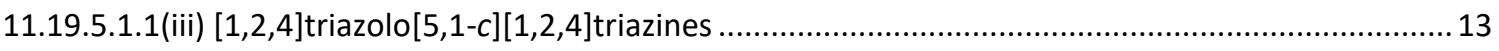

11.19.5.1.2 Construction of a new fused-ring with one bridgehead nitrogen atom ................................. 15

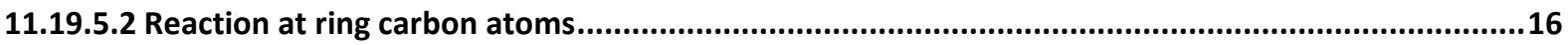

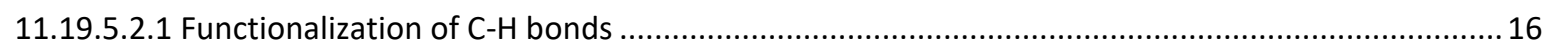

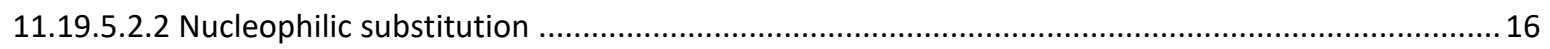

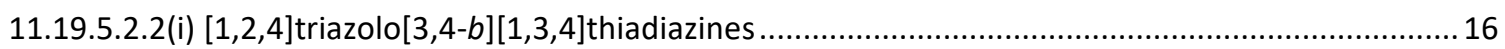

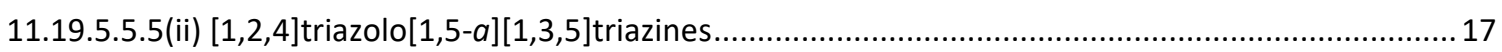

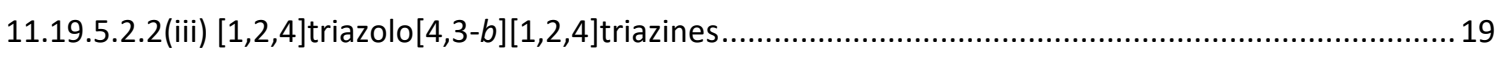

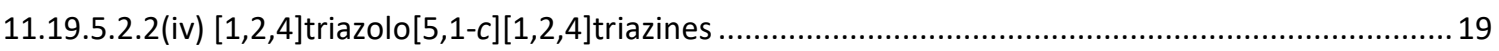

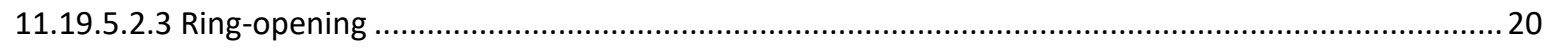

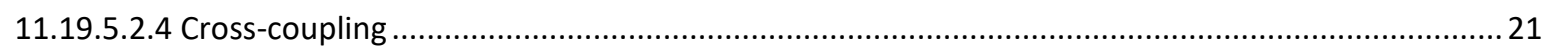

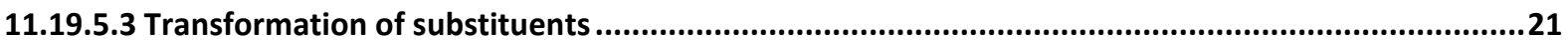

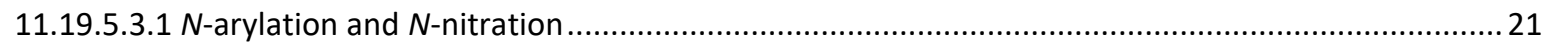

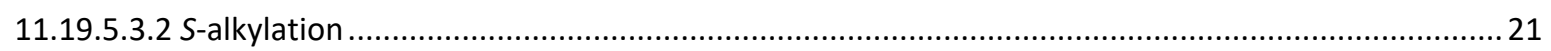

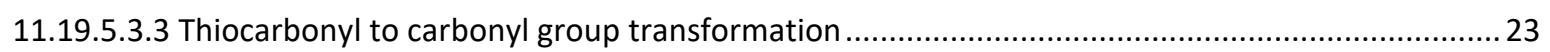

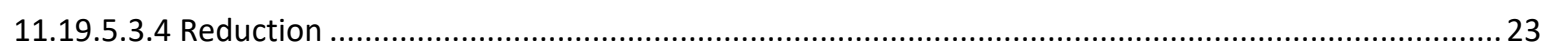

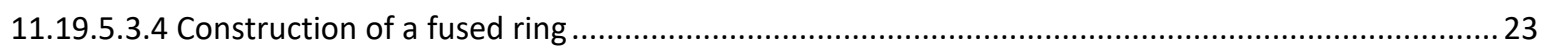

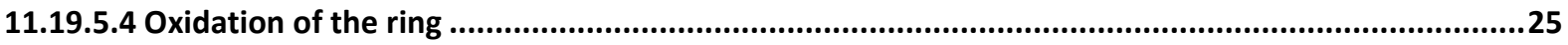

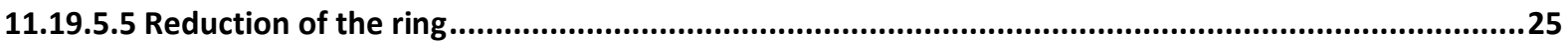

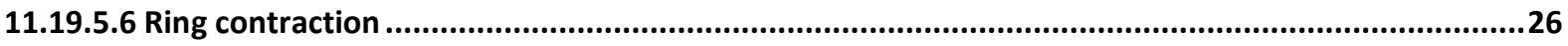

\subsubsection{RING SYNTHESIS THROUGH CYCLIZATION OR CYCLOCONDENSATION OF A}

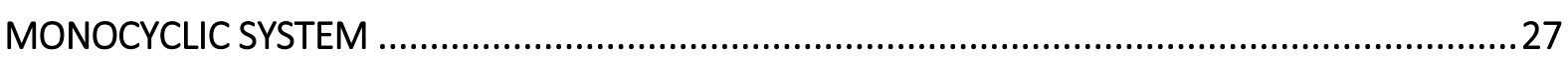

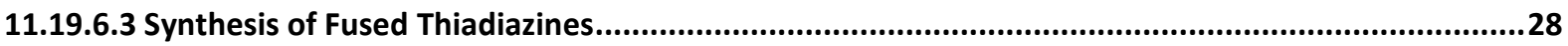

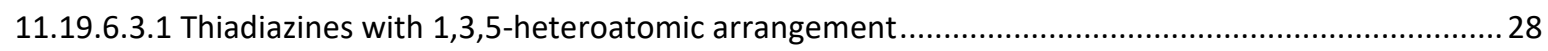

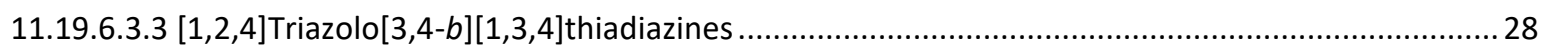

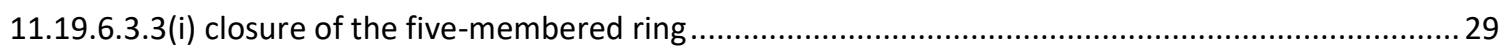

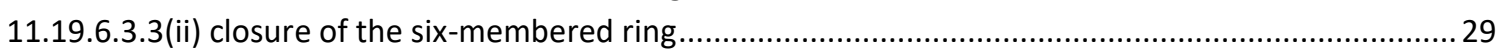


11.19.6.3.3(ii)(a) synthesis from 4-amino-4H-1,2,4-triazole-3-thiol derivatives .................................. 29

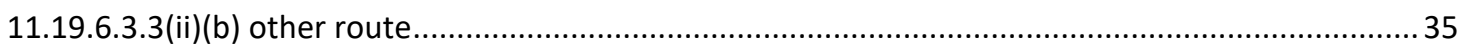

11.19.6.3.3(iii) construction of both rings (closure of the six-membered ring at the last step) ..................36

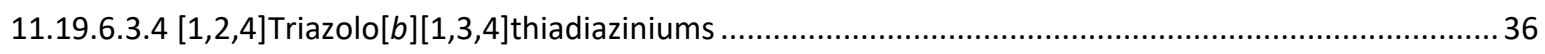

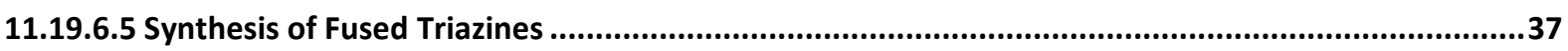

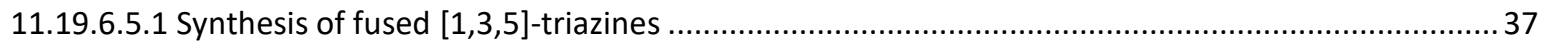

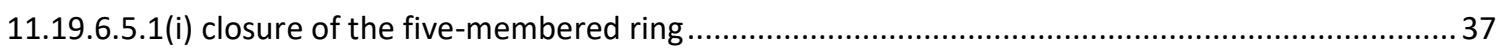

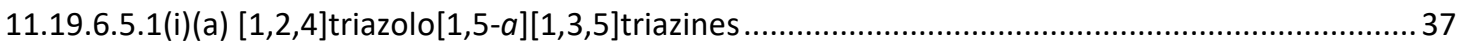

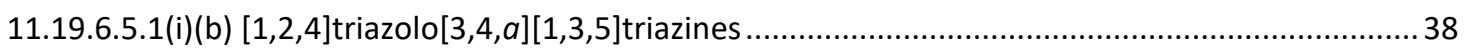

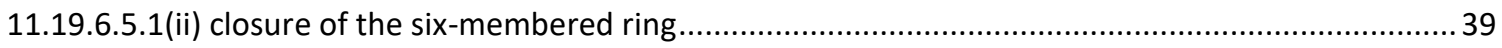

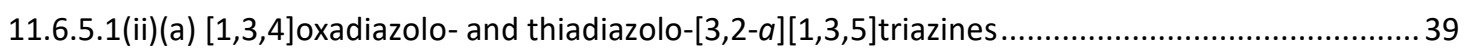

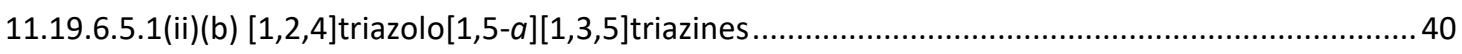

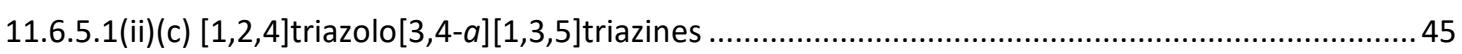

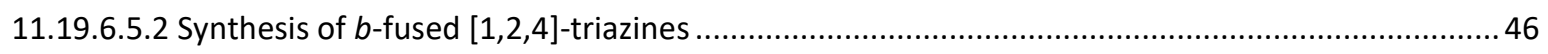

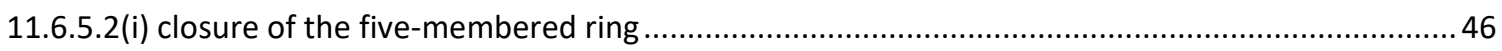

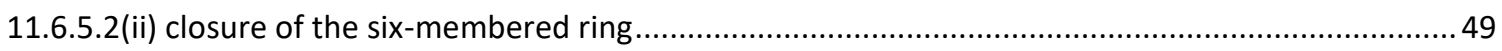

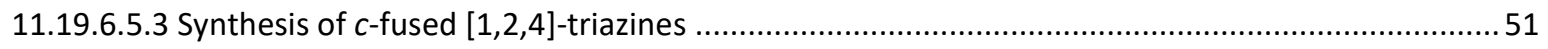

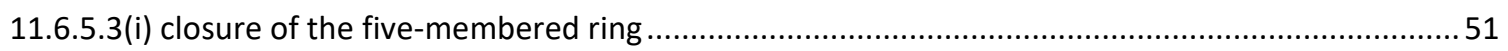

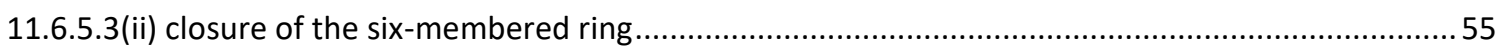

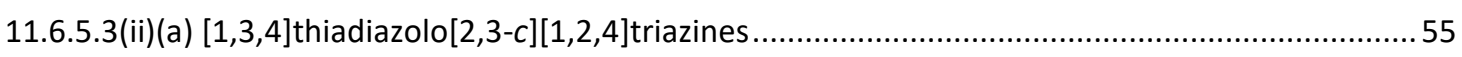

11.6.5.3(ii)(b) $[1,2,4]$ triazolo[5,1-c] $[1,2,4]$ triazines and $[1,2,3]$ triazolo[5,1-c] $[1,2,4]$ triazines ...............55

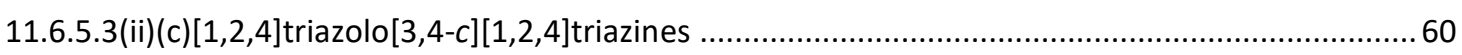

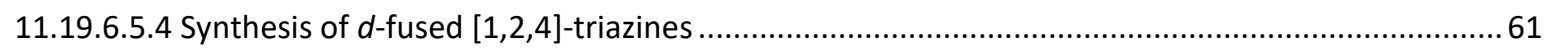

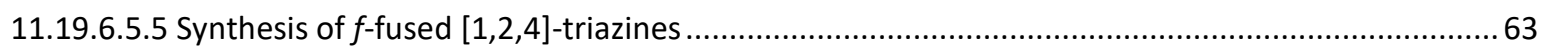

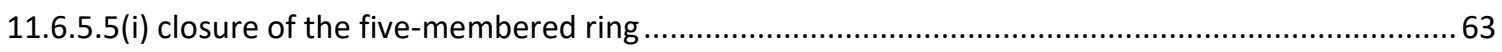

11.6.5.5(ii) construction of both rings (closure of the six-membered ring at the last step) ......................64

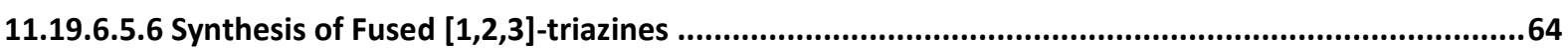

11.19.7 RING SYNTHESIS BY TRANSFORMATIONS OF ANOTHER BICYCLIC SYSTEM ...................65

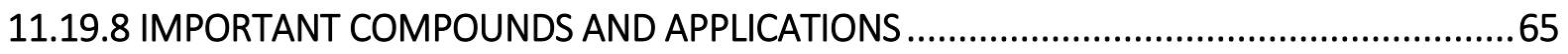

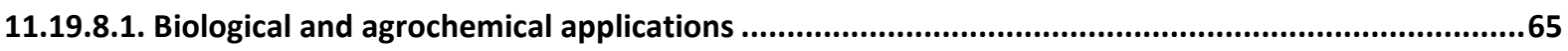

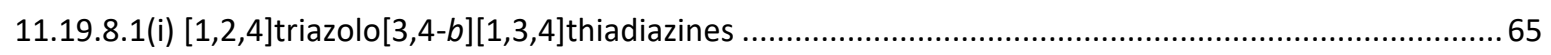

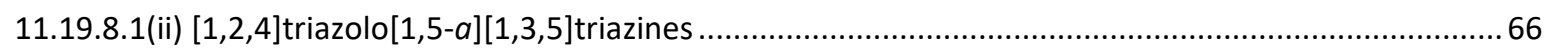

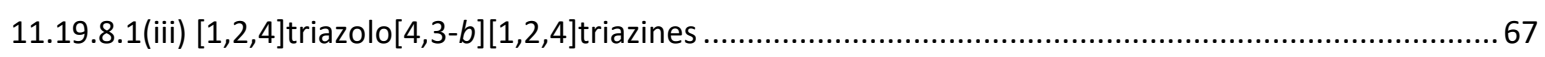

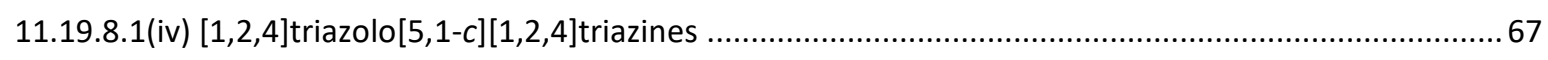

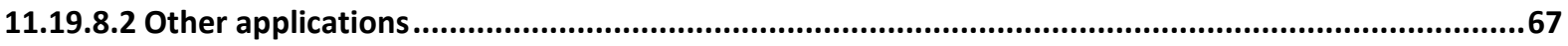

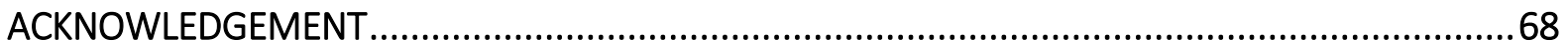

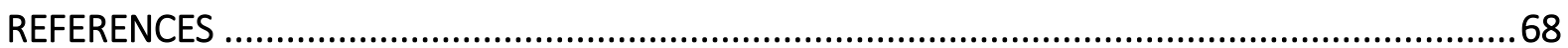




\subsubsection{Introduction}

This chapter focuses on the bicyclic 5-6 systems with one ring junction nitrogen atom and four extra heteroatoms in a 2:2 distribution over both rings. These systems have been previously reviewed in CHEC-II(1996) and CHEC-III(2008). ${ }^{1-2}$ Herein, literature between 2007-2019 is covered. Among all the possible ring systems, 18 different structural backbones have been reported during this period. They correspond to various triazolothiadiazines 1-4, oxadiazolotriazines 5, thiadiazolotriazines 6-7, and triazolotriazines 8-18. Consequently, the additional heteroatoms are nitrogen, sulfur and oxygen (Figure 1). <Figure 1 near here>

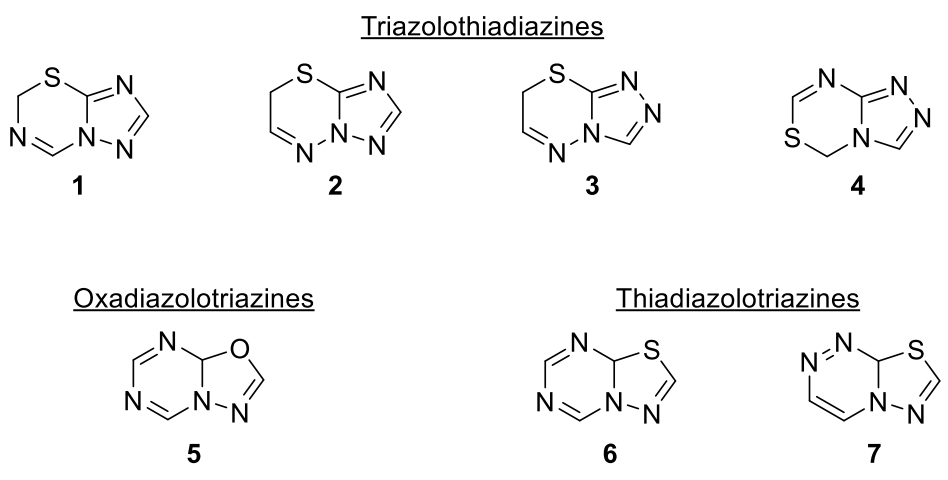

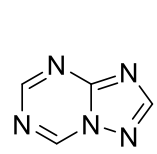

8

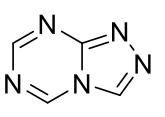

9

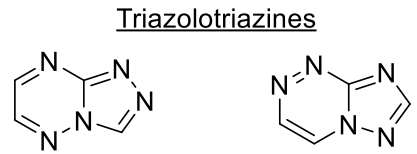

10<smiles>c1cn2cnnc2nn1</smiles>

12<smiles>c1cn2nncc2nn1</smiles>

13

$$
\begin{aligned}
& \begin{array}{l}
\mathrm{N}_{1} \sim \mathrm{N}=\mathrm{N}^{\mathrm{N}} \\
\mathrm{N}
\end{array} \\
& 14
\end{aligned}
$$
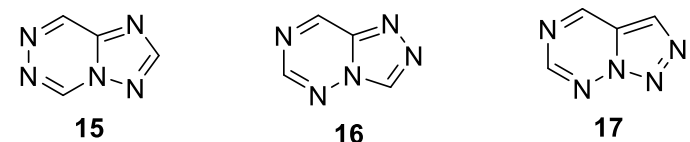

Figure 1

Fully as long as partially unsaturated systems are examined. Most references are devoted to $[1,2,4]$ triazolo[3,4- $b][1,3,4]$ thiadiazines 3 . Other important compounds are $[1,2,4]$ triazolo[1,5$a][1,3,5]$ triazines 8, [1,2,4]triazolo[4,3-b][1,2,4]triazines 10 and [1,2,4]triazolo[5,1-c][1,2,4]triazines 11. Other structures were discussed in CHEC-III(2008) but no new related references have appeared

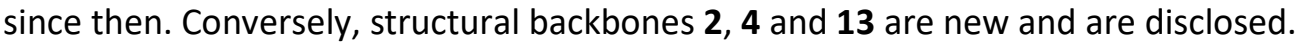

\subsubsection{Theoretical Methods}

In the course of the synthesis of $[1,2,4]$ triazolo[ $[1,2,4]$ triazines, the formation of $[1,2,4]$ triazolo[ $[1,5$ d] $[1,2,4]$ triazine 19 instead of expected $[1,2,4]$ triazolo[4,3-d][1, 2,4]triazine 20 (see section 11.19.6.5.4) was rationalized by DFT calculations using Gaussian 09 suit of programs $(6-311+G(2 d, p)$ 41WB97XD and 6-311+G(2d,p) WB97XD basis). The data confirmed that product 19 (arising from a Dimroth rearrangement) was thermodynamically more stable than 20 (Figure 2 ). ${ }^{3}<$ Figure 2 near here>. 


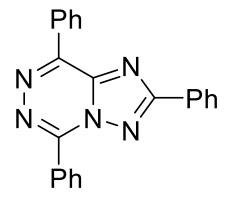

19<smiles>c1ccc(-c2nnc(-c3ccccc3)n3c(-c4ccccc4)nnc23)cc1</smiles>

20

Figure 2

The anion 21 of 5-amino-substituted [1,2,4]triazolo[1,5-a][1,3,5]triazin-7(3H)-one possesses five resonance structures allowing the alkylation with ethyl bromide to potentially take place at five reactive sites. The activation energy values for the ethylation of the less hindered positions (i.e. N3, $\mathrm{N} 1$ and $\mathrm{O}$ atoms) were calculated using the B3LYP/6-311++G(d,p) method. The lowest activation energy was found at the $\mathrm{N} 3$ atom but the difference with the $O$-alkylation was very small (only 1.1 $\mathrm{kJ} \cdot \mathrm{mol}^{-1}$ ). From a thermodynamic point of view, the energy of the N3-ethyl product was by far the lowest. The experimental result confirmed this computational study and only 3-ethyl$[1,2,4]$ triazolo[1,5-a][1,3,5]triazin-7(3H)-one 22 was isolated (see section 11.19.5.1.1) (Scheme 1). ${ }^{4}$ $<$ Scheme 1 near here>

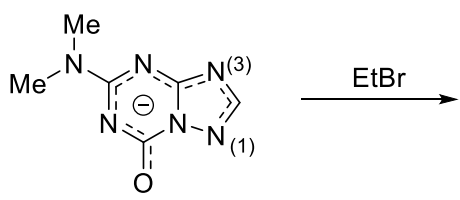

21<smiles>CCn1cnn2c(=O)nc(N(C)C)nc12</smiles>

22

Scheme 1

Theoritical $\log \mathrm{P}$, dipole moments and energies of the highest occupied and lowest unoccupied molecular orbitales (HOMO and LUMO) of various benzo[e][1,2,4]triazolo[3,4-c][1,2,4]triazines 23-25 were determined by quantum chemical calculations (Table 1, entries 1-3). ${ }^{5}$ Dipole moments and orbital energies have been also calculated for fused heterocyclic compounds 26-29. Experimental values of the LUMOs energies were determined after measurement of the redox potentials and were slightly higher than the calculated ones. In $\mathbf{2 8}$, the two nitrogen atoms lowered the LUMO energy by $0.24 \mathrm{eV}$ compared to 27 and 29. These results suggested that the presence of heteroatoms affected more the LUMOs energies than the extension of the conjugation. Such low LUMO value augured a potential use of $\mathbf{2 8}$ as a n-type active molecules for organic transistors and organic photovoltaics (Table 1, entries 4-7). ${ }^{6}$ With the aim to establish quantitative structure activity relationship (QSAR) for antifungal activities of $[1,2,4]$ triazolo[3,4-b][1,3,4]thiadiazines 30-31, log $P$ and polarizabilities were calculated (Table 1 , entries 8-9). ${ }^{7}<$ Table 1 near here> 
Table 1: Calculated log P, dipole moments, polarizabilities and HOMO/LUMO energies for various heterocycles

\begin{tabular}{|c|c|c|c|c|c|c|c|}
\hline Entry & Compound & $\log P$ & $\mu(D)$ & Pol. ${ }^{a}\left(\AA^{3}\right)$ & $\begin{array}{c}\text { HOMO } \\
(\mathrm{eV})\end{array}$ & $\begin{array}{c}\text { LUMO }^{\mathrm{b}} \\
(\mathrm{eV})\end{array}$ & Ref. \\
\hline 1 & & 1.34 & 7.517 & - & -7.511 & 4.018 & 5 \\
\hline 2 & & 1.11 & 5.784 & - & -7.793 & 3.666 & 5 \\
\hline 3 & & 2.91 & 7.19 & - & -7.169 & 3.919 & 5 \\
\hline 4 & & - & 11.2 & - & -6.32 & $\begin{array}{c}-3.12 \\
(-3.59)\end{array}$ & 6 \\
\hline 5 & & - & 10.1 & - & -6.10 & $\begin{array}{c}-3.38 \\
(-3.71)\end{array}$ & 6 \\
\hline 6 & & - & 5.8 & - & - & $\begin{array}{c}-3.56 \\
(-3.95)\end{array}$ & 6 \\
\hline 7 & & - & 10.2 & - & -6.05 & $\begin{array}{c}-3.38 \\
(-3.77)\end{array}$ & 6 \\
\hline 8 & & 2.64 & - & 42.56 & - & - & 7 \\
\hline 9 & & 0.96 & - & 33.68 & - & - & 7 \\
\hline
\end{tabular}

a Polarizability. ${ }^{b}$ Experimental values (based on measured redox potentials) are reported between brackets. 
Time-dependent density functional theory (TD-DFT) has been used to examine the relationship between molecular structure and the one- and two photon absorption properties of conjugated energetic molecules 4-amino-3,7-dinitro-[1,2,4]triazolo[5,1-c][1,2,4]triazine derivatives. Such study dealt with physical chemistry and will not be detailed in this chapter. ${ }^{8-9}$

\subsubsection{Experimental Structural Methods}

\subsubsection{NMR results}

${ }^{1} \mathrm{H}$ and ${ }^{13} \mathrm{C}$ NMR data for new compounds have been routinely reported. ${ }^{13} \mathrm{C}$ and ${ }^{15} \mathrm{~N}$ NMR spectra of isotopes $\left[{ }^{15} \mathrm{~N},{ }^{2} \mathrm{H}\right]$-containing bicycle 32 have been thoroughly analyzed (Table 2 ). ${ }^{10}<$ Table 2 near here>

Table 2: ${ }^{13} \mathrm{C}$ and ${ }^{15} \mathrm{~N}$ NMR data of compound 32 in DMSO- $d_{6}$

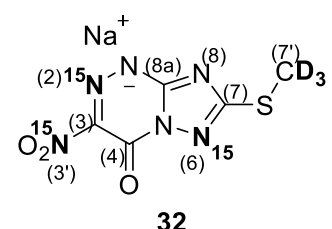

\begin{tabular}{ccc} 
& 32 \\
\hline Atom & $\delta(\mathrm{ppm})$ & $J(\mathrm{~Hz})$ \\
\hline $\mathrm{C}\left(7^{\prime}\right)$ & 13.4 & ${ }^{1} J_{\mathrm{C}, \mathrm{D}}=21$ \\
$\mathrm{C}(7)$ & 166.3 & ${ }^{2} J_{C, N(5)}=5.1 ;{ }^{3} J_{\mathrm{C}, \mathrm{D}}=0.7$ \\
$\mathrm{C}(8 \mathrm{a})$ & 160.7 & ${ }^{2} J_{C, N(2)}=2.1 ;{ }^{2} J_{C, N(5)}=0.4$ \\
$\mathrm{C}(3)$ & 145.15 & ${ }^{1} J_{C, N(2)}=1.8 ;{ }^{1} J_{C, N\left(3^{\prime}\right)}=23.4 ;{ }^{1} J_{C, N\left(3^{\prime}\right)}=23.4 ;{ }^{3} J_{C, N(1)}=1.4$ \\
$\mathrm{C}(4)$ & 143.4 & ${ }^{2} J_{C, N(2)}=1.3 ;{ }^{2} J_{C, N\left(3^{\prime}\right)}=5.3 ;{ }^{2} J_{C, N(5)}=3.3$ \\
$N(6)$ & 259.9 & - \\
$N(2)$ & 397.2 & ${ }^{2} J_{N(2), N\left(3^{\prime}\right)}=6.3$ \\
$N\left(3^{\prime}\right)$ & 368.4 & ${ }^{2} J_{N(2), N\left(3^{\prime}\right)}=6.3$ \\
\hline
\end{tabular}

The ${ }^{19} \mathrm{~F}$ NMR data of newly synthesized 3-fluoro[1,2,4]triazolo[5,1-c][1,2,4]triazin-4(1H)-one derivatives $\mathbf{3 3}$ have been reported. A significant downfield shift has been noticed for $\mathbf{3 3}$ (from -114 to $-115 \mathrm{ppm}$ ) compared to triazolopyrimidinones 34 (from -169 to $-171 \mathrm{ppm}$ ) which has been rationalized by the electron-withdrawing effect of the triazine nitrogen atom N2 (Figure 3). ${ }^{11}<$ Figure 3 near here> 
<smiles>O=c1c(F)n[nH]c2ncnn12</smiles>

${ }^{19} \mathrm{~F} \mathrm{NMR}\left(\mathrm{CDCl}_{3}\right): \delta-115.66 \mathrm{ppm}$<smiles>Cc1nc2[nH]nc(F)c(=O)n2n1</smiles>

${ }^{19} \mathrm{~F} \mathrm{NMR}\left(\mathrm{CDCl}_{3}\right): \delta-114.98 \mathrm{ppm}$<smiles>Cc1nc2[nH]nc(F)c(=O)n2n1</smiles>

${ }^{19} \mathrm{~F} \mathrm{NMR}\left(\mathrm{CDCl}_{3}\right): \delta-114.32 \mathrm{ppm}$<smiles>[R]c1nc2[nH]cc(F)c(=O)n2n1</smiles>

Figure 3

\subsubsection{Mass spectrometry}

Mass spectrometry has been routinely used for the characterization of new compounds through measurement of molecular ions. In some cases, more detailed fragmentations patterns have been analyzed. In a study on 2,6-disubstituted-6,7-dihydro-5H-1,2,4-triazolo[3,2-b]-1,3,5-thiadiazines (cf. Section 11.19.6.3.1), the analyses of the ESI-MS spectra have revealed a common fragmentation pattern. A representative example is depicted in scheme 2 for ion 35 . The loss of the substituent at the $\mathrm{C} 2$ position led to triazacyclobutadiene $\mathbf{3 6}$ which undergo elimination of sulfur to produce bicyclic 5-4 fragment 37. The cleavage of the $\mathrm{C}-\mathrm{N}$ bond at $\mathrm{N} 6$ position could be also clearly identified. $.^{12}<$ Scheme 2 near here $>$.<smiles>CC(C)Cc1nc2n(n1)CN(Cc1ccccc1)CS2</smiles>

35

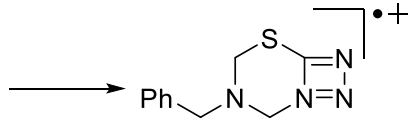

36<smiles>C[CH+]C1C2CN(Cc3ccccc3)CN1N2</smiles>

37

Scheme 2

Elimination of sulphur from the thiadiazine ring has been also observed for $7 \mathrm{H}$-[1,2,4]triazolo[3,4$b][1,3,4]$ thiadiazine derivative 38 leading to fragment $\mathbf{3 9}$. Fragmentation of the thiadiazine ring from molecular ion $\mathbf{3 8}$ gave also rise to thiazetine $\mathbf{4 0}$ and thiaziridine $\mathbf{4 1}$. The loss of benzonitrile $\mathbf{4 2}$ was characteristic of the 3-aryl-1,2,4-triazole moiety (Scheme 3). ${ }^{13}<$ Scheme 3 near here $>$

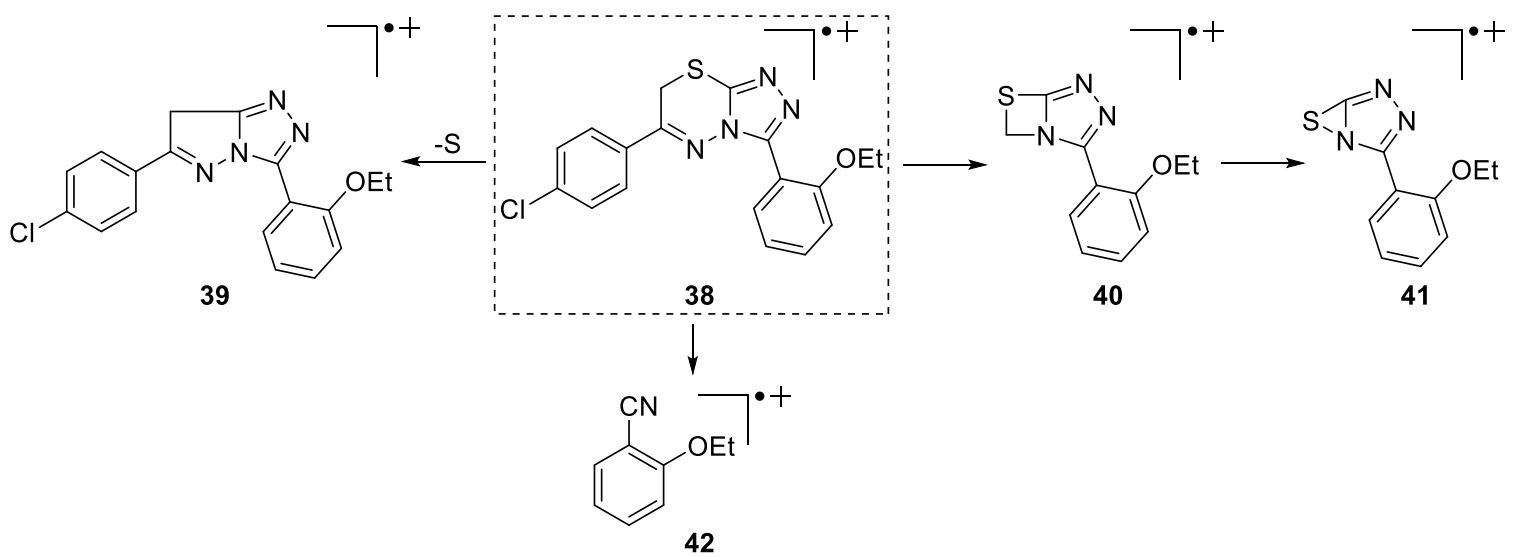

Scheme 3 


\subsubsection{X-Ray investigations}

The crystal structures of two $[1,3,4]$ triazolo[b][1,3,4]-thiadiazinium bromide salts $\mathbf{4 3}$ and $\mathbf{4 4}$ (cf. Section 11.19.6.3.4) were determined by Laus et al. (Figure 4). In the case of $\mathbf{4 3}$, the data were solved and refined in the monoclinic space group $P 2_{1} / n$. Numerous $\mathrm{C}-\mathrm{H} \cdots \mathrm{Br}$ contacts have been detected forming a three-dimensional network. For compound $\mathbf{4 4}$, the data were solved and refined in the monoclinic space group $P 2_{1} / c$. Three $\mathrm{CH}$... Br interactions allowed the bromide anions to link the cations into cyclic dimers. ${ }^{14}<$ Figure 4 near here $>$

$$
\begin{aligned}
& \text { 43: } \mathrm{X}=\mathrm{N}, \mathrm{Y}=\mathrm{CH}, 1 / 2 \mathrm{EtOH} \\
& \text { 44: } \mathrm{X}=\mathrm{CH}, \mathrm{Y}=\mathrm{N}
\end{aligned}
$$

Figure 4

For biological applications, many derivatives of bicyclic systems of this chapter have been designed and the structures of the newly synthesized compounds were confirmed by single crystal X-ray crystallography. Some examples are depicted in figure $5 .{ }^{15-16}$ Such analyses were very useful to establish the conformation of the molecules in the solid states. For triazolothiadiazine $\mathbf{4 7}$ the sixmembered thiadiazine ring is distorted from planarity and the two phenyl substituents are located nearly perpendicular to each other. ${ }^{17}$ The distortion of the thiadiazine ring has been also observed for compound $\mathbf{4 8}$ and $\mathbf{4 9}$. For the latter, the dihedral angle between the bicyclic system and the 2,4dichlorophenyl substituent is $50.74^{\circ} .{ }^{18-19}<$ Figure 5 near here><smiles>Brc1nc2n(n1)CC(c1ccc3ccccc3c1)=NN2</smiles>

45<smiles>Oc1ccc(-c2nnc3n2N=C(C(F)(F)F)CS3)cc1</smiles>

46<smiles>COc1cc(Cc2nnc3n2N=C(c2ccccc2)CS3)cc(OC)c1OC</smiles>

47<smiles>COc1ccc(CCc2nnc3n2N=C(c2ccccc2)CS3)cc1</smiles><smiles>COc1ccc2cc(C(C)c3nnc4n3N=C(c3ccc(Cl)cc3Cl)CS4)ccc2c1</smiles>

Figure 5

The distinction between regioisomer of heterocyclic compounds could not always be performed via NMR methods even with conventional ${ }^{1} \mathrm{H}-{ }^{1} \mathrm{H}$ and ${ }^{1} \mathrm{H}-{ }^{13} \mathrm{C}$ NMR correlation experiments or nuclear Overhauser effect (NOE) spectroscopy. As such, X-Ray analyses have been often used to ascertain the structure of products from reactions with multiple possible reaction sites or involving putative rearrangements. For instance, the structure of $[1,2,4]$ triazoloo[1,5- $d][1,2,4]$ triazine $\mathbf{5 0}$ was determined by X-Ray analysis. It was crucial to reveal that the product was not the $[1,2,4]$ triazolo $[4,3-d][1,2,4]$ triazine derivative and that the reaction probably involved a Dimroth 
rearrangement (cf. Section 11.19.6.5.4) (Figure 6). ${ }^{3}$ In the following sections (11.19.5; 11.19.6; 11.19.7), a precision will be added when the structure of the products has been certified by X-Ray analyses. <Figure 6 near here>

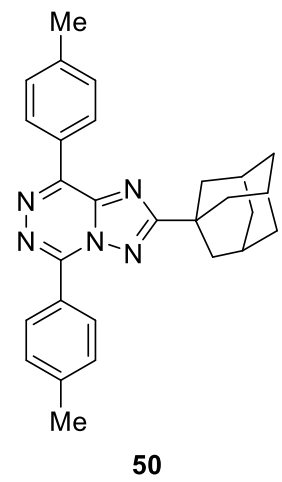

Figure 6

\subsubsection{Thermodynamic aspects}

The coordination of bicyclic fused ring system 3-benzyl-7-hydrazinyl-4H-[1,3,4]thiadiazolo[2,3c] $[1,2,4]$ triazin-4-one (ligand $\mathbf{H T T}$ ) to some metal ions have been studied. More particularly, HTT and three complexes have been subjected to thermal decomposition. The thermodynamic activation parameters of decomposition processes (i.e. activation energy $E^{*}$, enthalpy $\Delta H^{*}$, entropy $\Delta S^{*}$ and Gibbs free energy change $\Delta \mathrm{G}^{*}$ ) have been evaluated from the differential thermogravimetric (DTG) curves by the Coats-Redfern method. Some data are outlined in table $3 .{ }^{20}<$ Table 3 near here $>$

Table 3: Thermodynamic data of the thermal decomposition of metal complexes of HTT.<smiles>NNc1nn2c(=O)c(Cc3ccccc3)nnc2s1</smiles>

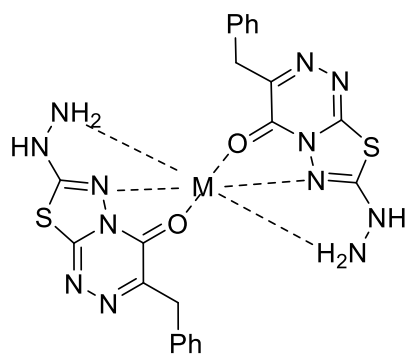

HTT

$\mathrm{M}=\mathrm{Fe}, \mathrm{Co}, \mathrm{Ni}$

\begin{tabular}{ccc|cccc}
\hline \multirow{2}{*}{ Complexes } & \multirow{2}{*}{$\mathrm{T}\left({ }^{\circ} \mathrm{C}\right)$} & \multirow{2}{*}{ Rate $\left(\mathrm{s}^{-1}\right)$} & \multicolumn{4}{|c}{ Thermodynamic data $\left(\mathrm{kJ} \cdot \mathrm{mol}^{-1}\right)$} \\
\cline { 4 - 7 } & & & $\mathrm{E}^{*}$ & $\Delta \mathrm{S}^{*}$ & $\Delta \mathrm{H}^{*}$ & $\Delta \mathrm{G}^{*}$ \\
\hline $\mathrm{HTT}$ & $25-430$ & $3.3 \times 10^{7}$ & 92.92 & -100.0 & 90.68 & 117.7 \\
{$\left[\mathrm{Fe}(\mathrm{HTT})_{2}\right] \mathrm{Cl}_{3}$} & $26-150$ & $4.0 \times 10^{11}$ & 80.23 & -53.00 & 79.92 & 101.1 \\
{$\left[\mathrm{Co}(\mathrm{HTT})_{2}\right] \mathrm{Cl}_{2}$} & $25-100$ & $1.6 \times 10^{13}$ & 98.15 & -41.3 & 97.69 & 195.4 \\
{$\left[\mathrm{Ni}(\mathrm{HTT})_{2}\right] \mathrm{Cl}_{2}$} & $28-141$ & $3.4 \times 10^{5}$ & 46.23 & -125.9 & 157.1 & 253.5 \\
\hline
\end{tabular}




\subsubsection{Reactivity}

\subsubsection{Reaction at ring nitrogen atoms}

\subsection{N-alkylation/acylation}

\subsubsection{1(i) $[1,2,4]$ triazolo[3,4-b][1,3,4]thiadiazines}

Direct glycosylation of compound $\mathbf{5 1}$ with glucopyranosyl bromide $\mathbf{5 2}$ in pyridine at room temperature offered a convenient selective synthesis of 2-glycosyl derivative $\mathbf{5 3}$ (Scheme 4). ${ }^{21}$ $<$ Scheme 4 near here>
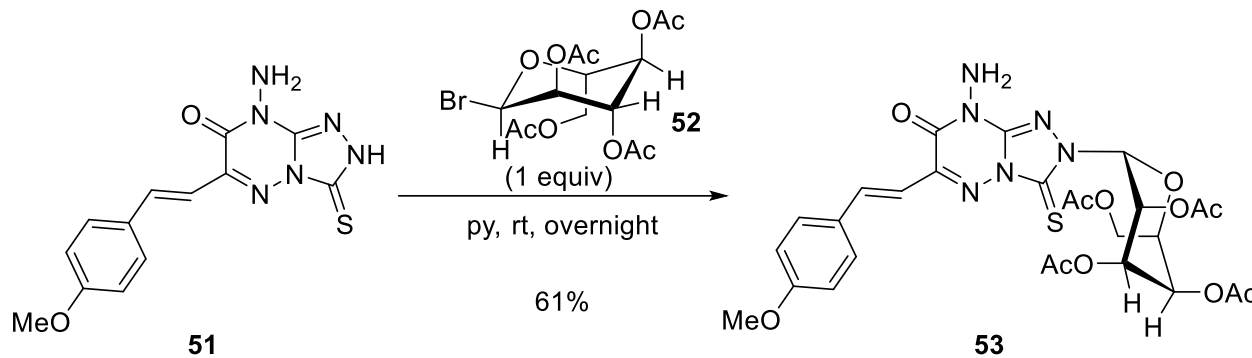

Scheme 4

Two examples of acylation of ring nitrogen atom of the aforementioned ring system are depicted in scheme 5. $\mathrm{N}$-acylation of dihydrotriazolothiadiazine $\mathbf{5 4}$ bearing a fused cyclopentyl-pyrazole substituent with acetic anhydride occurred selectively on the thiadiazine ring. ${ }^{22} \mathrm{~N}$-acylation of triazolothiadiazinone $\mathbf{5 6}$ with oxalyl chloride $\mathbf{5 7}$ or succinyl chloride $\mathbf{5 8}$ under phase-transfer catalysis produced dimers 59 (Scheme 5 ). ${ }^{23}<$ Scheme 5 near here $>$<smiles>[R]c1nnc2n1NCC(=O)S2</smiles>

56: $\mathrm{R}=\mathrm{H}, \mathrm{Me}, \mathrm{Et}$ (2 equiv)
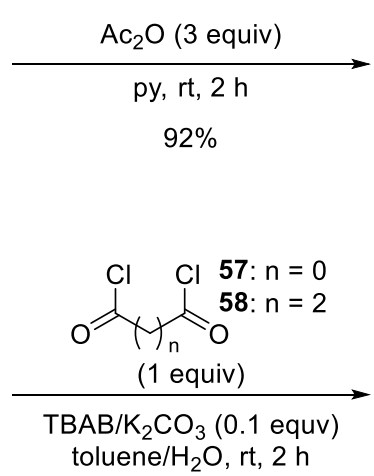

$49-58 \%$<smiles>CCCCCCN1C(c2ccc(OC)cc2)CSc2nnc(-c3[nH]nc4c3CCC4)n21</smiles>

55<smiles>[R]c1nnc2n1CC(=O)Sc1nnc([R])n1N(C(=O)C(C)=O)CC(=O)S2</smiles>

59

\section{Scheme 5}

\subsubsection{1(ii) $[1,2,4]$ triazolo[1,5-a][1,3,5]triazines}

Despite five resonance structures of the anion 61 , the $N$-alkylation of $[1,2,4]$ triazolo[1,5a] $[1,3,5]$ triazin-7(3H)-one 60 with bromoethane $\mathbf{6 2}$, allyl bromide 63 or (2-acetoxyethoxy)methyl bromide 64 occurred selectively at the N3 position. DFT calculations related to the ethylation reaction confirmed the experimental results (Scheme 6). ${ }^{4}<$ Scheme 6 near here $>$ 


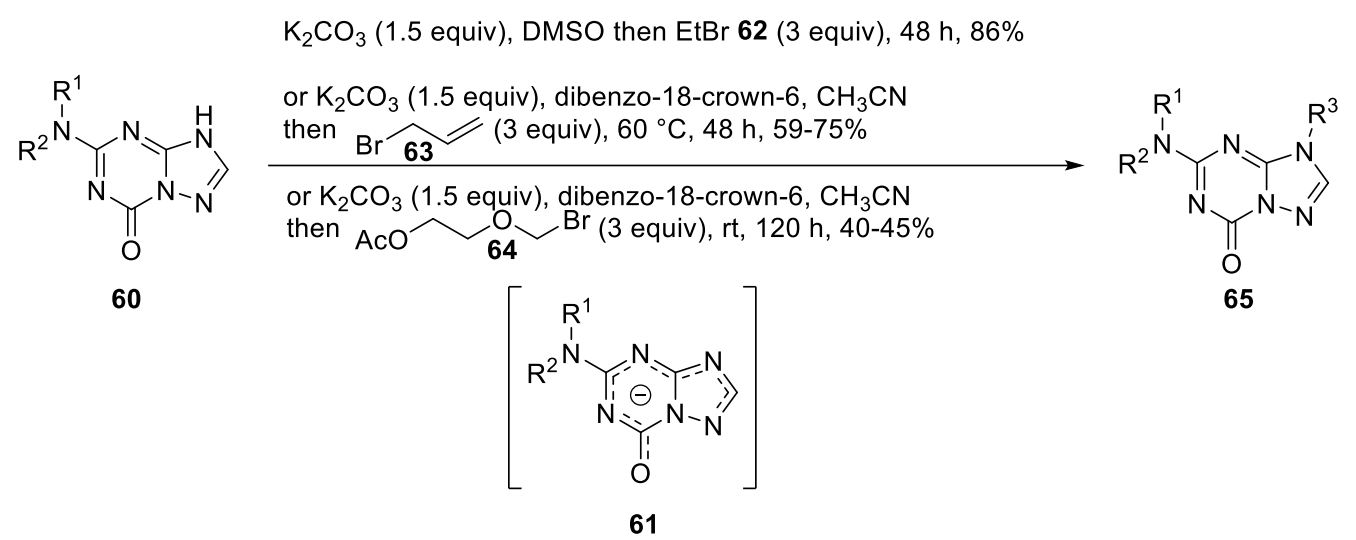

Scheme 6

\subsubsection{1(iii) [1,2,4]triazolo[5,1-c][1,2,4]triazines}

As depicted in scheme 7, N-alkylations and $\mathrm{N}$-glycosylations of 1,4-dihydro-[1,2,4]triazolo[5,1c] $[1,2,4]$ triazine derivatives 66 and 68 and $[1,2,4]$ triazolo[5,1-c][1,2,4]triazin-4(1H)-one derivatives 69 took place at the N1 position. $\mathrm{N}$-methylation of dihydro-triazolotriazinol 66 was performed with diisopropylethylamine and iodomethane. ${ }^{24} \mathrm{~N}$-alkylations of dihydro-triazolotriazines 68 and triazolotriazinones 69 were carried out by treatment of the corresponding sodium salts with bromoalkyle 70. ${ }^{25-26}$ The fusion of 69 with an excess of (2-acetoxyethoxy)methyl acetate 73 at $150{ }^{\circ} \mathrm{C}$ in the presence of $\mathrm{ZnCl}_{2}$ afforded regioselectively the corresponding 1-(2-acetoxyethoxy)methyl derivatives 74. ${ }^{27-28}$ Two methods were developed for the $\mathrm{N}$-glycosylation of 69: treatment of 69 with $\mathrm{N}, \mathrm{O}$-bis(trimethylsilyl)acetamide and trimethylsilyl triflate followed by addition of $\beta$-D-glucose pentaacetate 75 (method A) or reaction of the sodium salts of 69 with tetra-acetyl- $\alpha-D-$-bromoglucose 76 in DMF under heating (method $\mathrm{B}$ ). In both cases, the $\mathrm{N}$-glycosylations took place at the N1 position affording nucleosides 77 with $\beta$-configurations. The method $A$, which gave slightly better yields, was also applied to the incorporation of a tri-O-acetyl- $\beta$-D-ribofuranosyl group (Scheme 7). ${ }^{29}<$ Scheme 7 near here> 
<smiles>Cc1nc2n(n1)C(O)C([N+](=O)[O-])=NN2c1cccc(O)c1</smiles><smiles>[R]C1=Nn2nc([X])nc2NN1</smiles>

68: $\mathrm{X}=\mathrm{CH}_{2}$ 69: $\mathrm{X}=\mathrm{C}=\mathrm{O}$<smiles>[R]c1nc2[nH]nc([R])c(=O)n2n1</smiles>

$\mathrm{R}^{1}=\mathrm{H}, \mathrm{Me}, \mathrm{SMe}$ $\mathrm{R}^{2}=\mathrm{Ph}, \mathrm{NO}_{2}, \mathrm{CO}_{2} \mathrm{Et}$

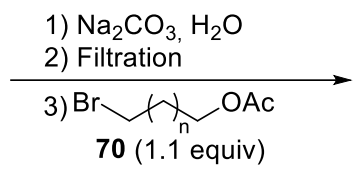

DMF, $100{ }^{\circ} \mathrm{C}, 2 \mathrm{~h}$ $60-76 \%$

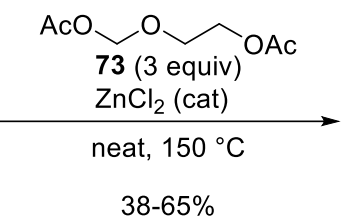

$38-65 \%$

method A: $(45-50 \%)$

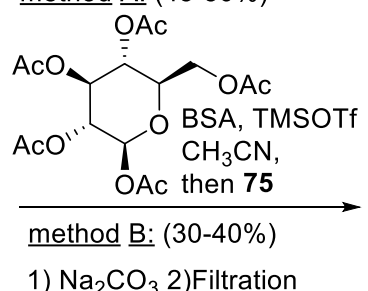

3)
OAc<smiles></smiles>

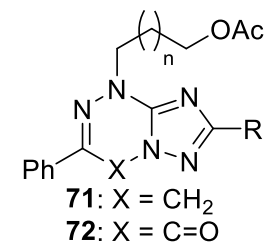<smiles>[R]c1nc2n(COCCOC(C)=O)nc([R])c(=O)n2n1</smiles>

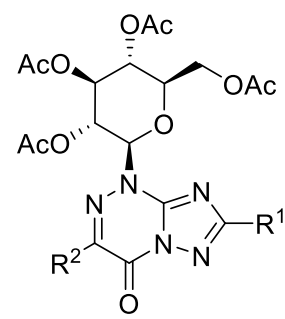

77

\section{Scheme 7}

Interestingly, it has been found that the adamantylation of $\left[{ }^{15} \mathrm{~N}_{2}\right]-[1,2,4]$ triazolo[5,1-c] $\left.] 1,2,4\right]$ triazin4(1H)-one 78 with adamantanol 79 in trifluoroacetic acid first occurred at the N8 position of the bicyclic system. Indeed, after five minutes under reflux, compound $\mathbf{8 0}$ was isolated. However, prolonged reflux with excess of 1-adamantanol $\mathbf{7 9}$ led to complete isomerization with attachment of the adamantyl group at the $\mathrm{N} 1$ position (compound 81). The structures of regioisomers $\mathbf{8 0}$ and $\mathbf{8 1}$ were determined by NMR spectroscopy with analysis of the ${ }^{1} \mathrm{H}-{ }^{15} \mathrm{~N}\left(J_{\mathrm{HN}}\right)$ and ${ }^{13} \mathrm{C}^{-15} \mathrm{~N}\left(J_{\mathrm{CN}}\right)$ coupling constants (Scheme 8). ${ }^{30}<$ Scheme 8 near here $>$<smiles>O=c1c(Br)n[nH]c2ncnn12</smiles>

78

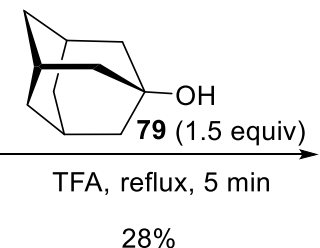

$28 \%$

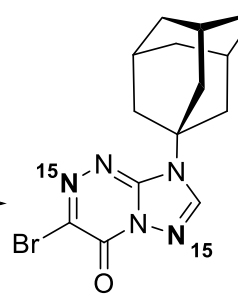

80

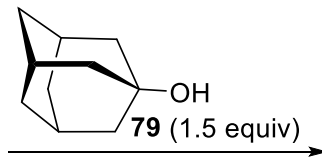

TFA, reflux, $6 \mathrm{~h}$ $43 \%$

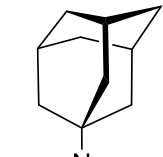<smiles></smiles>

81

Scheme 8 


\subsection{Construction of a new fused-ring with one bridgehead nitrogen atom}

Amino-triazolothiadiazine $\mathbf{8 2}$ was treated with phenacyl bromide $\mathbf{8 3}$ in ethanol allowed the building of a fused imidazole ring to afford tricyclic compound $\mathbf{8 4}$ in good yield (Scheme 9). ${ }^{31}<$ Scheme 9 near here>

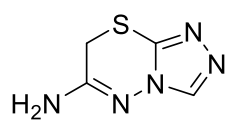

82

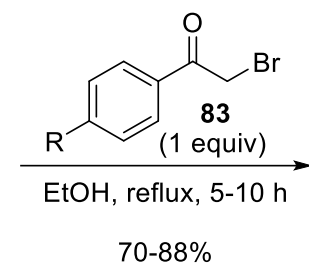

Scheme 9

Nucleophilic displacement of the thiomethyl group of triazolotriazine derivative $\mathbf{8 5}$ by hydrazine hydrate furnished the corresponding hydrazino derivative $\mathbf{8 6}$. The latter was not isolated and was directly engaged in a cyclocondensation with triethylorthoesters under heating in ethanol to afford bis-triazolotriazine derivatives 87 (Scheme 10). ${ }^{32}<$ Scheme 10 near here>

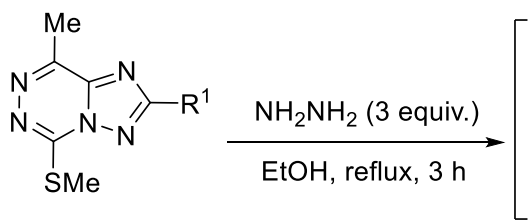

85<smiles>[R]c1nc2c(C)nnc(N)n2n1</smiles>

86<smiles>[R]c1ccc(-c2cnc3n2-n2cnnc2SC3)cc1</smiles>

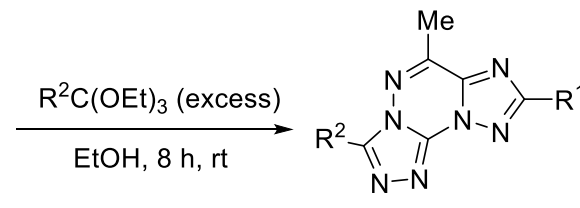

$51-67 \%$ (over 2 steps) $\quad 87$

$$
R^{1}=A r ; R^{2}=H, M e
$$

Scheme 10

Treatment of triazolotriazine $\mathbf{8 8}$ bearing a methylene group with $p$-toluenesulfonyl azide as diazotransfer reagent afforded tricyclic compound $\mathbf{9 1}$ in low yield. From a mechanistic point of view, the authors proposed that this interesting transformation would proceed through a diazo-transfer reaction to produce diazo 89 . A subsequent ring opening of the $(1,2,3)$-triazole would furnish bisdiazo intermediate $\mathbf{9 0}$ which would undergo two new cyclizations to build the novel-fused triheterocyclic product 91 (Dimroth rearrangement). ${ }^{33}$ (Scheme 11) <Scheme 11 near here>

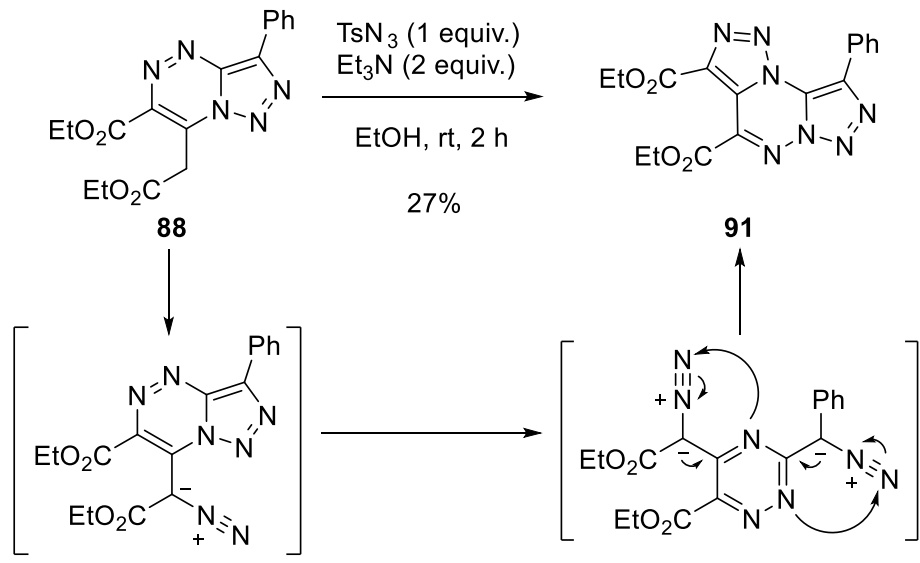

89 


\subsubsection{Reaction at ring carbon atoms}

\subsection{Functionalization of $\mathrm{C}-\mathrm{H}$ bonds}

As displayed in scheme 12, various functionalizations of the $\mathrm{C} 7$ atom of $[1,2,4]$ triazolo[3,4$b][1,3,4]$ thiadiazine derivatives have been reported. Bromination of $\mathbf{9 2}$ has been carried out with bromine and iodine as a catalyst in acetic acid to yield the corresponding 7-bromo derivatives 93. These compounds were prepared for further amination through nucleophilic substitution (see section 11.19.5.2.2). ${ }^{34}$ A Knoevenagel reaction between triazolothiadiazinone 94 and aromatic aldehydes 95 in the presence of a catalytic amount of sodium acetate in acetic acid furnished arylidenes $96 .{ }^{35}$ Treatment of $7 H-[1,2,4]$ triazolo[3,4- $\left.b\right][1,3,4]$ thiadiazine derivatives 97 with aryldiazoniums salts 98 in pyridine delivered phenylhydrazone derivatives $99 .^{36}<$ Scheme 12 near here><smiles>[R]c1nnc2n1NC(c1ccccc1)=CS2</smiles>

92<smiles>O=C1CSc2nnc(-c3ccccc3)n2N1</smiles>

94<smiles>[R]C1=Nn2c(C)nnc2SC1</smiles>

97
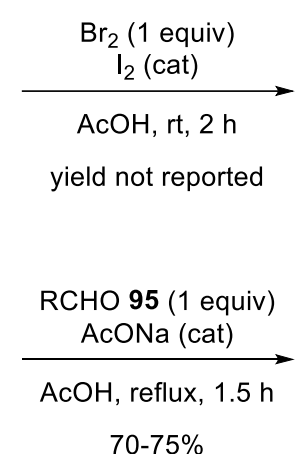

$70-75 \%$

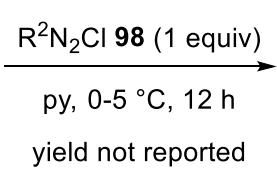

Scheme 12<smiles>[R]c1nnc2n1NC(c1ccccc1)=C(Br)S2</smiles>

93<smiles>[R]C=C1Sc2nnc(-c3ccccc3)n2NC1=O</smiles>

96: $\mathrm{R}=\mathrm{Ar}$

$\mathrm{NHR}^{2}$<smiles>[R]c1nn2c(C)nnc2sc1=N</smiles>

99: $\mathrm{R}^{1}=\mathrm{Me}, \mathrm{Ph} ; \mathrm{R}^{2}=\mathrm{Ar}$

\subsection{Nucleophilic substitution}

\subsubsection{2(i) $[1,2,4]$ triazolo[3,4-b][1,3,4]thiadiazines}

Treatment of thione derivative $\mathbf{1 0 0}$ with hydrazine hydrate in dioxane under reflux furnished diazene 101 with the removal of hydrogen sulfide gas (Scheme 13). ${ }^{37}<$ Scheme 13 near here $>$

$$
\text { yield not reported }
$$

100<smiles>c1ccc(-c2nnc3nnc(/N=N/c4nnc5nc(-c6ccccc6)c(-c6ccccc6)nn45)n3n2)cc1</smiles>

101

Scheme 13 


\subsubsection{5(ii) $[1,2,4]$ triazolo[1,5-a][1,3,5]triazines}

As shown in scheme 14, the substitution of 5,7-diphenoxy-[1,2,4]triazolo[1,5- $a][1,3,5]$ triazine derivative 102 by an amine occurred first at the $\mathrm{C7}$ position. For instance, treatment of 102 with an excess of ammonia in methanol produced 5-phenoxy-[1,2,4]triazolo[1,5-a][1,3,5]triazin-7-amine 103. The latter has been then engaged in a second nucleophilic substitution with various primary or secondary amines in ethanol at $120{ }^{\circ} \mathrm{C}$ to form $N^{5}$-alkyl-[1,2,4]triazolo[1,5-a][1,3,5]triazine-5,7diamines 104. Also of note, a disubstitution occurred when compound 103 reacted with an excess of mono Boc ethylenediamine 105 at $180{ }^{\circ} \mathrm{C}$ furnishing $N^{5,7}$-dialkyl-[1,2,4]triazolo[1,5-a][1,3,5]triazine5,7-diamines 106. The synthesis of [1,2,4]triazolo[1,5- $a][1,3,5]$ triazine-5,7-diamines 108 bearing two different alkylamino groups at $\mathrm{C} 5$ and $\mathrm{C} 7$ was performed by a first reaction between 102 and one equivalent of an alkylamine at $60^{\circ} \mathrm{C}$ producing $N$-alkyl-[1,2,4]triazolo[1,5-a][1,3,5]triazine-7-amines 107 in low to moderate yields. The second substitution could be performed in harsher reaction conditions affording 108 in moderate to good yields. Finally, $N^{5,7}$-dibenzyl-[1,2,4]triazolo[1,5a][1,3,5]triazine-5,7-diamines 109 was easily prepared from diphenoxy derivative 102 and an excess of dibenzyl amine (Scheme 14). ${ }^{38-40}<$ Scheme 14 near here $>$

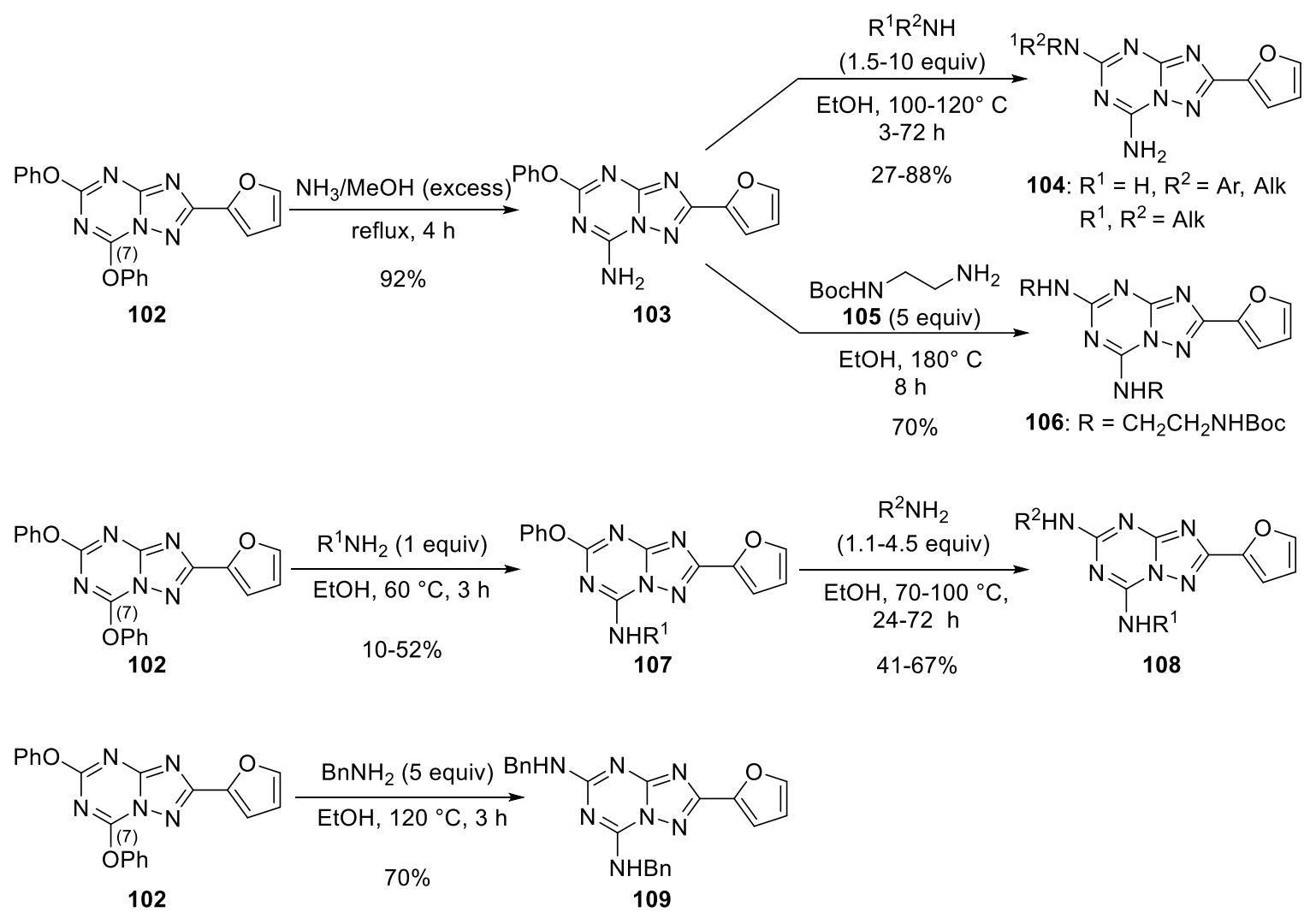

Scheme 14

5-(Methylsulfonyl)-[1,2,4]triazolo[1,5-a][1,3,5]triazin-7-amine $\mathbf{1 1 0}$ has also been used for the introduction of alkyl amines $\mathbf{1 1 1}$ at C5. As shown in scheme 15, with diisopropropyl amine in acetonitrile under heating, $\quad N^{5}$-alkyl-[1,2,4]triazolo[1,5-a][1,3,5]triazine-5,7-diamines 112 was obtained in good yields. ${ }^{41-42}$ Other procedures were also developed for the introduction of different alkylamines or alcohol at C5 from $\mathbf{1 1 0}$ but the yields were much lower (8-33\%). ${ }^{43-45}<$ Scheme 15 near here> 


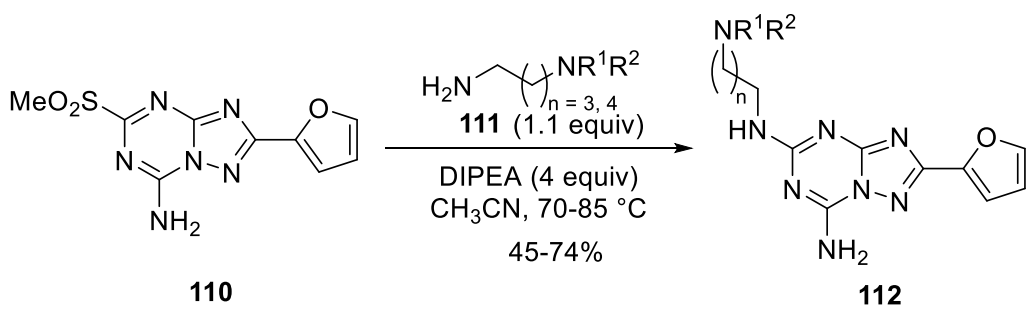

Scheme 15

As outlined in scheme 16, the synthesis of 1,2,4-triazolo[1,5-a][1,3,5]triazin-amines has been also performed by exploring the reactivity of highly electrophilic trichloromethyl-containing 1,3,5-triazine ring. The trichloromethyl substituent at $\mathrm{C} 7$ on compound $\mathbf{1 1 3}$ readily underwent nucleophilic substitution with primary alkyl or aromatic amines as long as secondary amines affording $N^{7}$ substituted-1,2,4-triazolo[1,5-a][1,3,5]triazin-5,7-diamines 114 in excellent yields. Interestingly, the substitution of trichloromethyl group at C5 of $\mathbf{1 1 5}$ was more problematic. ${ }^{46-47}$ Indeed, with an excess of benzylamine 116, the trichloromethyl substituent at C5 was untouched and only transamination at C7 was observed giving rise to compound $\mathbf{1 1 7}$ in moderate yield. With morpholine as a solvent, the substitution took place at both positions leading to dimorpholine-containing triazolotriazine $\mathbf{1 1 8}$ (Scheme 16). ${ }^{48}<$ Scheme 16 near here>

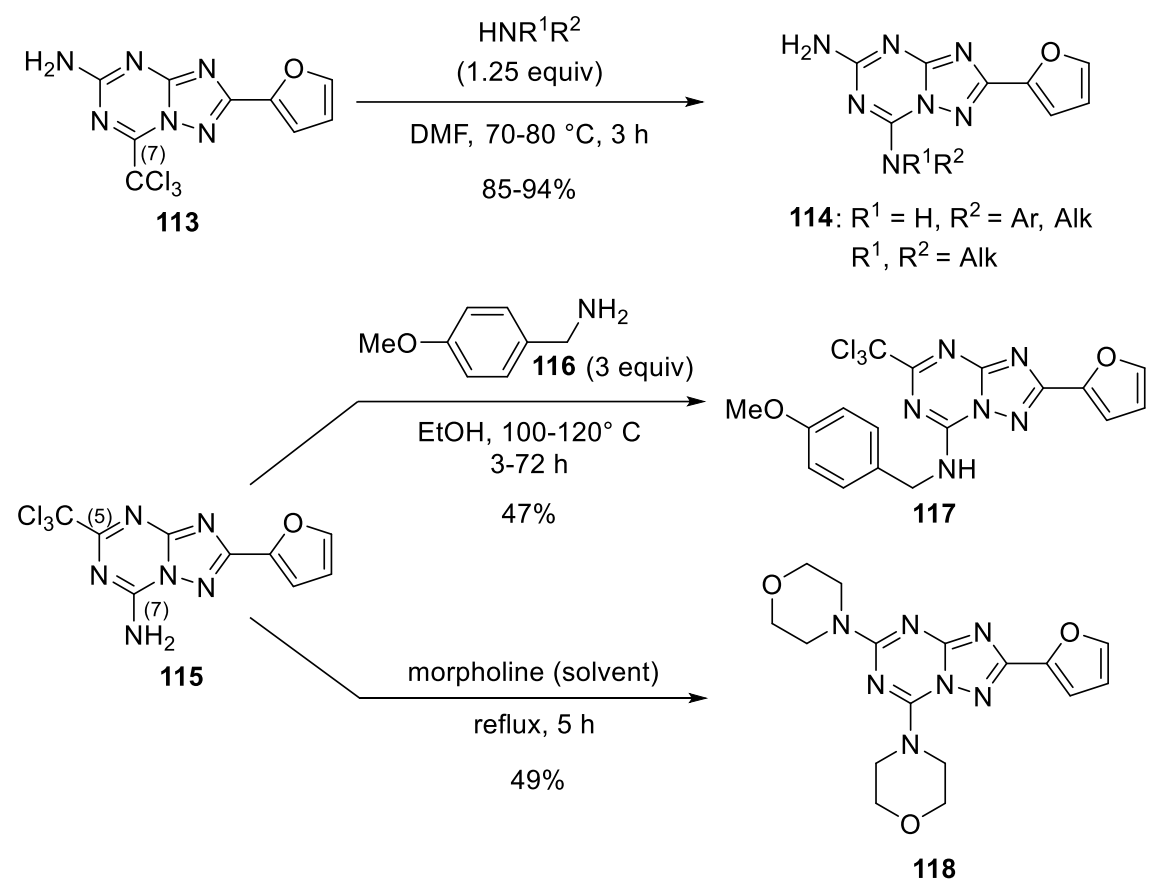

Scheme 16

Finally, the nucleophilic replacement of the methylthio group of triazolotriazinone $\mathbf{1 1 9}$ proceeded smoothly with a variety of amines affording amino-substituted heterocycles $\mathbf{1 2 0}$ in moderate to excellent yields (Scheme 17). ${ }^{48}<$ Scheme 17 near here> 
<smiles>CSc1nc(=O)[nH]c2nc(-c3ccccc3)nn12</smiles>

119

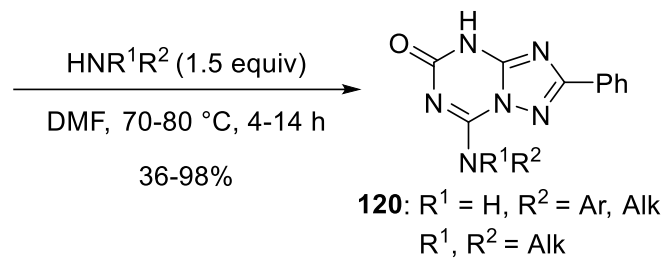

Scheme 17

\subsubsection{2(iii) [1,2,4]triazolo[4,3-b][1,2,4]triazine}

Coupling reaction between bromotriazolotriazine $\mathbf{1 2 1}$ and piperazine ester $\mathbf{1 2 2}$ with copper yielded amino derivative 123 (Scheme 18). ${ }^{34}<$ Scheme 18 near here><smiles>Cc1nnc2n1NC(=C(Br)c1ccccc1)SC2</smiles>

121

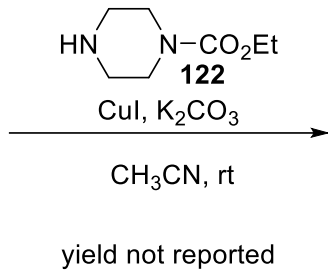

Scheme 18<smiles>CCOC(=O)N1CCN(C2=C(c3ccccc3)Nn3c(C)nnc3S2)CC1</smiles>

123

\subsubsection{2(iv) [1,2,4]triazolo[5,1-c][1,2,4]triazine}

As shown in scheme 19, replacement of the nitro group at C3 of various [1,2,4]triazolo[5,1c] $[1,2,4]$ triazine derivatives has been reported with different nucleophiles. Introduction of a morpholinyl substituent on $\mathbf{1 2 4}$ proceeded sluggishly with an excess of morpholine under reflux (see also section 11.19.5.2.3). ${ }^{49}$ Substitution with cysteine as $S$-nucleophile was easier producing cysteine-containing fused system 126. Similar transformation was also demonstrated with glutathione as $S$-nucleophile. ${ }^{50}$ The substitution of the nitro group of salt $\mathbf{1 2 7}$ by bromide was performed with acetyl bromide to furnish bromo derivative 128 in moderate yield. ${ }^{26}$ Nucleophilic addition of electron rich aromatic (hetero)cycles 130 on 3-nitro-1,4-dihydro-[1,2,4]triazolo[5,1c][1,2,4]triazin-4-ol 129 under acidic reaction conditions led to 3-nitro-4-aryl-1,4-dihydro$[1,2,4]$ triazolo[5,1-c][1,2,4]triazine 131 (Scheme 19). ${ }^{24}<$ Scheme 19 near here> 


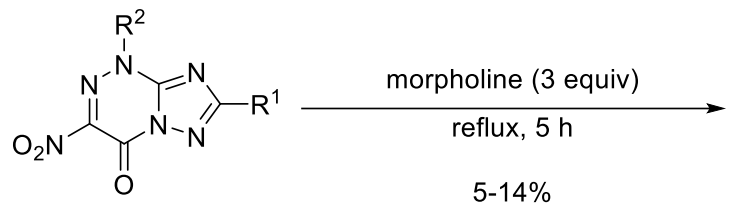

124: $R^{1}=H$, SMe. $R^{2}=$ Me, $t-B u$<smiles>[R]c1nc2n([R])nc([N+](=O)[O-])c(=O)n2n1</smiles>

124: $R^{1}=S M e ; R^{2}=A l k$<smiles>[NH3+][NH2+]C1=N[NH2+]C2=NC=[N+]N2C1=O</smiles>

127

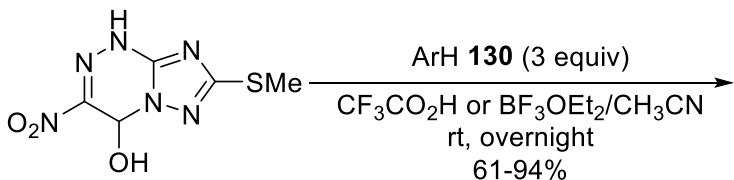

129

$61-94 \%$<smiles>[R]c1nc2n([R])nc(N3CCOCC3)c(=O)n2n1</smiles>

125

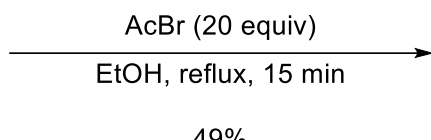

$49 \%$

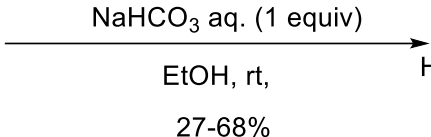

$27-68 \%$

\section{Scheme 19}

\subsection{Ring-opening}

Treatment of nitrotriazolotriazinones $\mathbf{1 3 2}$ with three equivalents of morpholine at room temperature resulted in the formation of morpholinium 133 via nucleophilic addition of the amine function to the carbonyl group (intermediate 134) and the ring opening of the triazine ring. Morpholine-containing hydrazone $\mathbf{1 3 6}$ was obtained from bromotriazolotriazinones $\mathbf{1 3 5}$ with a large excess of morpholine. Cyclization of $\mathbf{1 3 6}$ occurred upon heating at $120{ }^{\circ} \mathrm{C}$ to form nitrotriazolotriazinone 137 (Scheme 20). ${ }^{11}<$ Scheme 20 near here><smiles>[R16]c1nc2n([R])nc([N+](=O)[O-])c(=O)n2n1</smiles>

132<smiles>Cn1nc(Br)c(=O)n2ncnc12</smiles>

135

morpholine (15 equiv)

rt, $15 \mathrm{~min}$ $89 \%$<smiles>[R]c1nc(N([R])N=C(C(=O)N2CCOCC2)[N+](=O)[O-])n(N2CCOCC2)n1</smiles>

133<smiles>[R]c1nc2n(n1)C([R])(N1CCOCC1)C(NO)=NN([R])C2ON1CCOCC1</smiles>

134<smiles>CN(/N=C(/C(=O)N1CCOCC1)N1CCOCC1)N(C)c1ncn[nH]1</smiles>

Scheme 20 


\subsection{Cross-coupling}

Suzuki cross-couplings between 7-bromo-1,4-dihydro-[1,2,4]triazolo[5,1-c][1,2,4]triazine derivatives 138 and various boronic acids 139 furnished 7-aryl substituted derivatives 140 in good yields (Scheme 21). ${ }^{25}<$ Scheme 21 near here $>$

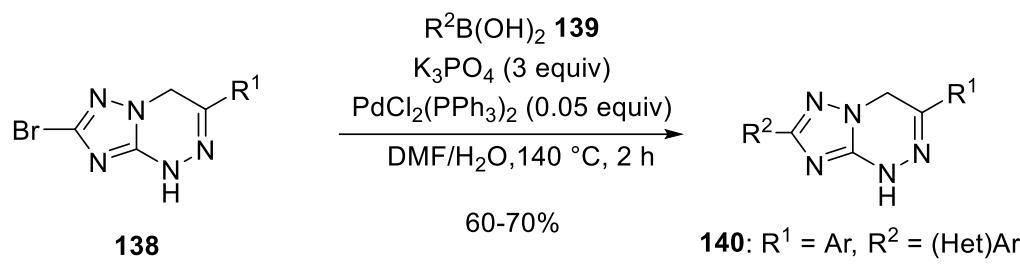

Scheme 21

\subsubsection{Transformation of substituents}

\subsubsection{1 $\mathrm{N}$-arylation and $\mathrm{N}$-nitration}

Arylation of the amino substituent of triazolotriazinone $\mathbf{1 4 1}$ has been reported through nucleophilic aromatic substitution with 9-chloro acridines $\mathbf{1 4 2}$ in DMF in the presence of triethylamine (Scheme 22). ${ }^{51-52}<$ Scheme 22 near here>.

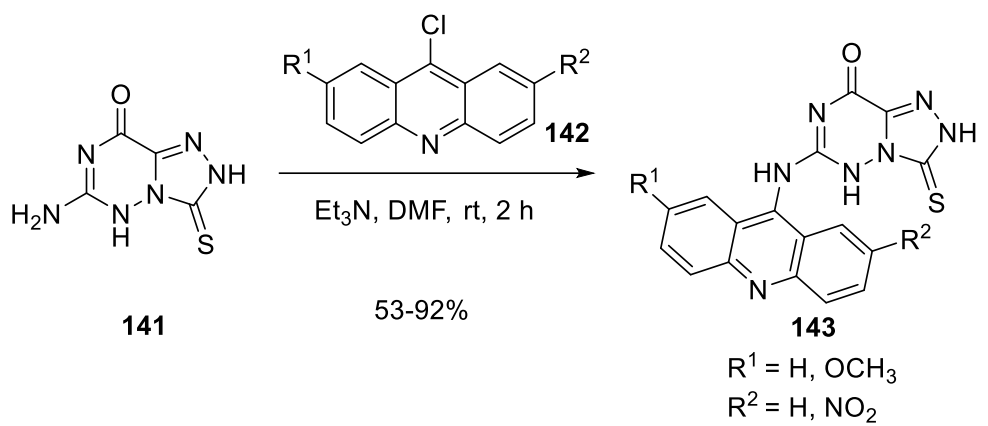

\section{Scheme 22}

Nitration of $[1,2,4]$ triazolo[1,5- $a][1,3,5]$ triazine-2,5,7-triamine 144 with nitric acid occurred only on the amino substituents at position 2 and 5 providing 2,5-dinitramide-7-amino derivative 145 . The corresponding salts $\mathbf{1 4 6}$ having various counter-cations were obtained by direct treatment with a base or through the intermediate formation of the silver salts (Scheme 23). ${ }^{53}<$ Scheme 23 near here $>$

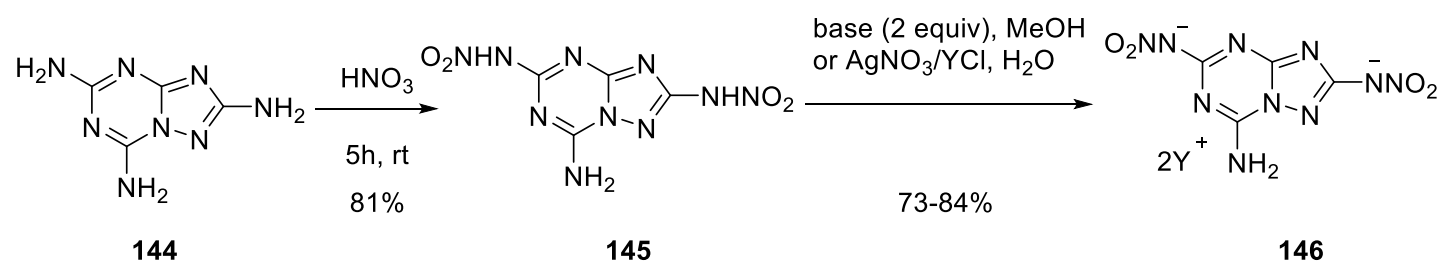

Scheme 23

\subsection{S-alkylation}

Reaction between thiols 147 and D-gluco-pyranosyl bromide 148 in the presence of potassium hydroxide gave the corresponding acetylated thioglycoside derivatives 149 in good yields. After that, 
the deacetylation proceeded efficiently by treatment with methanolic ammonia at $0{ }^{\circ} \mathrm{C}$ to furnish deacetylated glycoside $\mathbf{1 5 0}$ (Scheme 24). ${ }^{54}<$ Scheme 24 near here>

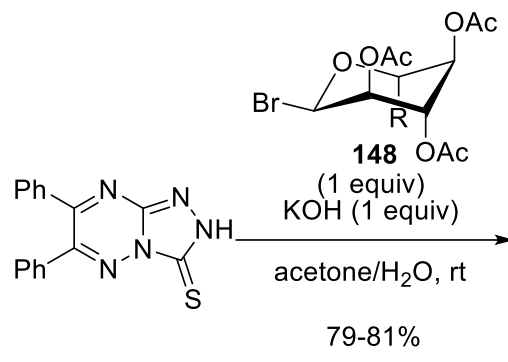

147

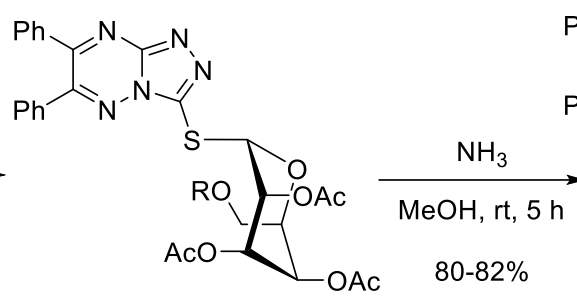

149: $R=H, A c$

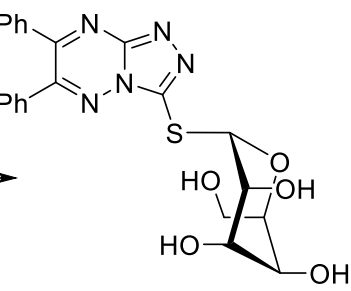

150

\section{Scheme 24}

As outlined in scheme 25, S-alkylation of thiooxo-heterocycles has been reported on various fused systems. Triazolotriazine-thiones $\mathbf{1 5 1}$ could be efficiently treated with methyl iodide in an aqueous solution of sodium hydroxide at room temperature to produce the corresponding (methylthio)triazolotriazine 152. Such product was prepared for further ipso-substitution of the thiomethyl group (cf. Section 11.19.5.1.2). ${ }^{32}$ Under similar reaction conditions, S-alkylation of thioxotriazolotriazinone 153 and 155 furnished alkylthio-triazolotriazinones 154 and 156. Methylthioderivative $\mathbf{1 5 6}$ has been treated with hydrogen peroxide in aqueous alkaline solution to form the corresponding triazolotriazine-dione 157. ${ }^{55-56}$ Finally, S-alkylation of the thiocarbonyl group of thiadiazole-thione $\mathbf{1 5 8}$ has been performed in DMF with potassium hydroxide to produce various thioalkyl derivatives 159 (Scheme 25). ${ }^{57}<$ Scheme 25 near here><smiles>Cc1n[nH]c(=S)n2nc([Al])nc12</smiles>

151<smiles>O=c1[nH]c(=S)[nH]c2nc([Al])nn12</smiles>

153

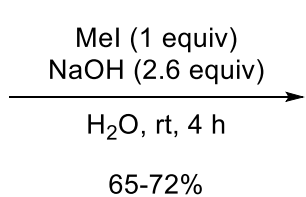

$\mathrm{RI}$ or $\mathrm{RBr}(1.5$ equiv) $\mathrm{NaOH}(2$ equiv)

$\mathrm{H}_{2} \mathrm{O}, \mathrm{rt}, 1 \mathrm{~h} 30$

$32-87 \%$<smiles>[R]c1nc2[nH]c(=O)[nH]c(=S)n2n1</smiles>

155: $R=M e, P h$

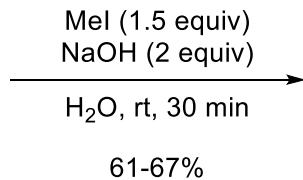

$61-67 \%$<smiles>CSc1nnc([As])c2nc([Al])nn12</smiles>

152

154: $R=M e, E t, B n$

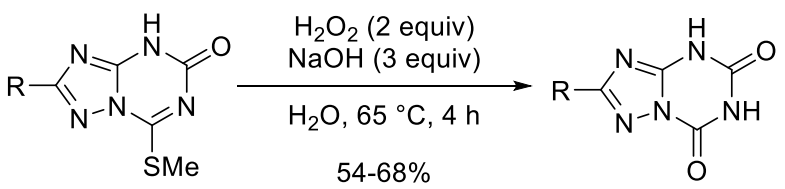

156

157

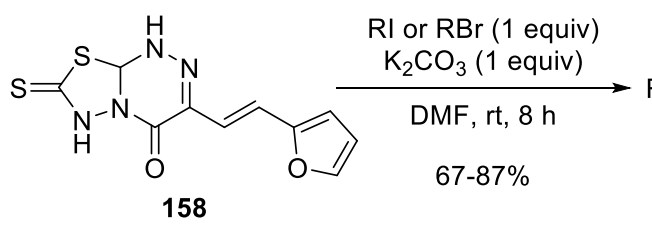<smiles>[R5]C1=NN2C(=O)C(/C=C/c3ccco3)=NNC2S1</smiles>

159: $\mathrm{R}=\mathrm{Me}, \mathrm{Et}, \mathrm{Pr}, \mathrm{Bu}$

Scheme 25 


\subsection{Thiocarbonyl to carbonyl group transformation}

Conversion of the thiocarbonyl group of thioxotriazolotriazinone $\mathbf{1 6 0}$ into the corresponding carbonyl group has been described by El-Barbary et al. with potassium permanganate at room temperature furnishing $\mathbf{1 6 1}$ in good yield (Scheme 26). ${ }^{21}<$ Scheme 26 near here>
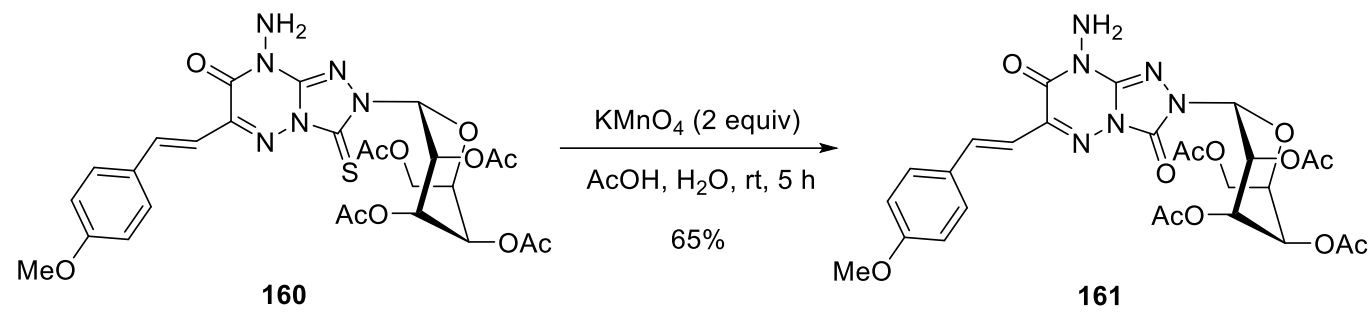

Scheme 26

\subsection{Reduction}

Sodium dithionite in an aqueous alkaline solution was used for selective reductions of the nitro group of dihydrotriazolotriazine 162. Partial hydrogenolysis of the methylsulfanyl substituent was observed with catalytic hydrogenation. ${ }^{24}$ In contrast, reduction of 3-nitro[1,2,4]triazolo[5,1c] $[1,2,4]$ triazin-4-amines 164 was carried out via catalytic hydrogenation over $\mathrm{Pd} / \mathrm{C}$ under high pressure to produce the corresponding 3,4-diamine derivatives 165. In this case, sodium dithionite was not suitable (Scheme 27). $.^{58}<$ Scheme 27 near here $>$<smiles>[R]C1C([N+](=O)[O-])=NNc2nc(S[Na])nn21</smiles>

162<smiles>[R]c1nc2nnc([N+](=O)[O-])c(N)n2n1</smiles>

164

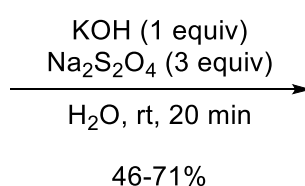

$46-71 \%$

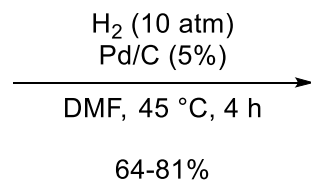

Scheme 27<smiles>[R]C1C(N)=NNc2nc(SC)nn21</smiles>

163: $R=($ het)Ar<smiles>[R]c1nc2nnc(N)c(N)n2n1</smiles>

165: $R=$ Me, 3-py

\subsection{Construction of a fused ring}

By taking advantage of the cyano and amino substituents of triazolotriazine 166, various fused tricyclic compounds have been built: refluxing in formic acid or in a solution of aromatic ketones $\mathbf{1 6 7}$ in acetic acid afforded pyrimidones 168 and 169; treatment with formamide allowed the construction of amino-pyrimidine 170. Alternatively, condensation with triethylorthoformate yielded ethyl acetamidate 171, which has been used in turn for the formation of polyheterocyclic fused systems. As such, treatment of $\mathbf{1 7 1}$ with hydrazine hydrate or aniline $\mathbf{1 7 2}$ in ethanol at low temperature furnished pyrimidine imine 173. Conducting the latter transformation under reflux led to arylamino- or hydrazinyl- pyrimidines 174. Finally, reaction between acetamidate 171 and hydrazide $\mathbf{1 7 5}$ in refluxing phosphorus oxychloride gave rise to tetracyclic compound $\mathbf{1 7 6}$ (Scheme 28). ${ }^{59}<$ Scheme 28 near here $>$ 


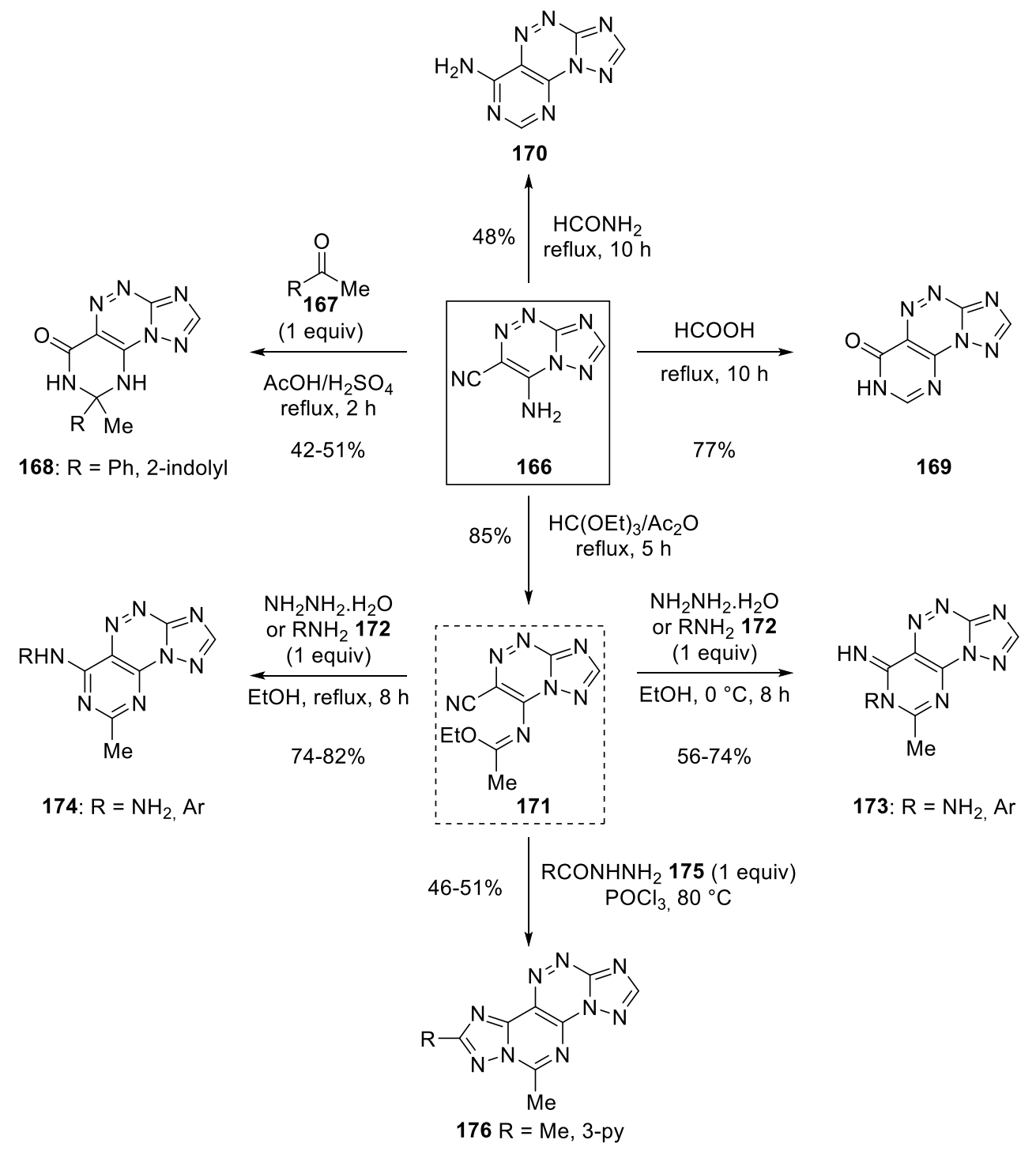

Scheme 28

Condensation of $[1,2,4]$ triazolo[5,1-c][1,2,4]triazine-3,4-diamines 177 with triethylorthoformate under reflux allowed the building of tricyclic system 178 with a fused-imidazole (Scheme 29)..$^{58}$ $<$ Scheme 29 near here><smiles>Cc1nc2nnc(N)c(N)n2n1</smiles>

177

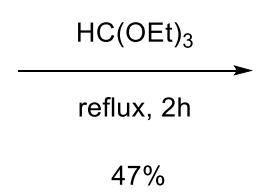

Scheme 29

Intramolecular condensation of the aminophenyl substituent with the carbonyl group of thiadiazolotriazinone derivative $\mathbf{1 7 9}$ occurred in DMF under reflux furnishing indole-fused thiadiazolotriazine $\mathbf{1 8 0}$ (Scheme 30 ). $.^{60}<$ Scheme 30 near here> 
<smiles>Nc1ccc(F)cc1-c1nnc2sc(-c3ccc(F)cc3)nn2c1=O</smiles>

179

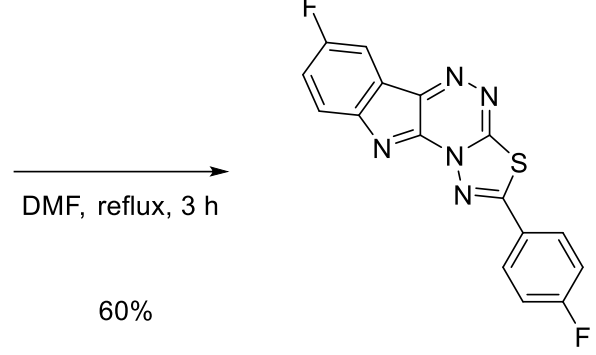

180

Scheme 30

\subsubsection{Oxidation of the ring}

Aromatization of 1,4-dihydro-[1,2,4]triazolo[5,1-c][1,2,4]triazines 181 by oxidative dehydrogenation with 2,3-dichloro-5,6-dicyano-1,4-benzoquinone (DDQ) in methanol resulted in the formation of the corresponding 6-aminoazolo[5,1-c]triazine derivatives $\mathbf{1 8 2}$ in good yields. Other oxidizing agents such as potassium permanganate, hydrogen peroxide, potassium hexacyanoferrate(III), ammonium persulfate and phenyliodine diacetate were not suitable for this transformation (Scheme 31). ${ }^{24}$ $<$ Scheme 31 near here>

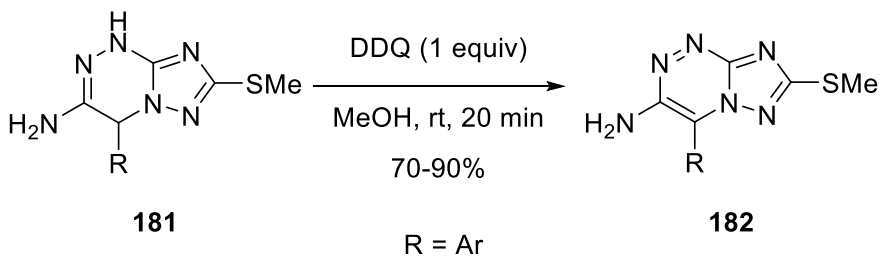

\section{Scheme 31}

\subsubsection{Reduction of the ring}

Treatment of triazolothiadiazine $\mathbf{1 8 3}$ with sodium borohydride yielded the corresponding dihydrothiadiazine 184 (Scheme 32). $.^{22}<$ Scheme 32 near here>

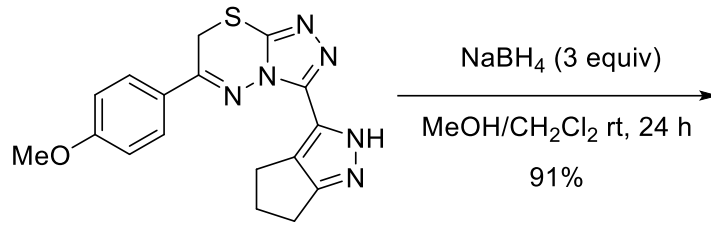

183

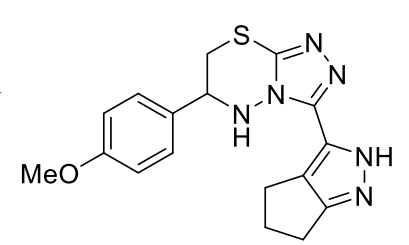

184

\section{Scheme 32}

Removal of the bromo substituent of 7-bromo-1,4-dihydro-[1,2,4]triazolo[5,1-c][1,2,4]triazines 185 has been carried out through catalytic hydrogenation over Pd/C (Scheme 33). ${ }^{25}<$ Scheme 33 near here><smiles>Brc1nc2n(n1)CC(c1ccccc1)=NN2</smiles>

185

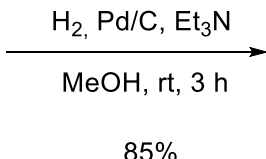

$85 \%$<smiles>c1ccc(C2=NNc3ncnn3C2)cc1</smiles>

186

Scheme 33 


\subsubsection{Ring contraction}

This section concerns only triazolothiadiazines of type $\mathbf{3}$ in which contraction of the six-membered ring has been observed under some reaction conditions. Contraction of the thiadiazinone ring occurred when $5 H$-[1,2,4]triazolo[3,4-b][1,3,4]thiadiazin-6(7H)-one derivative 187 was treated with thiolates 188 in dichloromethane under reflux affording [1,2,4]triazolo[3,4-b][1,3,4]thiadiazole derivatives 190. This transformation would involve the formation of episulphonium 189, which would undergo ring opening by thiolates 188 (Scheme 34). ${ }^{61}<$ Scheme 34 near here>

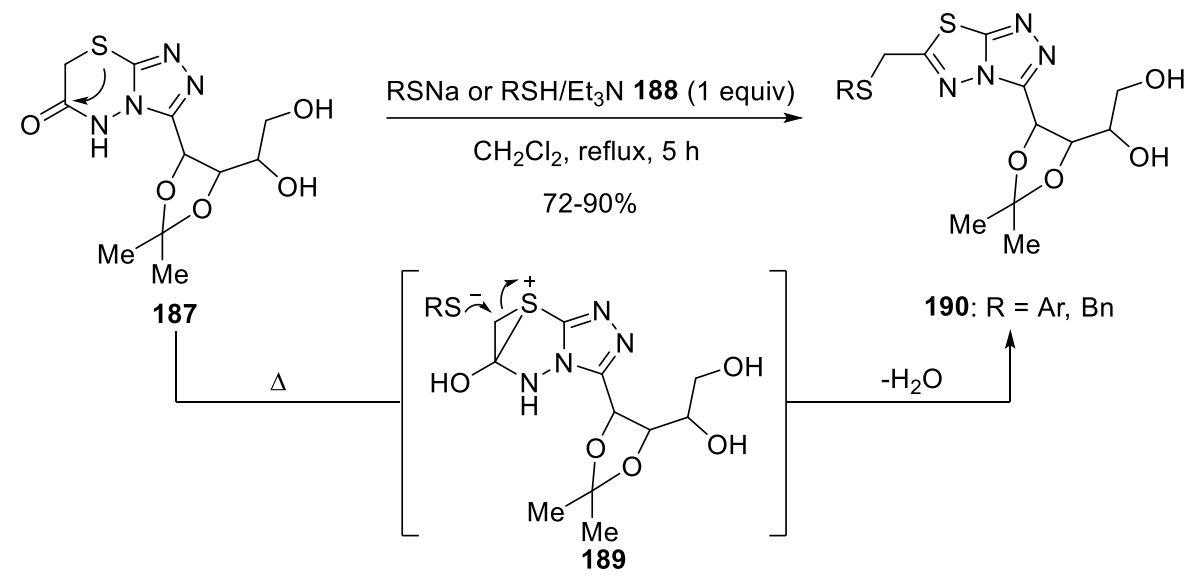

Scheme 34

Heating $7 H$-[1,2,4]triazolo[3,4-b][1,3,4]thiadiazine derivatives 191 in acetic anhydride readily resulted in a ring-contraction of the fused six-membered thiadiazine leading to 1-acetyl-7acetylsulfanyl-1H-pyrazolo[5,1-c][1,2,4]triazoles 192. A one-pot conversion to pyrazolo[5,1c][1,2,4]triazole 193 was performed by subsequent treatment with hydrogen chloride through deacetylation/desulfurization. Alternatively, fused heterocycles 193 was also obtained by pyrolysis of 191 (Scheme 35). ${ }^{62-64}<$ Scheme 35 near here>

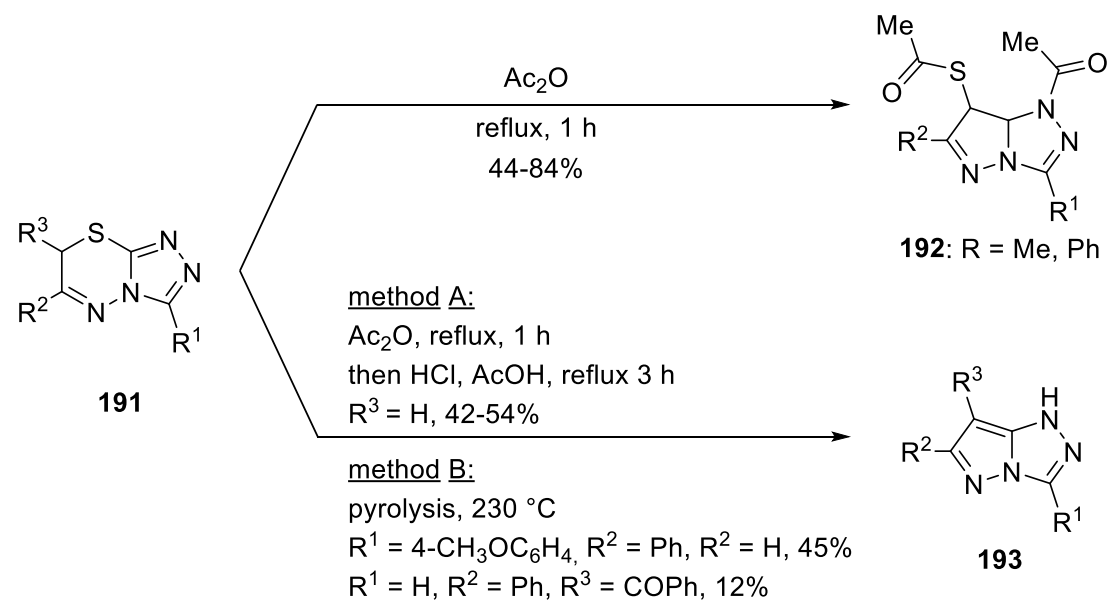

Scheme 35 


\subsubsection{Ring Synthesis through cyclization or cyclocondensation of a monocyclic system}

The synthesis of the bicyclic 5-6 systems mainly involved the construction of the second heterocycle by cyclization or cyclocondensation of the first cycle. In some cases, the two cycles have been built in tandem or one-pot sequential two-step processes from acyclic compounds or from another ring. Because of the quite large number of possible ring systems belonging to this chapter, this section is divided according to the structure of the six-membered ring. As depicted in figure 7, the synthesis of fused-thiadiazines with [1,3,5]- and [1,3,4]-heteroaromatic arrangements will be discussed first. Then, the preparation of fused triazines with [1,3,5]-, [1,2,4]- and [1,2,3]- arrangements will be reviewed sequentially. For fused $[1,2,4]$ triazines, the site of the fusion (i.e., $b-, c-, d$-, and $f$-fusion) will be distinguished due to the abundance of data. Also of note, in each section, processes involving the closure of the five- or the six-membered rings have been differentiated when appropriate. Such organization was also used in CHEC-III(2008). It has the advantage to highlight the use of versatile common starting materials for the construction of various fused systems (Figure 7). <Figure 7 near here>

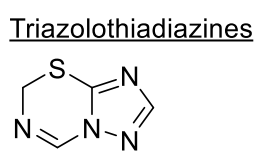

1<smiles>C1=Nn2ncnc2SC1</smiles>

2

Fused $[1,3,5]$ triazines<smiles>C1=NC=NC2OC=NN12</smiles>

5<smiles>C1=NC=NC2SC=NN12</smiles>

6<smiles>C1=Nn2cnnc2SC1</smiles>

3<smiles>c1ncn2ncnc2n1</smiles>

8<smiles>C1=Nc2nncn2CS1</smiles><smiles>c1ncn2cnnc2n1</smiles>

9

$\underline{b-F u s e d}[1,2,4]$ triazines<smiles>c1cnn2cnnc2n1</smiles>

10

c-Fused [1,2,4]triazines<smiles>C1=CN2N=CSC2N=N1</smiles>

7<smiles>c1cn2ncnc2nn1</smiles>

11<smiles>c1cn2cnnc2nn1</smiles>

12<smiles>c1cn2nncc2nn1</smiles>

13

d-Fused [1,2.4]triazines

$\mathrm{N}$
$\mathrm{N}$
$\mathrm{N}$

14

$N=N$
1
$N \geqslant N-N$

15

f-Fused [1,2,4]triazines<smiles>c1ncc2nncn2n1</smiles><smiles>c1ncc2ncnn2n1</smiles>

16

Fused [1,2,3]triazines

$\mathrm{N}_{\mathrm{N}^{-} \mathrm{N}-\mathrm{N}}^{\mathrm{N}}$

18

Figure 7 


\subsubsection{Synthesis of Fused Thiadiazines}

\subsection{Thiadiazines with 1,3,5-heteroatomic arrangement}

The preparation of 2,6-disubstituted-6,7-dihydro-5H-1,2,4-triazolo[3,2-b]-1,3,5-thiadiazines has been reported by Tozkoparan et al. (Scheme 36). In their study, a bis-three-component Mannich type reaction between various 1,2,4-triazole-5-thiones 194, primary alkyl amines and formaldehyde furnished the corresponding fused heterocyclic derivatives 196 in moderate to high yields (up to $88 \%) .{ }^{12}<$ Scheme 36 near here $>$

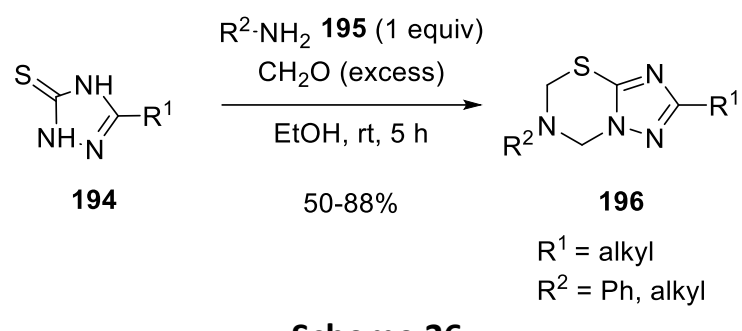

\section{Scheme 36}

Hajri et al. have reported that treatment of $\mathrm{N}-(4 \mathrm{H}-1,2,4-$ triazol-3-yl) carboximidates 197 with carbon disulfide in the presence of pyridine would afford [1,2,4]triazolo[4,3-c][1,3,5]thiadiazine-5-thiones 198 in good yields. The authors assumed that the reaction would proceed through the regioselective nucleophilic addition of N4 nitrogen atom of 198. Alternatively, the reaction of 197 with an equimolar of sodium thiocyanate would allow the construction of $[1,2,4]$ triazolo[4,3c] $[1,3,5]$ thiadiazin-5-imines in moderate yields. The structures of obtained regioisomers were not ascertained by X-Ray analyses (Scheme 37 ). $.^{65}<$ Scheme 37 near here $>$

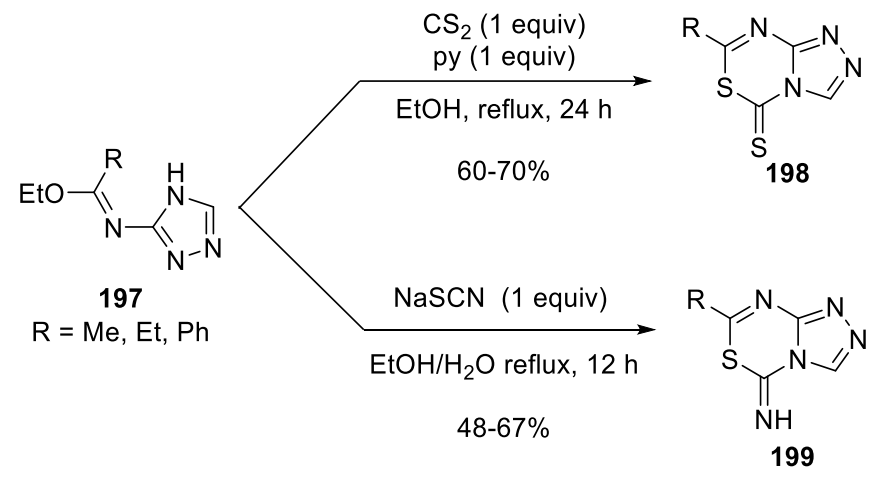

Scheme 37

\subsubsection{3 $[1,2,4]$ Triazolo[3,4-b][1,3,4]thiadiazines}

As already mentioned above, among all the possible ring systems of this chapter, the most extended literature concerns derivatives of this ring system (type 3 ). Indeed, this skeleton represents an important class of heterocyclic compounds possessing a wide range of biological activities and many derivatives have been synthesized during the last period. Full description of all particular compounds cannot be covered in this chapter. Extensive literature data can be found in CHEC-II(1996) and CHECIII(2008). Herein, only transformations involving new type of reactive partners will be summarized. 


\subsubsection{3(i) closure of the five-membered ring}

Cyclocondensation of 2-hydrazinyl-6H-1,3,4-thiadiazines $\mathbf{2 0 0}$ with orthoesters $\mathbf{2 0 1}$ in the presence of trifluoroacetic acid furnished triazolothiadiazines 202 in good to excellent yields (Scheme 38). ${ }^{66}$ $<$ Scheme 38 near here $>$

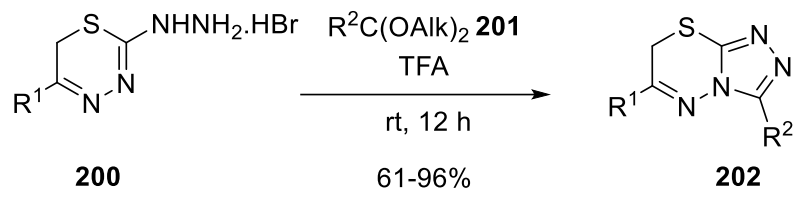

\section{Scheme 38}

\subsubsection{3(ii) closure of the six-membered ring}

11.19.6.3.3(ii)(a) synthesis from 4-amino-4H-1,2,4-triazole-3-thiol derivatives

As displayed in Scheme 39, condensation of 4-amino-4H-1,2,4-triazole-3-thiols 203 with various ketones bearing a leaving group at the $\alpha$-position of the carbonyl function represents one of the most efficient way for the construction of this ring system (see also CHEC-III(2008) and CHECII(1996)). Dihydroindeno derivatives 205 have been obtained in good yields from 2-tosyloxy-1indanones 204. ${ }^{67}$ lodine-mediated in-situ generation of $\alpha$-iodo-ketones from 3 -acetyl-coumarines 206 under microwave irradiation allowed the construction of coumarinyl-triazolothiadiazines $\mathbf{2 0 7 .} .^{68}$ Similar strategy has been used for the synthesis of cinnoline derivatives 209. ${ }^{69}$ Visible-light mediated bromination of $\beta$-diketones $\mathbf{2 1 0}$ with $\mathrm{N}$-bromo succinimide (NBS) furnished regioselectively 6 -methyl 2-aroyl substituted triazolothiadiazines $\mathbf{2 1 1}$ in excellent yields. A solvent free protocol was also established with a catalytic amount of $p$-toluene sulfonic acid with slightly lower yields. ${ }^{70}$ Reactions with acetyl or benzoyl formic acids 212 in phosphorus oxychloride under reflux yielded $7 \mathrm{H}$ $[1,2,4]$ triazolo[3,4-b][1,3,4]thiadiazin-7-ones $213 .{ }^{71}$ Condensation with $\alpha, \beta$-dibromoketones 214 gave rise to arylidene derivatives $215 .{ }^{72-74}<$ Scheme 39 near here $>$ 


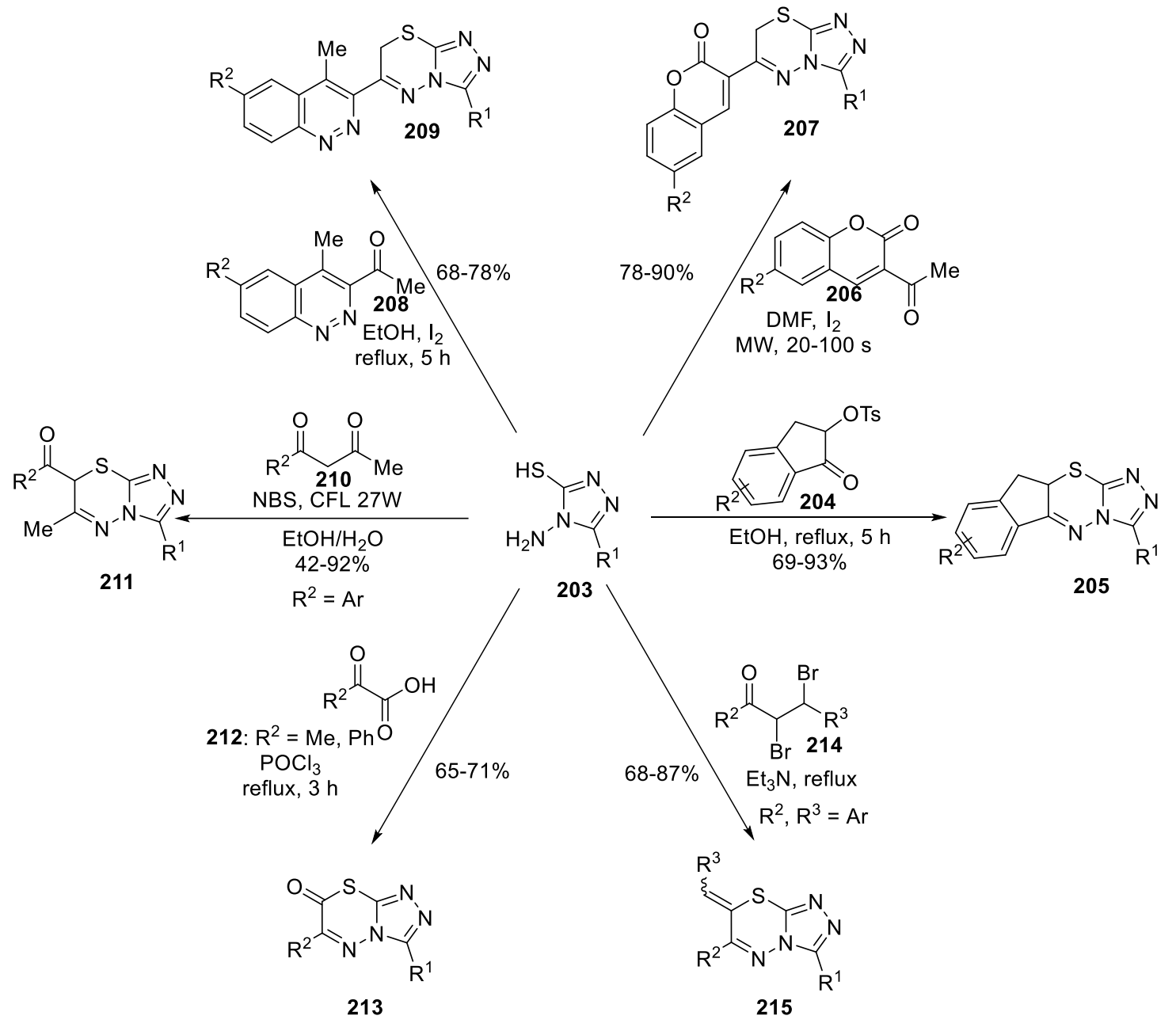

Scheme 39

7-alkoxy-6-aryl-[1,2,4]triazolo[3,4-b][1,3,4]thiadiazine derivatives 217 were synthesized upon treatment of 203a with $\alpha, \alpha$-dibromoacetophenones $\mathbf{2 1 6}$ in different alcohols under reflux (Scheme 40). ${ }^{75}<$ Scheme 40>

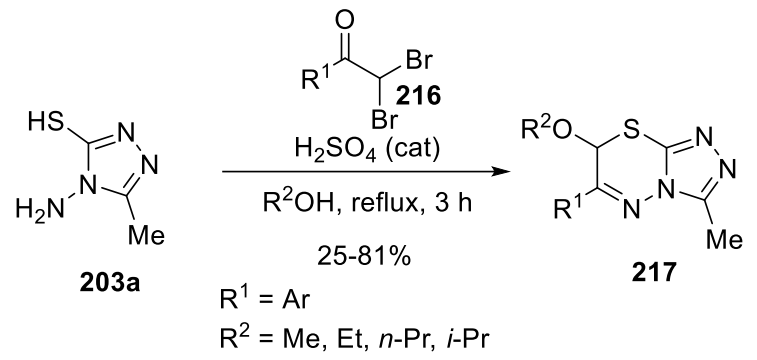

Scheme 40

Reactions of 4-amino-4H-1,2,4-triazole-3-thiols 203b with ketones 218 in boiling acetic acid in the presence of a catalytic amount of sulfuric acid afforded triazolothiadiazine $\mathbf{2 1 9}$ in moderate to good yields. According to the authors, the transformation might proceed through the formation of disulphide 220, which would undergo intramolecular nucleophilic substitutions with the enamine functions (Scheme 41). ${ }^{76}<$ Scheme 41 near here $>$ 


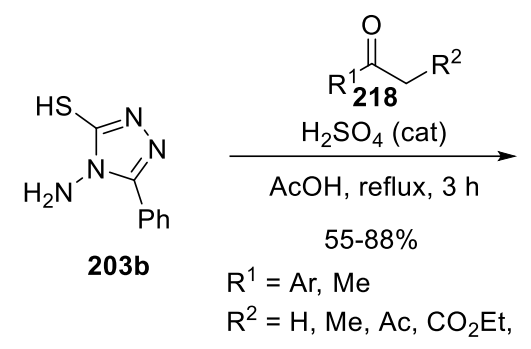<smiles>[R]C1=NN2C(=NC1)N=C([2H])SC2[R]</smiles>

219<smiles>[R]C=C([R])Nn1c(SSc2nnc(-c3ccccc3)n2NC([R])=C[R])nnc1-c1ccccc1</smiles>

220

Scheme 41

Esters and acyl chlorides have also been employed as electrophiles. Chloroacetyl chloride 221 furnished 6-chloro-triazolothiadiazine 222; ${ }^{77}$ oxalyl chloride 223 and bromomalonate 225 led to triazolothiadiazin-6-ones 224 and triazolothiadiazin-6,7-diones 226 respectively (Scheme 42).7,78 $<$ Scheme 42 near here>

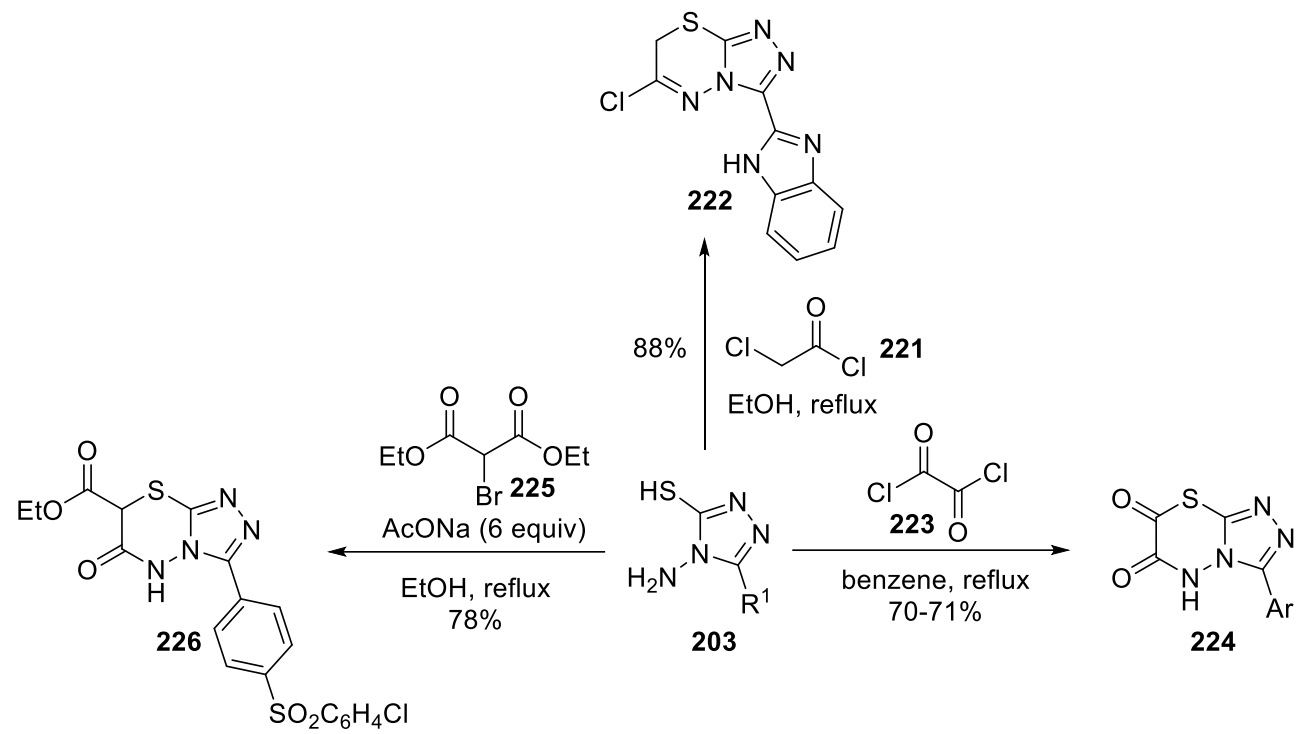

\section{Scheme 42}

Treatment of $\mathbf{2 0 3}$ with 2-chloracetonitrile $\mathbf{2 2 7}$ in the presence of sulphuric acid immobilized on silica gel under microwave irradiation afforded triazolothiadiazin-6-amine 228 (Scheme 43). ${ }^{79}$ Also under microwave irradiation, cyclocondensation with 2,3-dibromosuccinic acid 229 furnished diacid derivatives $\mathbf{2 3 0}$ in high yields. ${ }^{80}<$ Scheme 43 near here>

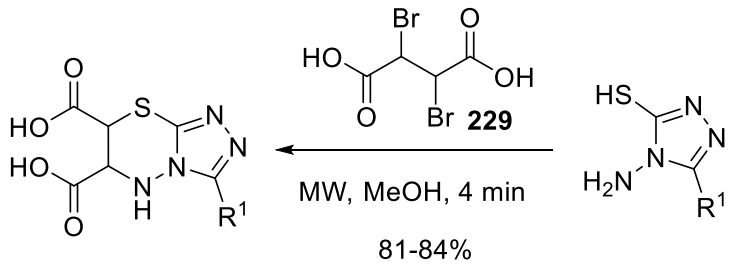

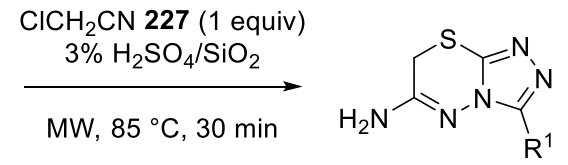

$65 \%$

228: $\mathrm{R}^{1}=3,4-\mathrm{Cl}_{2} \mathrm{C}_{6} \mathrm{H}_{4}$

Scheme 43

Triazoles 203 reacted also with alkynes; namely dimethylacetylene dicarboxylate 231 and dibenzoylacetylene $\mathbf{2 3 3}$. The corresponding highly functionalized triazolothiadiazines $\mathbf{2 3 2}$ and $\mathbf{2 3 4}$ were obtained in good to excellent yields (Scheme 44 ). ${ }^{81-82}<$ Scheme 44 near here $>$ 
<smiles>O=C(c1ccccc1)c1ccccc1</smiles>

234

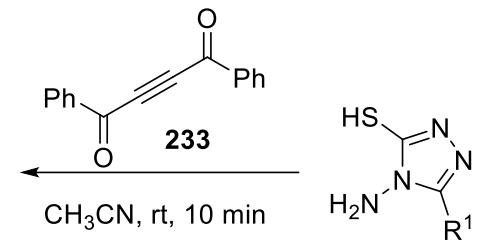

$98 \%$

203

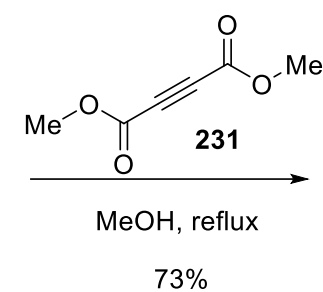

$73 \%$<smiles>[R1]c1nnc2n1N=C(O)/C(=C\C(C)=O)S2</smiles>

232

Scheme 44

As shown in scheme 45, various polycyclic derivatives have also been obtained from 203. 2-bromoindandione 235 and 2-bromo-3-hydroxynaphtalene-1,4-dione 237 produced regioselectively tetracyclic linear derivative 236 and fused indanones 238 in excellent yields. ${ }^{83-84}$ Similar transformation was performed under microwave irradiation in the presence of piperidine as a base. ${ }^{85}$ Borate complex $\mathbf{2 3 9}$ of 7-chloro-6-fluoro-quinolinone carboxylic acid underwent regioselectively bisnucleophilic aromatic substitution under microwave irradiation in the presence of a catalytic amount of DABCO to form quinoline derivative $\mathbf{2 4 0}$ in high yields. ${ }^{86}$ Compound $\mathbf{2 0 3}$ was adsorbed on alumina and treated with 2,3-dichloroquinoxaline $\mathbf{2 4 1}$ under microwave irradiation to furnish fused systems $\mathbf{2 4 2} .{ }^{87}$ Treatment of 5-hydroxycoumarin derivative $\mathbf{2 4 3}$ with two equivalents of triazole 203 gave rise to coumarino-triazolothiadiazine 244. It has been assumed that this reaction proceeded through the cyclization of disulphide intermediate $245 .{ }^{88}<$ Scheme 45 near here $>$ 


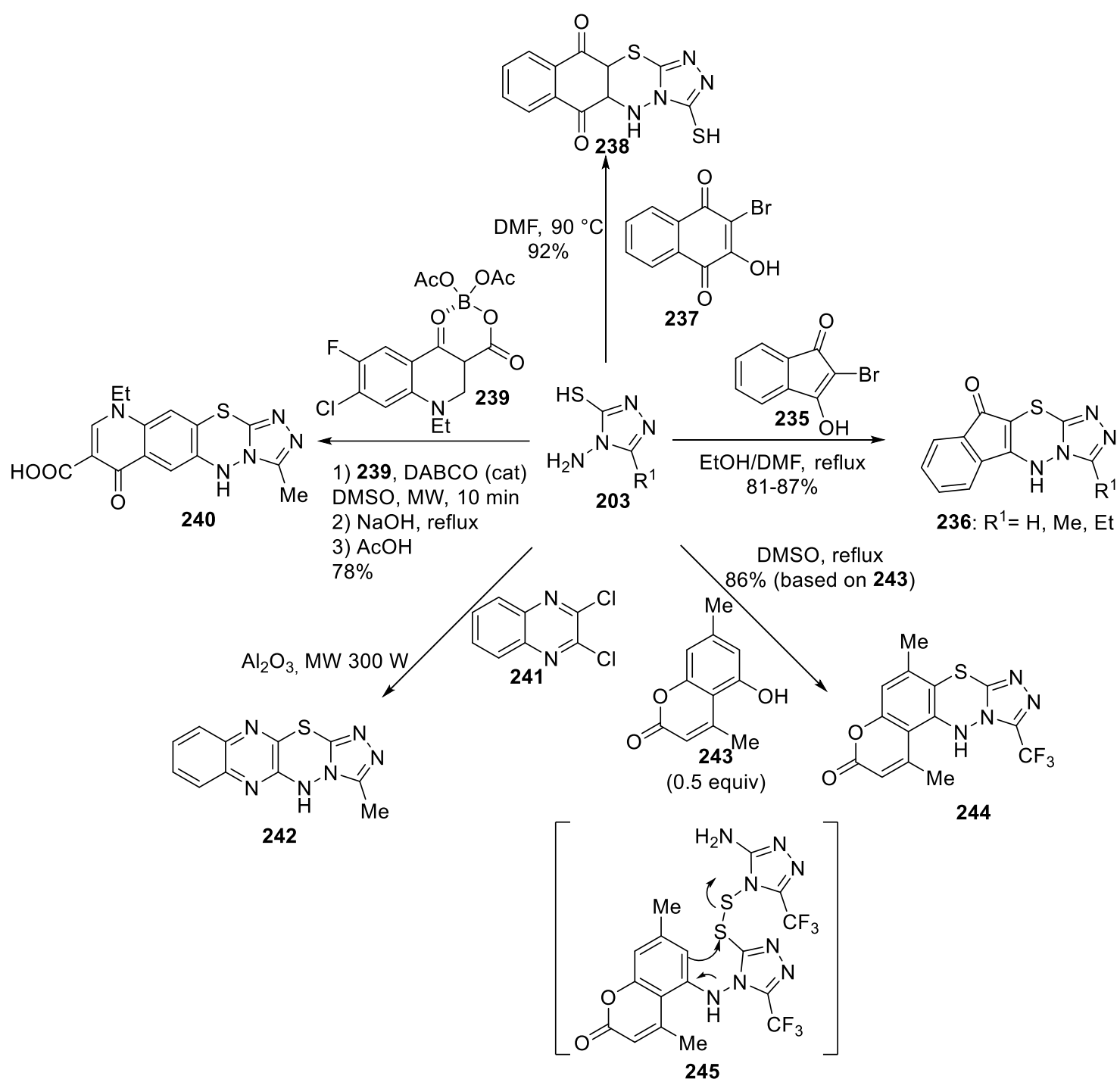

Scheme 45

A three-component reaction between triazoles 203, aromatic aldehydes 246 and cyclohexyl isocyanide $\mathbf{2 4 7}$ has been developed. The reaction was performed under microwave irradiation with a catalytic amount of indium trichloride furnishing triazolothiadiazines $\mathbf{2 4 8}$ in high yields in very short reaction times (Scheme 46). ${ }^{89}<$ Scheme 46 near here $>$

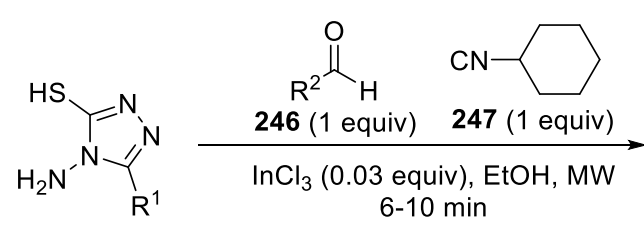

203

$75-85 \%$

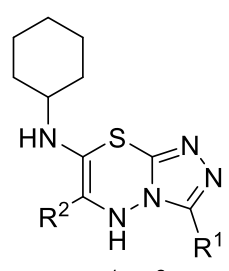

248: $R^{1}, R^{2}=A r$

Scheme 46

Adsorbtion of 203, chloroacetic acid 249 and sodium methoxide over alumina followed by microwave irradiation produce $[1,2,4]$ triazolo[3,4- $b][1,3,4]$ thiadiazin-6(7H)-one 250. ${ }^{90}$ Alternatively, simple solvent-free reaction of $\mathbf{2 0 3}$ with $\mathbf{2 4 9}$ and potassium carbonate under microwave irradiation was also possible. ${ }^{91}$ (Scheme 47 ) <Scheme 47 near here> 


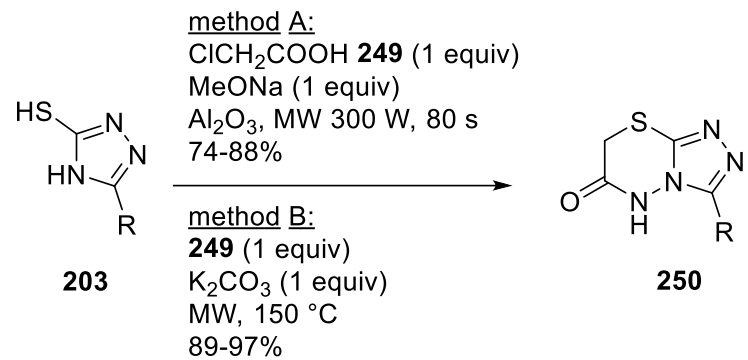

Scheme 47

As depicted in scheme 48, various 3-thioether-4H-1,2,4-triazol-4-amine derivatives have been employed in intramolecular processes. Intramolecular cyclocondensation of the amino group with the carbonyl function of amide $\mathbf{2 5 1}$ allowed the construction of fused thiadiazines rings $\mathbf{2 5 2}$. Similarly, condensation with the carbonyl group of mercapto-naphtalene-1,4-dione substituent of 253 furnished fused system 254. ${ }^{92-93}$ The alkyne functional group of propargyl thioether 255 underwent intramolecular hydroamination in the presence of a catalytic amount of heteropolyacids to build 6-methyl-triazolothiadiazine $\mathbf{2 5 6} .{ }^{94}$ Intramolecular aromatic nucleophilic substitution $\left(\mathrm{S}_{N} \mathrm{Ar}\right)$ of heteroaryl thiother 257 furnished pyrimido[5,4-e][1,2,4]triazolo[3,4-b][1,3,4]thiadiazines 258 in good yields. ${ }^{95}$ Other series of pyrimidotriazolothiadiazines have been also reported via similar direct $\mathrm{S}_{N} \mathrm{Ar}$ of bomopyrimidine thiothers ${ }^{96-97}$ or with a preceding S-N type Smiles rearrangement. ${ }^{98}$ These $^{2}$ works, dealing with the construction of polyheterocyclic compounds, go little beyond the scope of this chapter and will not be described in any further details. <Scheme 48 near here><smiles></smiles>

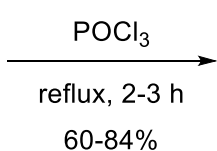<smiles>[R]c1ccc(NC2=CSc3nnc(-c4cc(F)c(Cl)cc4Cl)n3N2)cc1</smiles><smiles>[R]c1nnc(SC2CC(=O)c3ccccc3C2=O)n1N</smiles>

253

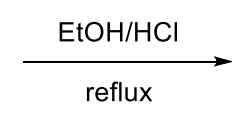

$56-82 \%$<smiles></smiles>

254<smiles>[R]c1nnc(SCC#C)n1N</smiles>

255

$$
\begin{aligned}
& \stackrel{\mathrm{H}_{14}\left[\mathrm{NaP}_{5} \mathrm{~W}_{29} \mathrm{MoO}_{110}\right]}{(0.05 \text { equiv })} \\
& \underset{\mathrm{AcOH}, \text { reflux }}{\longrightarrow}
\end{aligned}
$$

$75-86 \%$<smiles>[R]c1nnc2n1NC(C)=CS2</smiles><smiles>[R10]Nc1nc(C)c(Br)c(Sc2nnc(Sc3nc([N+]([R])=O)nc(N[R10])c3Br)n2N)n1</smiles>

$\underset{\mathrm{CH}_{3} \mathrm{CN} \text {, reflux }}{\stackrel{\mathrm{NaNH}_{2} \text { (3 equiv) }}{\longrightarrow}}$ $70-77 \%$<smiles>[R16]Nc1nc([NH2+])c(Br)c(Sc2nnc3n2Nc2c(C)nc(N[R10])nc2S3)n1</smiles>

Scheme 48 
Cyclocondensation of bis(3-thioether-4H-1,2,4-triazol-4-amine) derivative 259 with bis(aldehydes) $\mathbf{2 6 0}$ in refluxing acetic acid afforded macrocycles $\mathbf{2 6 1}$ in decent yields. The reaction might have proceeded via initial formations of macrocyclic diimines 262. The latter would undergo intramolecular Mannich-type reactions with in-situ generated vinylogous ketene acetals to form the two triazolothiadiazines rings (Scheme 49 ). ${ }^{99}<$ Scheme 49 near here $>$<smiles>CCOC(=O)c1sc2sc(C(=O)OCC)c(CSc3nnc(-c4ccccc4)n3N)c2c1CSc1nnc(-c2ccccc2)n1N</smiles>

259

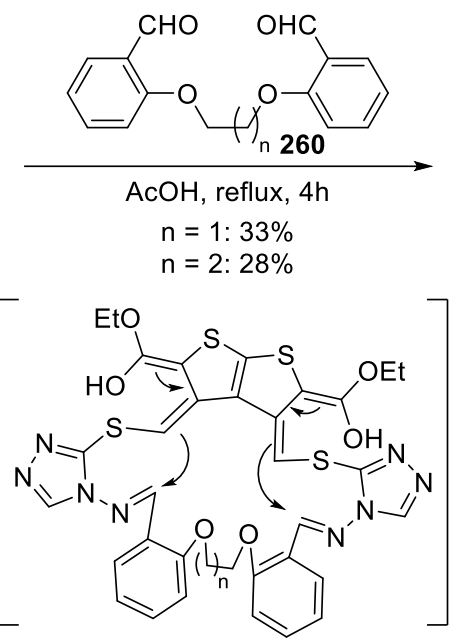

262

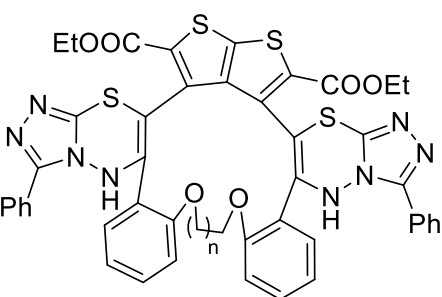

261

Scheme 49

Addition of thioalkyl-containing phosphonates 264 to 4-(benzylideneamino)-4H-1,2,4-triazole-3-thiol derivatives $\mathbf{2 6 3}$ in the presence of a catalytic amount of DDQ led to 7-phosphonate substituted triazolothiadiazines 265. Under these oxidative reaction conditions, the cyclization occurred via elimination of the thioalkyl group (Scheme 50). ${ }^{100}<$ Scheme 50 near here $>$

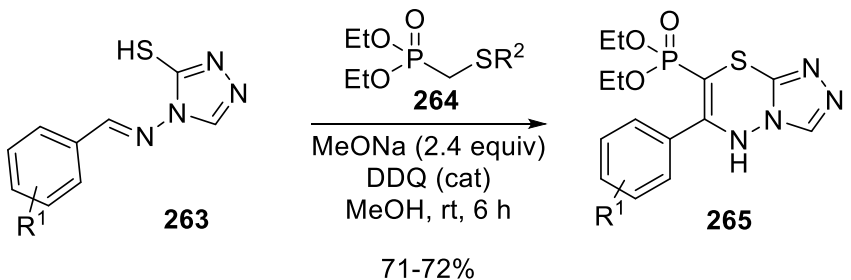

Scheme 50

11.19.6.3.3(ii)(b) other route

Treatment of amino-triazole $\mathbf{2 6 6}$ with dimedone 267, sulphur powder and iodine as a catalyst under sonication produced fused system 268 in high yield (Scheme 51). ${ }^{101}<$ Scheme 51 near here>

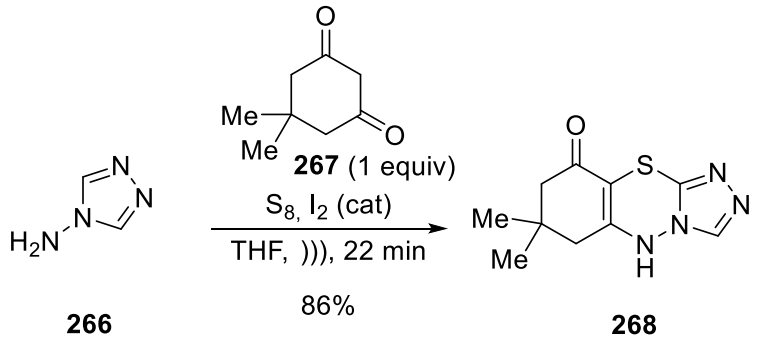

Scheme 51 


\subsubsection{3(iii) construction of both rings (closure of the six-membered ring at the last step)}

A one-pot sequential multi-components reaction between thiosemicarbazides $\mathbf{2 6 9}$, carboxylic acids 270 and substituted 3-(2-bromoacetyl)coumarins $\mathbf{2 7 1}$ has been developed. This convenient procedure was performed under solvent-free conditions delivering the bicyclic systems $\mathbf{2 7 2}$ in high yields (Scheme 52). ${ }^{102}<$ Scheme 52 near here $>$<smiles>NNC(=S)NN</smiles>

269

270<smiles>[R]c1cc([R])c2oc(=O)c(C(=O)CBr)cc2c1</smiles>

271<smiles>[Te][Te]</smiles>

$82-95 \%$<smiles>[R]c1cc([R])c2oc(=O)c(C3=NN4C(=NNC4[R1])SC3)cc2c1</smiles>

272

Scheme 52

Reaction of 5-aryl-1,3,4-oxadiazole-2-thiol $\mathbf{2 7 3}$ with (bromoacetyl)coumarine $\mathbf{2 7 4}$ in the presence of sodium acetate in boiling acetic acid followed by the addition of hydrazine hydrate afforded triazolothiadiazine $\mathbf{2 7 7 .} .^{103}$ The transformation would have proceeded through the in-situ generation of thioether $\mathbf{2 7 5}$ followed by ring opening of the oxazole moiety via hydrazone 276. Similar deconstruction of oxadiazole rings in acetic acid with hydrazine have also been reported from isolated thioether derivatives of type 275. ${ }^{104-108}$ Such transformations delivered usually the corresponding triazolothiadiazines in high yields (Scheme 53). <Scheme 53 near here>

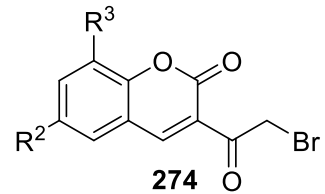<smiles>[R]c1nnc(S)o1</smiles>

273
AcONa (1 equiv), $\mathrm{AcOH}, 60^{\circ} \mathrm{C}, 1 \mathrm{~h}$ and then $\mathrm{NH}_{2} \mathrm{NH}_{2} \cdot \mathrm{H}_{2} \mathrm{O}$ (1 equiv), $80^{\circ} \mathrm{C}, 2 \mathrm{~h}$

$80-86 \%$<smiles>[R]C(=O)CSc1nnc([R])o1</smiles>

276<smiles>[R]c1cc([R7]#[R])c2oc(=O)c(C3=NN4C([R])N=NC4SC3)cc2c1</smiles>
277: $R^{1}=A r$

Scheme 53

\subsubsection{4 $[1,2,4]$ Triazolo[b][1,3,4]thiadiaziniums}

With the aim to determine their crystal structures (cf. Section 11.19.3.2), $[1,2,4]$ triazolo $[b][1,3,4]$ thiadiazinium bromide salts $\mathbf{4 3}$ and $\mathbf{4 4}$ were prepared by reacting the corresponding $N$-amino- $N$ '-methyl-1,2,4-triazolo-5-thiones $\mathbf{2 7 8}$ and $\mathbf{2 7 9}$ with phenacyl bromide in ethanol (Scheme 54). ${ }^{14}<$ Scheme 54 near here $>$

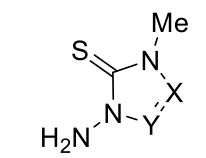

278: $X=N, Y=C H$

279: $\mathrm{X}=\mathrm{CH}, \mathrm{Y}=\mathrm{N}$

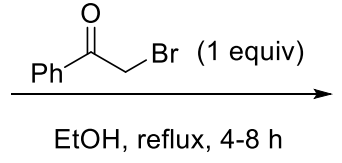

Scheme 54

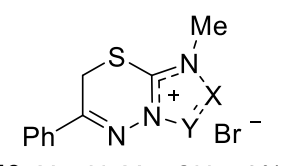

43: $\mathrm{X}=\mathrm{N}, \mathrm{Y}=\mathrm{CH}, 50 \%$

44: $X=\mathrm{CH}, Y=N, 75 \%$ 


\subsubsection{Synthesis of Fused Triazines}

\subsection{Synthesis of fused [1,3,5]-triazines}

Since 2007, the preparation of four bicyclic skeletons with fused 1,3,5-triazines has been reported:
$[1,3,4]$ oxadiazolo[3,2- $a][1,3,5]$ triazines
5, $\quad[1,3,4]$ thiadiazolo $[3,2-a]$
$[1,3,5]$ triazines
6,

$[1,2,4]$ triazolo $[1,5-a][1,3,5]$ triazines 8 and $[1,2,4]$ triazolo[4,3,a][1,3,5]triazines 9 (see Figure 7$)$. While triazolotriazines 8-9 have been synthesized through either the ring closure of the 5- or the 6membered rings, oxadiazolo- and thiadiazolo-triazines 5-6 have been prepared only via the late construction of the 6-membered ring.

\subsubsection{1(i) closure of the five-membered ring}

\subsubsection{1(i)(a) $[1,2,4]$ triazolo[1,5-a] [1,3,5]triazines}

Important transformations for the construction of this fused system through the ring closure of the 5-membered ring have already been reviewed in CHEC-II(1996) and CHEC-III(2008). Herein are described some complementary approaches.

Cyclodehydration of hydrazides $\mathbf{2 8 0}$ in anhydrous xylene with an excess of phosphorus pentoxide and hexamethyldisiloxane (HMDSO) led to the formation of triazolotriazine $\mathbf{2 8 1}$ via in-situ Dimroth type rearrangement. Due to stability problems, $\mathbf{2 8 1}$ was transformed directly to the corresponding amino-derivatives $\mathbf{2 8 2}$ by treating with methanolic ammonia (Scheme 55). ${ }^{40,109}<$ Scheme 55 near here>

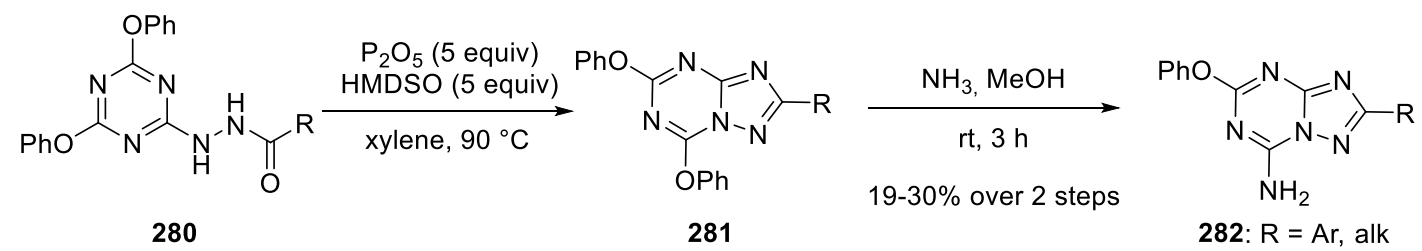

\section{Scheme 55}

Copper-catalyzed oxidative (3+2)-cycloadditions between 1,3,5-triazin-2-amines $\mathbf{2 8 3}$ and aryl nitriles $\mathbf{2 8 4}$ furnished fused systems $\mathbf{2 8 5}$ in moderate to good yields. The structure of the products was confirmed by single crystal X-ray structure analysis (Scheme 56). ${ }^{110}<$ Scheme 56 near here $>$

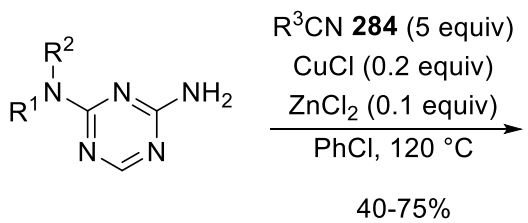

283<smiles>[R]Nc1ncn2nc([R])nc2n1</smiles>

285: $R^{3}=A r$

\section{Scheme 56}

Condensation of 6-hydrazinyl-1,3,5-triazin-2-one derivatives $\mathbf{2 8 6}$ with triethyl orthoformate proceeded via a Dimroth-type rearrangement to afford triazolotriazinones $\mathbf{2 9 0}$. Indeed, nucleophilic addition of in-situ generated ethanol to the carbonyl group of fused intermediate $\mathbf{2 8 7}$ would open the triazine ring and generate 288. A rotation of 1,2,4-triazole ring around the $\mathrm{C}-\mathrm{N}$ sigma bond would allow the ring closure of 1,2,4-triazine to take place on intermediate $\mathbf{2 8 9}$ giving rise to thermodynamically more stable bicyclic compounds $\mathbf{2 9 0}$. The position of the proton on these 
products depends on the substituents of the exo-amino group at $\mathrm{C} 5$. The structures of the products have been unambiguously proven by X-Ray analyses (Scheme 57). ${ }^{111}$ Similar transformations have also been reported in formic acid instead of triethyl orthoformate with slightly lower yields. ${ }^{112}$ $<$ Scheme 57 near here><smiles>[R]NC1=NC(=O)NC(NN)N1</smiles>

286<smiles>[R]N([R])c1nc(=O)n2cn[nH]c2n1</smiles>

287

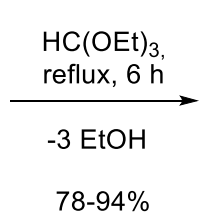

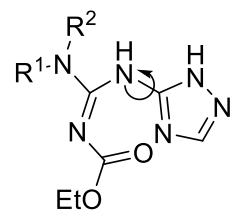

288<smiles></smiles>

$290 a$<smiles>[R]Nc1nc(=[18O])n2nc[nH]c2n1</smiles><smiles>[R]NC(=Nc1nnc(CC)o1)OC(=O)OCC</smiles>

289

Scheme 57

Oxidative cyclization of hydrazones $\mathbf{2 9 1}$ with lead(IV) tetraacetate in acetic acid proceeded also via a Dimroth-type rearrangement to produce 2-aryl-substituted triazolotriazinones 292 . The structure was also confirmed by X-ray crystal structure analysis (Scheme 58). ${ }^{113}<$ Scheme 58 near here $>$<smiles>[R]C=NNC1NC(=O)N=C([R1])N1</smiles>

291

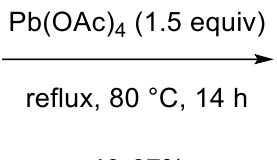

$49-67 \%$<smiles>[R]Nc1nc2nc([R])[nH]c(=O)n2n1</smiles>

292: $R^{3}=A r$

Scheme 58

\subsubsection{1(i)(b) $[1,2,4]$ triazolo[3,4,a] $[1,3,5]$ triazines}

Only one example of preparation of $[1,2,4]$ triazolo[3,4-a][1,3,5]triazines through the ring closure of the five-membered ring has been reported during the last decade. It concerns the potassium salts 296 of 5-dinitromethyltriazolotriazine derivatives, which have been synthesized in three steps from zwitterionic hydrazino compounds 293: formation of ethoxymethylidenehydrazino derivatives 294 by heating in triethylorthoformate, treatment with potassium hydroxide in methanol to afford potassium salt 295 followed by construction of the five-membered ring by heating in dimethylsulfoxide. X-ray crystal structure analyses have proven the structure of the products (Scheme 59). ${ }^{114}<$ Scheme 59 near here>

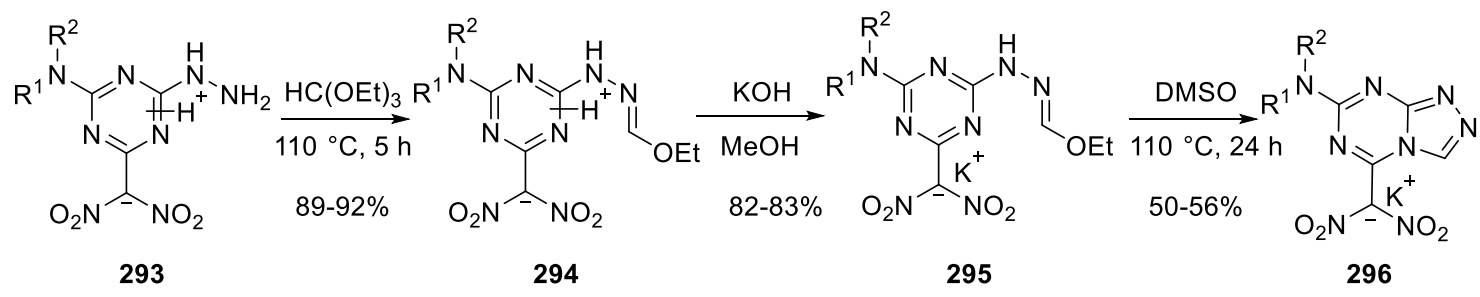

\section{Scheme 59}




\subsubsection{1(ii) closure of the six-membered ring}

11.6.5.1(ii)(a) [1,3,4]oxadiazolo- and thiadiazolo-[3,2-a][1,3,5]triazines

All the reported procedures for the access to this fused ring systems rely on the use of 2-amino1,3,4-oxa- or thia-diazole derivatives which undergo a cyclocondensation or an intramolecular cyclization to build the triazine ring.

Cyclization of ureas 297 with ethyl chloroformate yielded [1,3,4]oxadiazolo[3,2-a][1,3,5]triazine-5,7diones 298 . Alternatively, treatment with carbon disulfide furnished 5-thioxo derivatives 299 (Scheme 60). Good yields were obtained with both procedures (Scheme 60). ${ }^{115}<$ Scheme 60 near here>

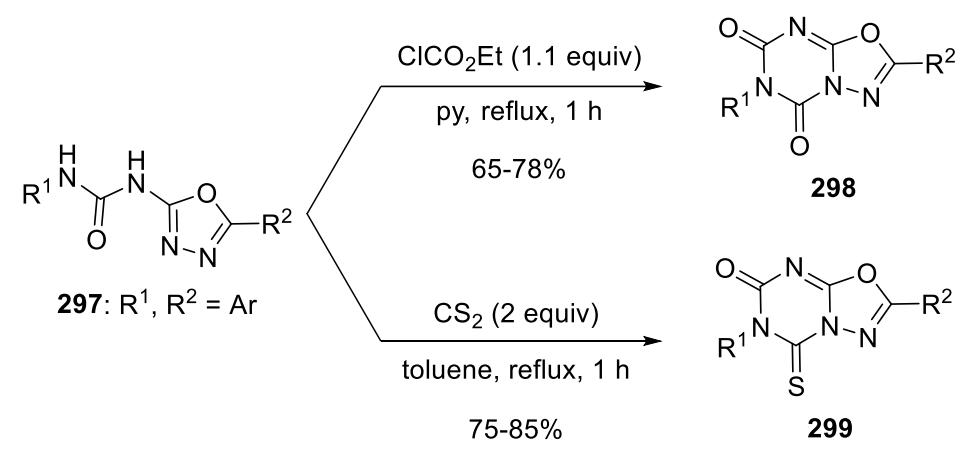

Scheme 60

Cyclodehydration of $\mathrm{N}$-(carbamothioyl)acetamides $\mathbf{3 0 0}$ with phosphorus pentachloride in refluxing phosphorus oxychloride furnished [1,3,4]thia- and oxadiazolo[3,2-a][1,3,5]triazine-7-thiones 301 (Scheme 61). ${ }^{116}<$ Scheme 61 near here $>$<smiles>[R]C(=O)NC(=S)Nc1n[nH]c(-c2[nH]c3ccc([R])cc3c2-c2ccccc2)n1</smiles>

300

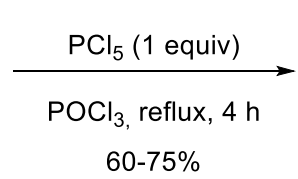

$60-75 \%$ $X=O, S$

$\mathrm{R}^{1}=\mathrm{Me}, \mathrm{Ph} ; \mathrm{R}^{2}=\mathrm{Me}, \mathrm{Cl}, \mathrm{Br}$<smiles>[R]c1ccc2[nH]c(-c3[X]c4nc(=S)nc([R])n4n3)c(-c3ccccc3)c2c1</smiles>

301

Scheme 61

As depicted in scheme 62, oxadiazolo[3,2-a][1,3,5]triazine-5-thione derivatives have been synthesized from imines 302. Treatment with ammonium thiocyanate in dioxane under reflux afforded various 7-aryl-substituted fused systems $\mathbf{3 0 3}$ while the use of phenyl isocyanate in refluxing toluene gave rise to 6-phenyl-7-aryl-disubstuted derivatives 304. In both cases, moderate to good yields were obtained. ${ }^{117} \mathrm{~A}$ multicomponent reaction between imines 302, aromatic aldehydes 305 and ammonium thiocyanate under microwave irradiation produced dihydro-oxadiazolotriazines 306 in good yields (the diastereoselectivities were not reported). ${ }^{118}$ (Scheme 62) <Scheme 62 near here> 


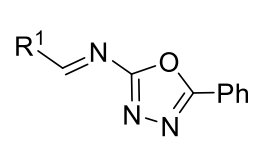

302: $R^{1}=A r$

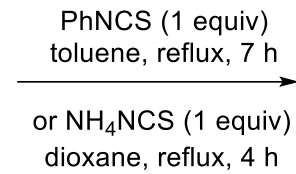

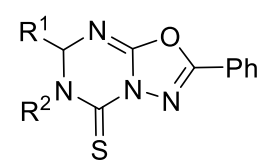

303: (from $\left.\mathrm{NH}_{4} \mathrm{NCS}\right) \mathrm{R}^{2}=\mathrm{H}, 63-86 \%$

304 (from PhNCS): $\mathrm{R}^{2}=\mathrm{Ph}, 60-83 \%$

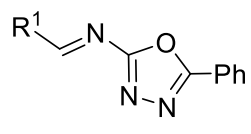

302: $\mathrm{R}^{1}=\mathrm{Ar}$

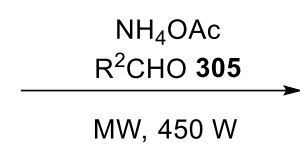

$55-83 \%$<smiles>[R]C1N=C2OC(c3ccccc3)=NN2C([R])N1</smiles>

306: $R^{1}=A r$

Scheme 62

2-Amino-1,3,4-thiadiazole $\mathbf{3 0 7}$ has been directly engaged in a multicomponent reaction with aromatic aldehydes $\mathbf{3 0 8}$ and acetamide produced thiadiazolotriazines $\mathbf{3 0 9}$ in excellent yields. The reactions were carried out in toluene under reflux in the presence of a catalytic amount of benzene sulphonamide dibromide. (Scheme 63$)^{119}<$ Scheme 63 near here $>$

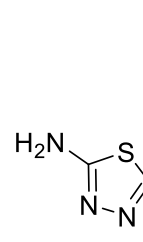

307

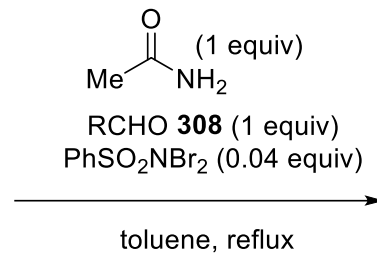

$90-95 \%$

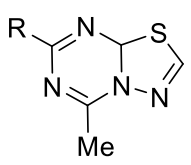

309: $\mathrm{R}=\mathrm{Ar}$

\section{Scheme 63}

\subsubsection{1(ii)(b) $[1,2,4]$ triazolo[1,5-a] $[1,3,5]$ triazines}

The access to $[1,2,4]$ triazolo[1,5- $a][1,3,5]$ triazines through the construction of the 6 -membered ring was achieved from 3-amino-1,2,4-triazole derivatives.

Dimethylformimidamides $\mathbf{3 1 0}$ reacted smoothly with cyanamide in the presence of sodium methoxide under heating to afford 7-amino-triazolotriazine 311. A modest yield of $32 \%$ was obtained from unsubstituted $\mathbf{3 1 0}$ while a substantial improvement was observed with a phenyl or 2aminophenyl substituent. ${ }^{120} \mathrm{~A}$ more convenient procedure was thereafter reported by directly engaging 3-amino-1,2,4-triazoles $\mathbf{3 1 2}$ in a three-component reaction with triethyl orthoformate and cyanamide under microwave irradiation. In this case, higher yields were obtained with very short reaction times (Scheme 64). ${ }^{121-122}<$ Scheme 64 near here>

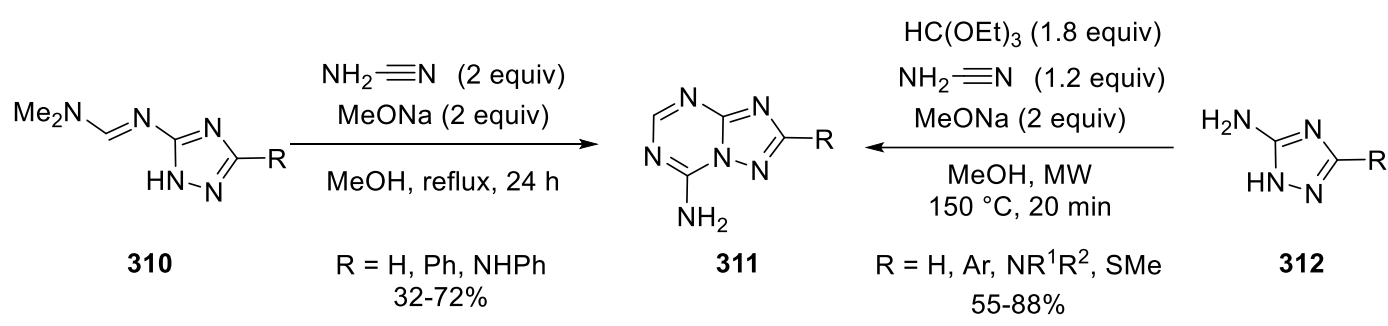

\section{Scheme 64}

It has been demonstrated that $\mathrm{N}$-cyanodithioiminocarbonate 313 can react with 3 -amino-1,2,4triazole 312 providing an access to 5-(methylthio)-[1,2,4]triazolo[1,5-a][1,3,5]triazin-7-amine 314, a 
synthetic intermediate of high interest. The reaction was carried out under neat at high temperature (Scheme 65). ${ }^{43-44,123}<$ Scheme 65 near here>

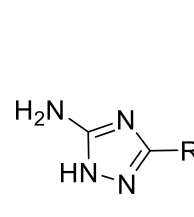

312

$$
\text { NC、N }{ }_{\mathrm{SMe}}^{\mathrm{SMe}}
$$

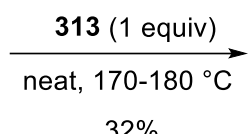

$\mathrm{R}=2$-furyl<smiles>[R]c1nc2nc(SC)nc(N)n2n1</smiles>

314

Scheme 65

Condensation of guanidine $\mathbf{3 1 5}$ with aromatic aldehydes $\mathbf{3 1 6}$ in the presence of a catalytic amount of piperidine in refluxing ethanol allowed the isolation of 6,7-dihydro-[1,2,4]triazolo[1,5a] $[1,3,5]$ triazin-5-amine 317 in very good yields (Scheme 66). ${ }^{124}<$ Scheme 66 near here $>$

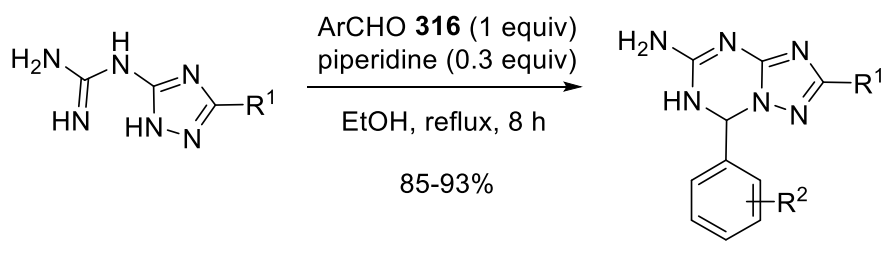

315

317: $R^{1}=2-p y, 3-p y, R^{2}=F, C F_{3}$

\section{Scheme 66}

The synthesis of 5,7-diaminotriazolotriazine $\mathbf{3 1 9}$ was achieved via the reaction of 3-amino-1,2,4triazole $\mathbf{3 1 2}$ with cyanoguanidine $\mathbf{3 1 8}$ in water containing a catalytic amount of concentrated hydrochloric acid. The reaction mechanism is assumed to proceed through the nucleophilic addition of the triazole exocyclic amino function on the cyano group of cyanoguanidine followed by subsequent cyclization through elimination of one molecule of ammonia (Scheme 67). ${ }^{125-126}$ $<$ Scheme 67 near here>

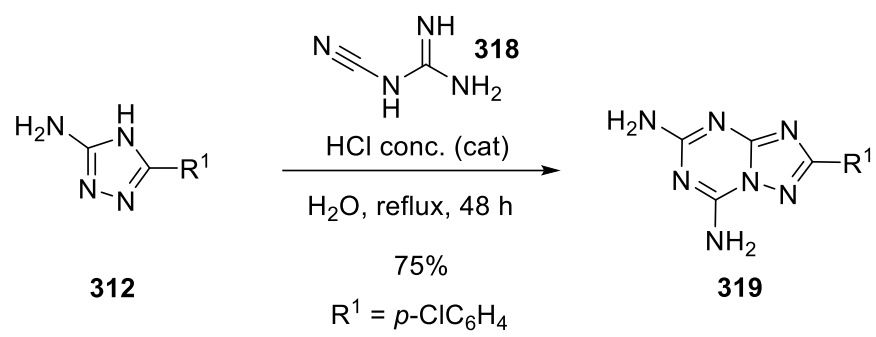

Scheme 67

Reaction of polychloro 2-azabutadiene $\mathbf{3 2 0}$ with 3-amino-1,2,4-triazoles $\mathbf{3 1 2}$ in the presence of triethylamine produced N1-imino triazole $\mathbf{3 2 1}$ which cyclized to dichloromethyl-containing triazolotriazine 322 upon treatment with sodium methoxide (Scheme 68). ${ }^{127}$ The structures were confirmed by X-Ray analysis. <Scheme 68 near here> 


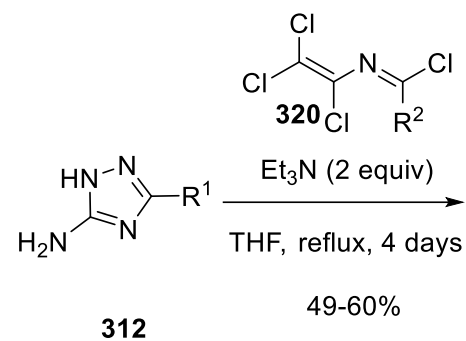

312<smiles>[R]C(=NC(Cl)=C(Cl)Cl)n1nc([R])nc1N</smiles>

$68-92 \%$<smiles>[R]c1nc2nc(C(Cl)Cl)nc([R])n2n1</smiles>

322

$\mathrm{R}^{1}=\mathrm{Ph}, \mathrm{CF}_{3}, \mathrm{SMe}$ $\mathrm{R}^{2}=\mathrm{Ph}, 4-\mathrm{MeC}_{6} \mathrm{H}_{4}$

\section{Scheme 68}

As shown in scheme 69, various trichloromethyl-containing triazolotriazines have been synthesized by using trichloroacetonitriles as reactive partners. 3-amino-1,2,4-triazoles 312 reacted with trichloroacetamide to afford trichloroacetamidines 323. The latter was subsequently cyclocondensed with triethyl orthoformate under reflux to form 5-trichloromethyl triazolotriazines 324a. ${ }^{128}$ Treatment of guanidine $\mathbf{3 2 5}$ with trichloroacetonitrile in toluene under reflux afforded 7amino derivative 324b through the elimination of ammonia. Alternatively, 7-thiomethyl derivative $324 \mathrm{c}$ was obtained from methyl carbamodithioate 326 through the elimination of hydrogen sulfide. ${ }^{48}$ Finally, the use of guanidine $\mathbf{3 1 5}$ furnished 5-amino-7-trichloromethyl triazolotriazines $\mathbf{3 2 7}$ in excellent yield (Scheme 69). ${ }^{46-47}<$ Scheme 69 near here>

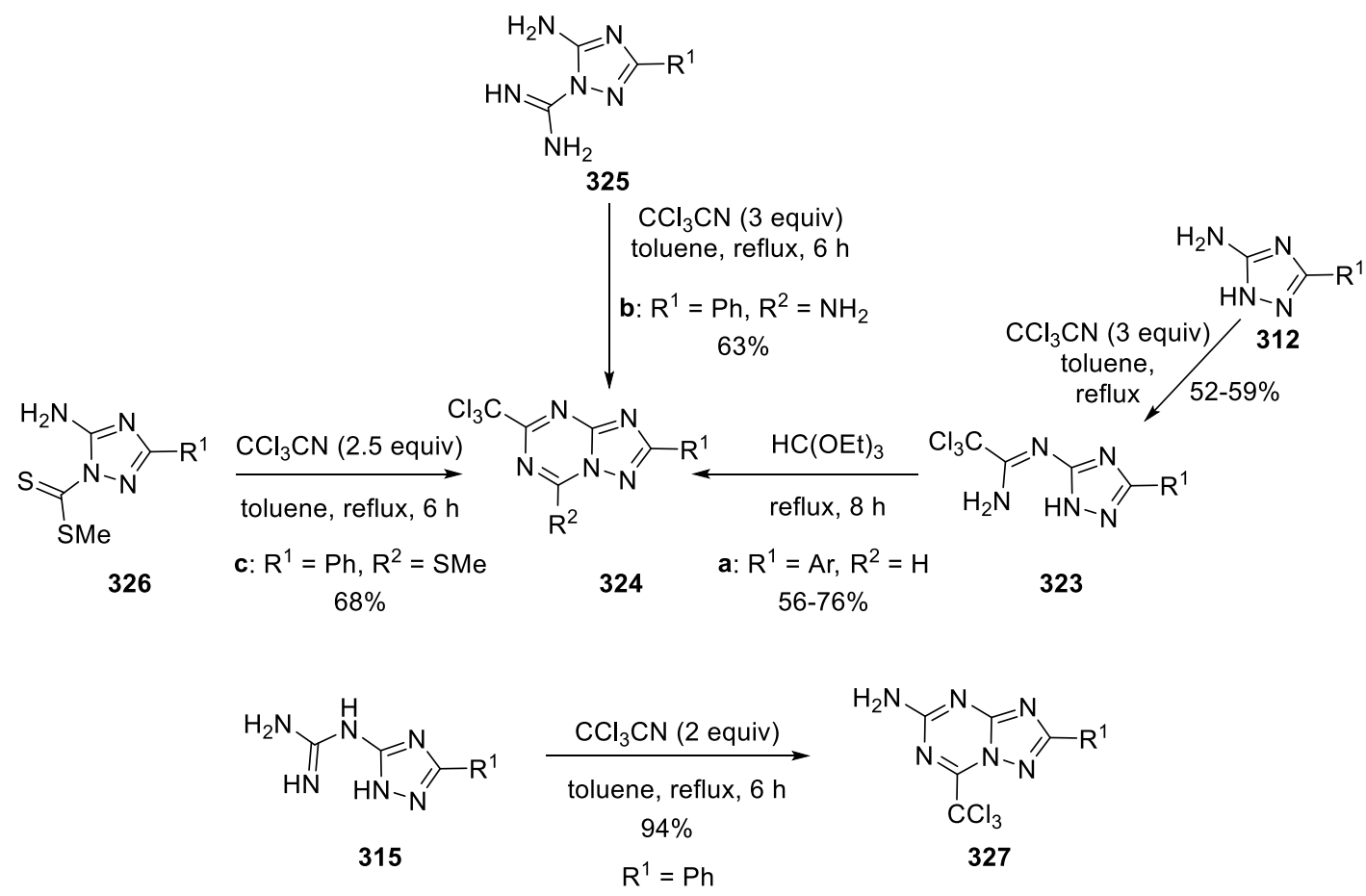

\section{Scheme 69}

It is worth mentioning that analogous reactions from guanidines $\mathbf{3 1 5}$ or $\mathbf{3 2 5}$ in ethanol instead of toluene proceeded through elimination of chloroform and resulted in the formation of 5,7diaminotriazolotriazines 319 . The role of ethanol in this reaction was tentatively explained by initial formation of imidate $\mathbf{3 2 8}$ which would react with the guanidine group to produce adduct $\mathbf{3 2 9}$. Subsequent elimination of chloroform would afford intermediate 330, which would undergo intramolecular cyclocondensation giving rise to $\mathbf{3 1 9}$ (Scheme 70 ). $.^{46-48}<$ Scheme 70 near here $>$ 

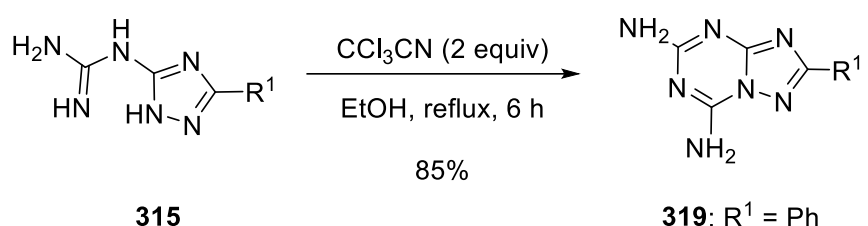<smiles>CCOC(C)(C)[Mg]O[Mg]</smiles><smiles>[R]c1nc(N)n(C(=N)N)n1</smiles>
319: $\mathrm{R}^{1}=\mathrm{Ph}$

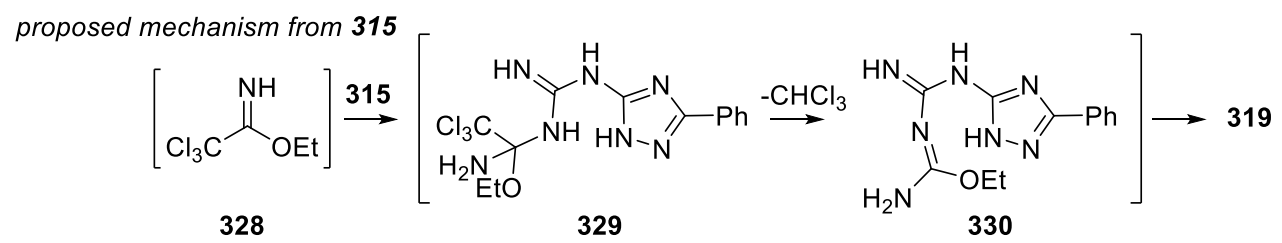

Scheme 70

Oxidative annulation reaction of amidines 331 with benzaldehyde produced 5,7diphenyltriazolotriazine 335. In this transformation, condensation of $\mathbf{3 3 1}$ with benzaldehyde would form intermediate 332. The latter would cyclize in the presence of a catalytic amount of copper (I) and iodine through complex $\mathbf{3 3 3}$ to build dihydrotriazine $\mathbf{3 3 4}$ followed by oxidation with 2,3dichloro-5,6-dicyano-1,4-benzoquinone (DDQ) (Scheme 71). ${ }^{129}<$ Scheme 71 near here $>$

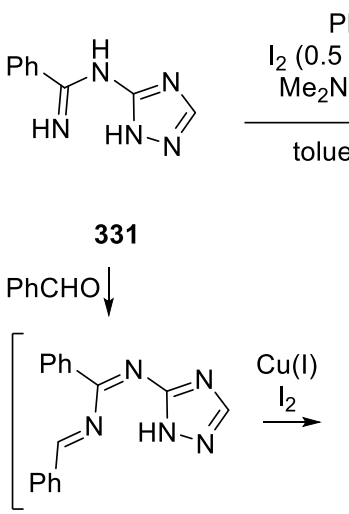

332
$\mathrm{PhCHO}$ ( 1.5 equiv) ( 0.5 equiv), Cul (0.1 equiv) $\mathrm{Me}_{2} \mathrm{NCH}_{2} \mathrm{CO}_{2} \mathrm{H}$ (0.2 equiv)

toluene, reflux, then $D D Q$

$50 \%$<smiles>c1ccc(-c2nc(-c3ccccc3)n3ncnc3n2)cc1</smiles>

335

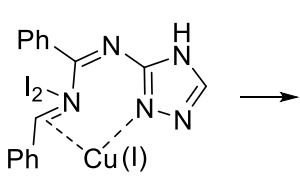

333<smiles>c1ccc(C2=Nc3nc(-c4ccccc4)nn3C(c3ccccc3)N2)cc1</smiles>

334

\section{Scheme 71}

$\mathrm{Rh}$ (III)-catalyzed imidoyl C-H amidation/cyclodehydration of $\mathbf{N}$-triazolo imines $\mathbf{3 3 6}$ with dioxazolone 337 enabled the construction of 5,7-disubstitued triazolotriazine $\mathbf{3 3 8}$ in moderate yields (Scheme 72). ${ }^{130}<$ Scheme 72 near here $>$

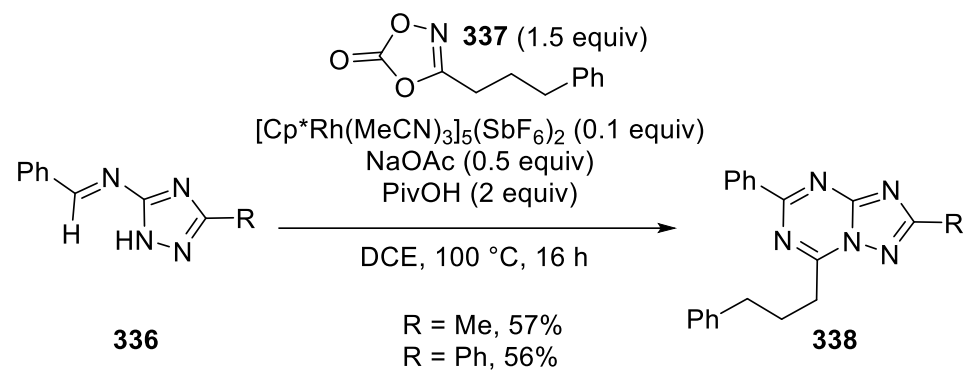

\section{Scheme 72}

Heating a solution of 3-amino-1,2,4-triazole $\mathbf{3 1 2}$ and 4-oxo-1,3-benzoxazinium perchlorate $\mathbf{3 3 9}$ in DMF furnished bicyclic system 340. According to the authors, the exocyclic nitrogen atom of $\mathbf{3 1 2}$ would react with the electrophilic carbonyl site of salt 339 (Scheme 73 ). ${ }^{131}<$ Scheme 73 near here $>$ 


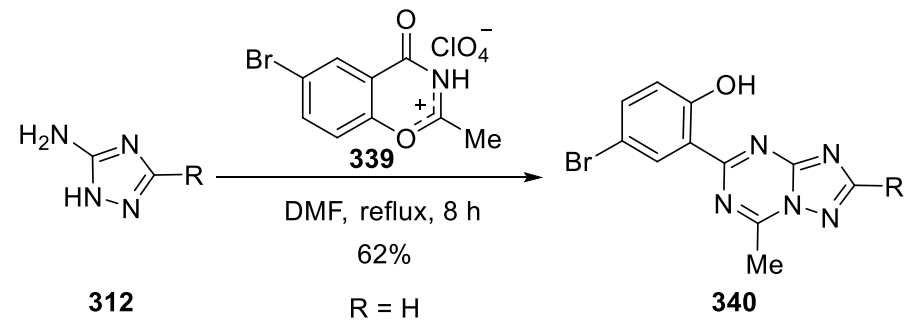

Scheme 73

$[1,2,4]$ Triazolo[1,5- $a][1,3,5]$ triazin-7-one derivatives $\mathbf{3 4 3}$ have been accessed through the reaction between 1,2,4-triazole-3,5-diamine $\mathbf{3 4 1}$ and $\mathrm{N}$-triazolide imidates $\mathbf{3 4 2}$ in good yields. The structure of the reported bicyclic compounds has been unambiguously proven by X-ray crystallography (Scheme 74). ${ }^{132}<$ Scheme 74 near here $>$

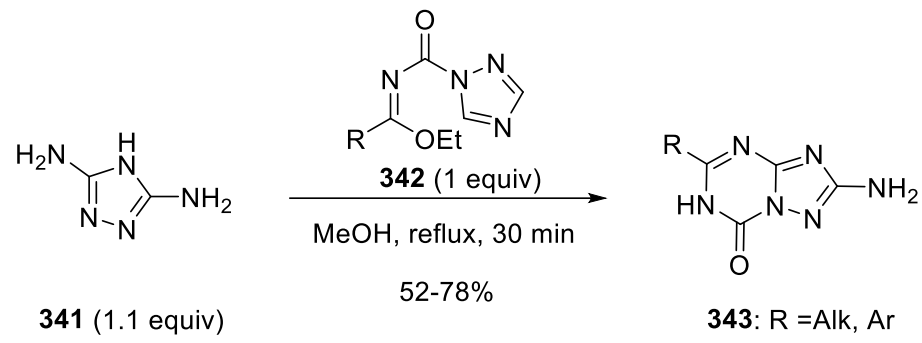

Scheme 74

As summarized in scheme 75, reactions between 3-amino-1,2,4-triazoles $\mathbf{3 1 2}$ and iso(thio)cyanate derivatives provide efficient ways for the construction of various $[1,2,4]$ triazolo[1,5- $a][1,3,5]$ triazin(thi)ones or triazin-diones over two steps. The use of benzoylisothiocyanate $\mathbf{3 4 4}$ yielded the corresponding open chain thiourea analogue $\mathbf{3 4 5}$ which cyclized to the triazolotriazine-5-thione derivative 346 upon heating under reflux in DMF. ${ }^{88}$ The use of ethoxycarbonyliso(thio)cyanates 347 and $\mathbf{3 4 8}$ in DMF gave the (thio)ureas $\mathbf{3 4 9}$ and $\mathbf{3 5 0}$ derivatives which upon heterocyclization in alkaline medium led to triazolotriazine-5,7-diones 351 and 5-thioxotriazolotriazine-7-ones 352 respectively. ${ }^{55-56,133-134}$ Interestingly, when the reaction between $\mathbf{3 1 2}$ and $\mathbf{3 4 8}$ was carried out under kinetic control in acetone, it was possible to isolate the thiourea $\mathbf{3 5 3}$ arising from the $\mathrm{N}$-alkylation of the triazole ring. As such, cyclization in ethanolic sodium hydroxide under reflux yielded 7thioxotriazolotriazine-5-ones $\mathbf{3 5 4} .{ }^{56}$ (Scheme 75 ) <Scheme 75 near here> 
reaction with benzoyl isothiocyanates

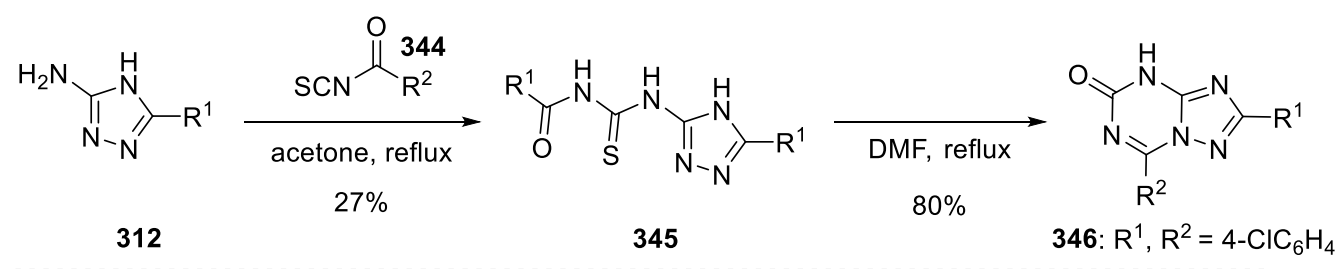

reactions with ethoxycarbonyl iso(thio)cyanates
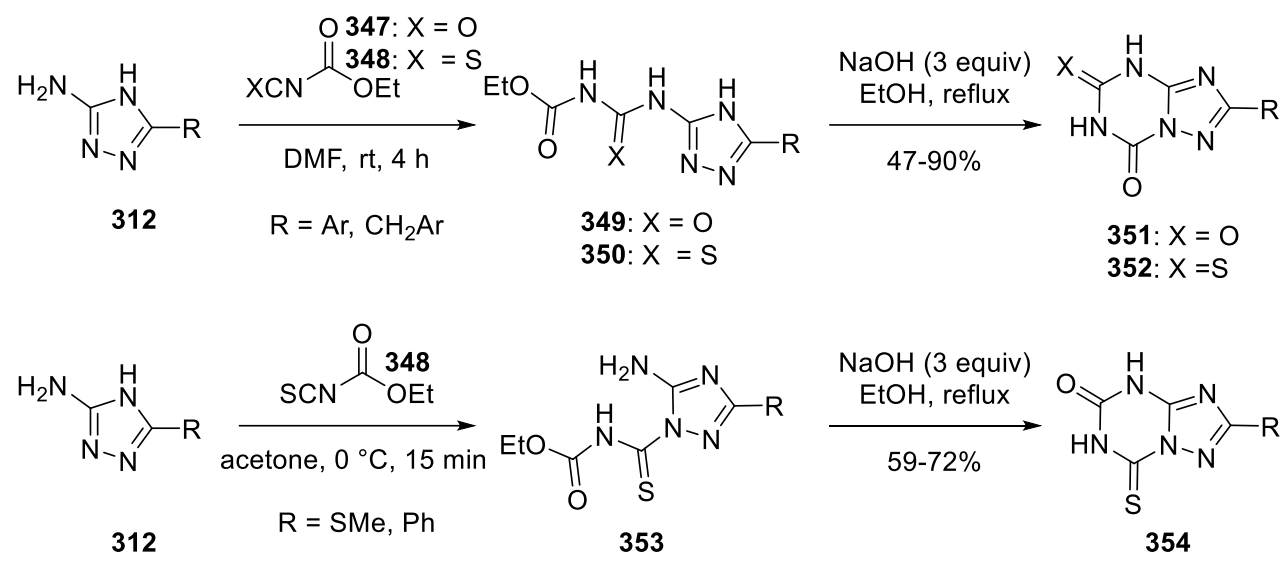

Scheme 75

\subsubsection{1(ii)(c) [1,2,4]triazolo[3,4-a][1,3,5]triazines}

Recently, Hajri et al. have reported the synthesis of triazolotriazin-amines $\mathbf{3 5 6}$ through the reaction between carboximidates $\mathbf{3 5 5}$ and cyanamide in methanol under reflux (Scheme 76). ${ }^{65}$ The same authors prepared dihydrotriazolotriazines $\mathbf{3 5 9}$ by cyclocondensation of amidines $\mathbf{3 5 7}$ with carbonyl compounds 358 in the presence of a catalytic amount of $p$-toluenesulfonic acid in 1,4-dioxane under reflux. ${ }^{135}$ Unfortunately, there was no X-ray crystallography analyses to ascertain the structure of the obtained regioisomers of type $[1,2,4]$ triazolo[3,4- $a][1,3,5]$ triazines rather than $[1,2,4]$ triazolo[1,5a] $[1,3,5]$ triazine. $<$ Scheme 76 near here><smiles>[R]C(=Nc1ncn[nH]1)OCC</smiles>

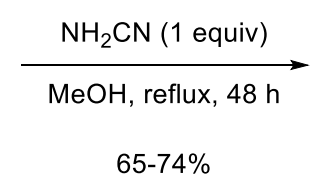

355<smiles>[R][Y]([R])=Nc1ncn[nH]1</smiles>

357<smiles>[R]c1nc(N)n2cnnc2n1</smiles>

$\mathrm{R}=\mathrm{Me}, \mathrm{Et}, \mathrm{Ph}$

356

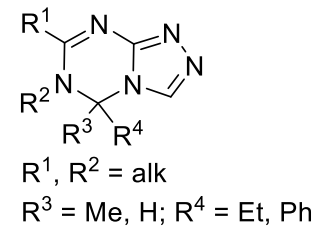

359

Scheme 76 


\subsection{Synthesis of $b$-fused $[1,2,4]$-triazines}

During the last period, $[1,2,4]$ triazolo[4,3-b][1,2,4]triazines (structures 10 ) are the only type of $[1,2,4]$ triazines which have been described with $b$-fusion. The construction of these fused bicyclic systems could proceed either through the ring closure of the five-membered ring or the six-membered ring.

\subsubsection{2(i) closure of the five-membered ring}

3-Hydrazino-1,2,4-triazine and their derivatives were suitable starting materials for the cyclization of 1,2,4-triazole rings with $b$-fusion (Table 4 ). In these cases, the heterocyclization of such compounds proceeded regioselectively at the $\mathrm{N} 2$ atom of the triazine ring providing the $[1,2,4]$ triazolo[4,3$b][1,2,4]$-triazine derivatives and not [1,2,4]triazines with $c$-fusions (see section 11.6.5.3(i)). For instance, reaction of $\mathbf{3 6 0}$ with carbon disulfide in refluxing ethanol in the presence of potassium hydroxide allowed the construction of fused 1,2,4-triazole-3-thione 361 in good yield (entry 1). . $^{37,54}$ Treatment of $\mathbf{3 6 0}$ with benzoyl cyanide furnished fused system $\mathbf{3 6 2}$ through elimination of hydrogen cyanide and water (entry 2). Interestingly, diimino derivative $\mathbf{3 6 3}$ was obtained upon condensation with two equivalents of cycanoacetic acid (entry 3). ${ }^{136}$ Thermal cyclocondensation of hydrazine 360 with triethyl orthoformate afforded triazolotriazine 365 (entry 4). ${ }^{137}$ Hydrazides 366 (easily prepared via EDCl-mediated coupling of hydrazine $\mathbf{3 6 0}$ with 2-arylacetic acids) could cyclize to triazolotriazines 367 under heating in acetic acid in moderate to excellent yields (entry 5). ${ }^{138-139}$ Of note, such an approach has been applied to the synthesis $\mathrm{CF}_{2}$-containing compounds. Treatment of hydrazone 368 with bromine in acetic acid under heating resulted in the formation of dihydro-triazolotriazine 369 (entry 6). ${ }^{140}$ Such a cyclization has been also carried out from hydrazone $\mathbf{3 7 0}$ in refluxing anhydride acetic allowing the construction of $\mathrm{N}$-acetyl triazoles $\mathbf{3 7 1}$ in good yields (entry 7). ${ }^{54}<$ Table 4 near here> 
Table 4: Preparation of $[1,2,4]$ triazolo[4,3-b]triazines from 3-hydrazino-1,2,4-triazine and their derivatives.

\begin{tabular}{|c|c|c|c|c|c|}
\hline Entry & Starting material & Reaction conditions & Product & Yield & Ref. \\
\hline 1 & 360 & $\begin{array}{l}\mathrm{CS}_{2}, \mathrm{KOH}, \mathrm{EtOH}, \\
\text { reflux, } 15 \mathrm{~h}\end{array}$ & 361 & $78 \%$ & 37,54 \\
\hline 2 & 360 & $\begin{array}{c}\text { PhCOCN (2 equiv), } \\
\text { DMF, reflux, } \\
2 \mathrm{~h}\end{array}$ & & $57 \%$ & 136 \\
\hline 3 & 360 & $\begin{array}{c}\mathrm{CNCH}_{2} \mathrm{COOH} \\
\text { (2 equiv), DMF, } \\
\text { reflux, } 2 \mathrm{~h}\end{array}$ & 363 & $69 \%$ & 136 \\
\hline 4 & 364 & $\mathrm{HC}(\mathrm{OEt})_{3}$, reflux, $2 \mathrm{~h}$ & 365 & $63 \%$ & 137 \\
\hline 5 & $\begin{array}{c}X=H, F \\
R=A r, O A \\
366\end{array}$ & $\mathrm{AcOH}, 100^{\circ} \mathrm{C}, 2 \mathrm{~h}$ & 367 & $63-88 \%$ & $138-139$ \\
\hline 6 & $\begin{array}{l}=\mathrm{Cl}, \mathrm{Br} \\
368\end{array}$ & $\mathrm{Br}_{2}, \mathrm{AcOH}, \mathrm{rt}, 2 \mathrm{~h}$ & 369 & $61-76 \%$ & 140 \\
\hline 7 & $\begin{array}{l}=N \\
n=3,4 \quad O H \\
370\end{array}$ & $\mathrm{Ac}_{2} \mathrm{O}$, reflux, $1 \mathrm{~h}$ & $\begin{array}{l}\mathrm{AcO}^{X} \\
371\end{array}$ & $75-78 \%$ & 54 \\
\hline
\end{tabular}

In a similar fashion, 3-hydrazino-1,2,4-triazin-5-ones have been employed to access triazolotriazinone derivatives. For example, acylation of $\mathbf{3 7 2}$ with $\mathrm{N}, \mathrm{N}$-dimethylcarbamoyl bromide $\mathbf{3 7 3}$ led to the formation of bicyclic compound $\mathbf{3 7 4}$ in $\mathbf{7 8 \%}$ yield. It is worth mentioning that this cyclization did not occur when the phenyl group was replaced by a tert-butyl substituent at $\mathrm{C} 6$ (Scheme 77). ${ }^{141}<$ Scheme 77 near here> 


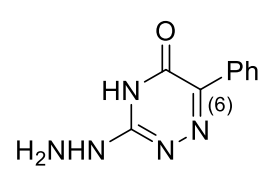

372

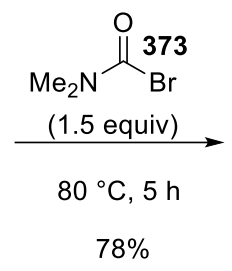

Scheme 77<smiles></smiles>

374

As depicted in scheme 78, the multi nucleophilic centered 4-amino-hydrazinotriazinones $\mathbf{3 7 5}$ have been also demonstrated as versatile building blocks for the construction of various heterocyclic derivatives bearing the 1,2,4-triazine moiety. More specifically, the construction of triazolotriazines has been performed in acetic acid under reflux to produce the 6-methyl derivative $\mathbf{3 7 6}$ in good yield. ${ }^{142}$ Condensation of $\mathbf{3 7 5}$ with triethyl orthoformate in refluxing ethanol in the presence of a catalytic amount of acetic acid furnished triazolotriazine 377. ${ }^{143}$ Alternatively, thioxotriazolotriazinone $\mathbf{3 7 8}$ could be obtained by treatment of $\mathbf{3 7 5}$ with carbon disulfide in pyridine under reflux. ${ }^{21}<$ Scheme 78 near here $>$

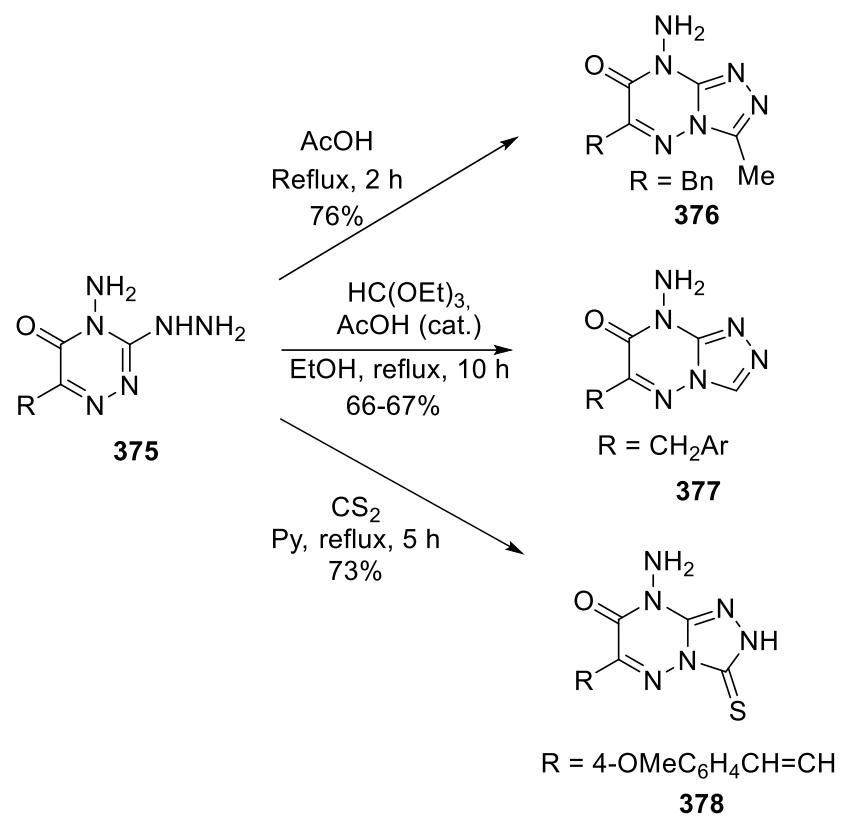

Scheme 78

Finally, reaction of $\mathbf{3 7 5}$ with various carbonyl compounds allowed the regioselective formation of the corresponding hydrazones 379. The latter could be treated with acetic anhydride to access triacetylated heterobicyclic derivatives 380. ${ }^{142}$ Noteworthy, such an approach has been employed for the construction of spirocyclic compounds $\mathbf{3 8 1}$ by using isatin as carbonyl derivative (Scheme 79). ${ }^{143}<$ Scheme 79 near here> 


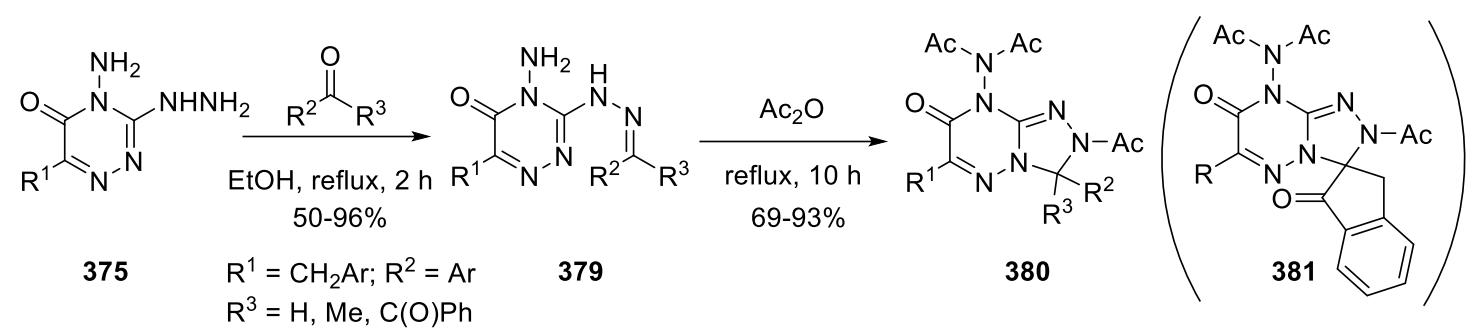

Scheme 79

Treatment of thiosemicarbazide $\mathbf{3 8 2}$ with methyl iodide and sodium acetate in boiling ethanol afforded the triazolotriazine 383. From a mechanistic point of view, methylation of the thione sulfur would furnish the corresponding thioether which would undergo intramolecular cyclization at N2 of the 1,2,4-triazin-5(2H)-one $\mathbf{3 8 3}$ to build the triazole ring after elimination of methylmercaptan (Scheme 80). ${ }^{144}$ In contrast, using dicyclohexylcarbodiimide as alkylating agent led to the $c$-fused 1,2,4-triazine through cyclization at N4 (see section 11.6.5.3(i)). <Scheme 80 near here>

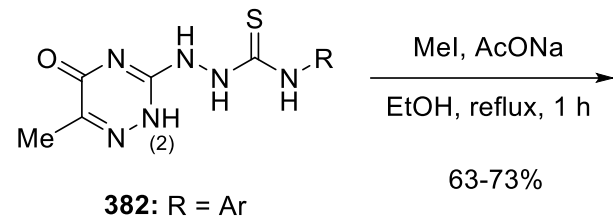

Scheme 80

\subsubsection{2(ii) closure of the six-membered ring}

As previously mentioned in CHEC-III(2008), all procedures for the synthesis of [1,2,4]triazolo[4,3b] $[1,2,4]$ triazine derivatives (structures 10 ) by cyclization of the six-membered ring exploit the reactivity of 3,4-diamino[1,2,4]triazoles 384 . These bis-nucleophiles can easily react with various reagents bearing two electrophilic sites in vicinal positions (Table 5). For instance, Fusco et al. have reported the condensation of such diamines with various cyclic 1,2-aromatic diketones 385 to furnish the corresponding multicyclic ring systems 386 (entry 1). ${ }^{6}$ The reaction was carried out in acetic acid under reflux overnight. Symmetric compound $\mathbf{3 8 8}$ has been obtained by using tetraketone $\mathbf{3 8 7}$ (entry 2). The same kind of transformation has been described by Nami et al. with isatin 389 in methanol under reflux producing tricyclic compound 390 in good yield (entry 3). ${ }^{145} 3-(\alpha-$ tosyloxyacetyl)coumarins $\mathbf{3 9 1}$ (easily prepared from 3-acetylcoumarins and Köser reagent) has been also used as efficient reaction partners to access various coumarinyl-containing triazolotriazines $\mathbf{3 9 2}$ in high yield. The reaction proceeded successfully in ethanol under reflux in the presence of a catalytic amount of potassium carbonate (entry 4). $.^{146}<$ Table 5 near here> 
Table 5: Construction of $[1,2,4]$ triazolo[4,3-b][1,2,4]triazines by condensation of diamines 25 with bis-electrophilic reagents

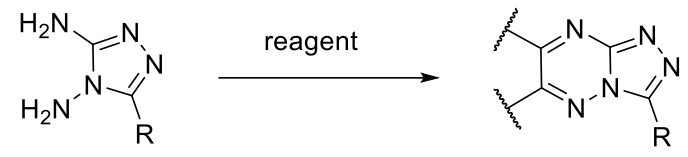

384

Entry Reaction conditions

A simple, efficient and environmentally friendly approach has been reported by Zonouzi and Mahdavi et al. via a three-component reaction of diamines 384, aldehyde 393 and isocyanide 394 under solvent-free condition at $150{ }^{\circ} \mathrm{C}$. The reactions went to completion within 4 hours furnishing the corresponding products 395 in high yields. From a mechanistic point of view, regioselective condensation of aldehyde $\mathbf{3 9 3}$ with the 4-amino substituent of $\mathbf{3 8 4}$ would form imine $\mathbf{3 9 6}$ which would undergo nucleophilic addition of isocyanide 394 to produce intermediate 397 . Building of the six-membered ring by intramolecular addition of the 3-amino substituent on the nitrilium followed by subsequent tautomerization and aerobic oxidation of $\mathbf{3 9 8}$ would yield triazolotriazines 395 (Scheme 81). ${ }^{147}<$ Scheme 81 near here> 


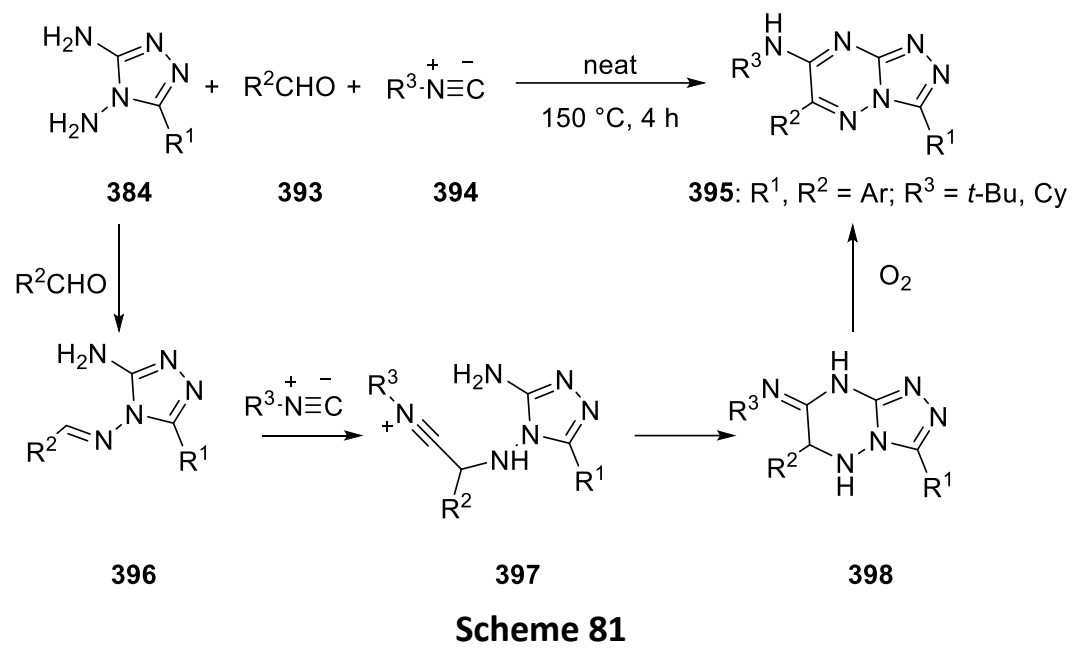

\subsection{Synthesis of $c$-fused $[1,2,4]$-triazines}

\subsubsection{3(i) closure of the five-membered ring}

As depicted in scheme 82, 4-amino-3-mercapto[1,2,4]triazine-5(4H)ones 399 are versatile starting reagents for the construction of various c-fused 1,2,4-triazin-4-ones. Condensation with an equimolar amount of carboxylic acid in refluxing phosphorus oxychloride offered a rapid access to $4 H$-[1,3,4]thiadiazolo[2,3-c][1,2,4]triazin-4-ones 400. Aromatic as long as aliphatic carboxylic acids could be efficiently used and high yields were generally obtained. ${ }^{148-155}$ Treatment with ethylcyanoacetate in polyphosphoric acid under heating produced acetate derivative $\mathbf{4 0 1}$ in good yield through elimination of ammonia. ${ }^{156}$ Reaction with ethyl chloroformate delivered fused 1,3,4thiadiazolidin-2-one $\mathbf{4 0 2}$ while thione derivatives $\mathbf{4 0 3}$ were obtained by treatment with carbon disulfide in an ethanolic solution of potassium hydroxide. ${ }^{57,157}$ Addition of ammonium thiocyanate to compound 399 in glacial acetic acid yielded fused 1,2,4-triazolidine-3-thione $\mathbf{4 0 4}^{157}$ while $\mathrm{N}$-phenyl substituted derivative $\mathbf{4 0 5}$ has been produced in excellent yield by treatment with phenyl isothiocyanate in the presence of potassium carbonate. ${ }^{148}$ (Scheme 82 ) <Scheme 82 near here> 


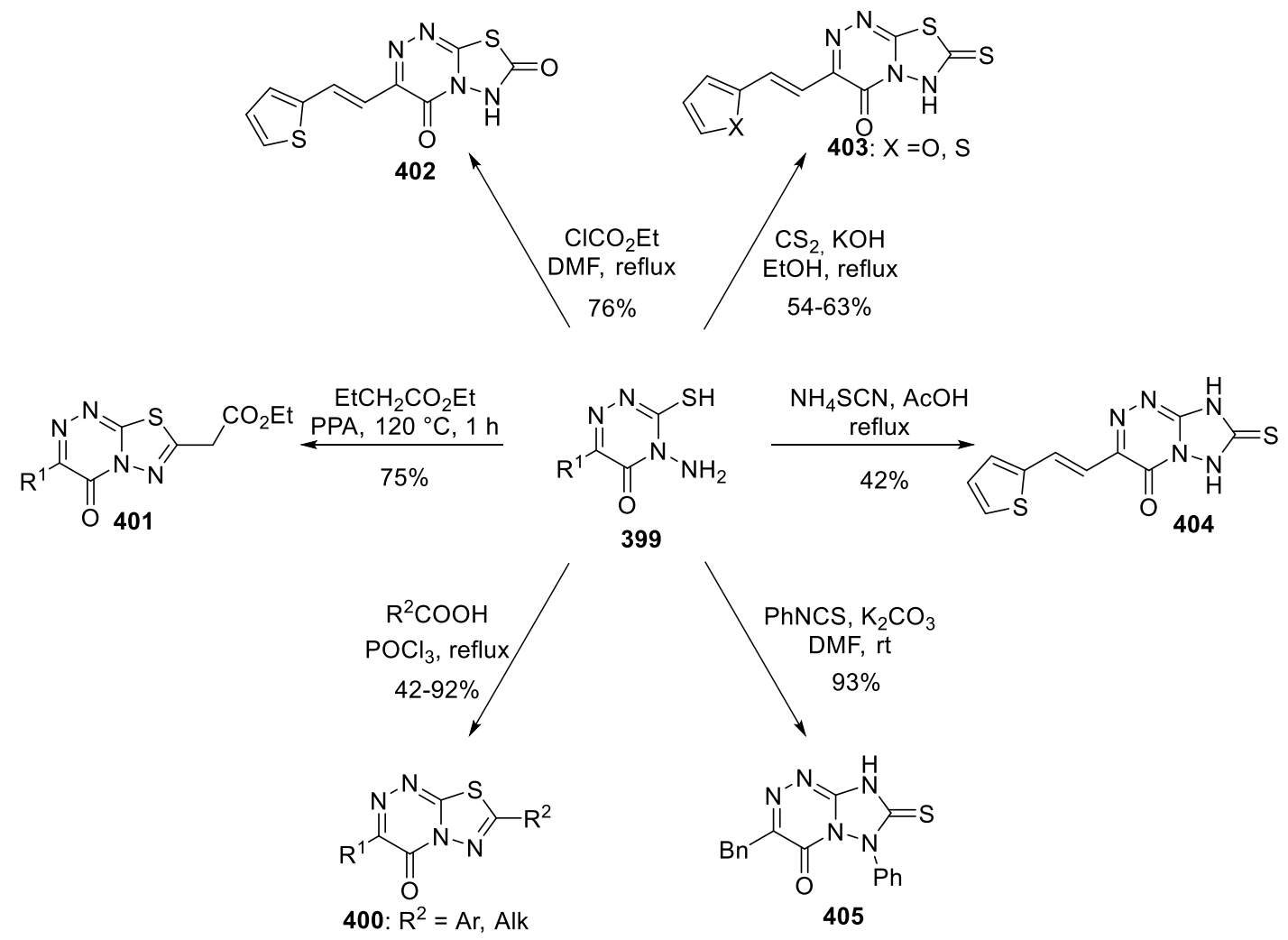

Scheme 82

Reaction between methylthio derivative 406 and benzoyl isothiocyanate 407 enabled the construction of fused thiadiazole $\mathbf{4 0 8}$ in moderate yield. ${ }^{158}$ This transformation has been also reported via a three-component reaction between triazinone 399, aroyl chlorides 409 and ammonium thiocyanate $\mathbf{4 1 0}$ in the presence of a catalytic amount of $\mathrm{N}$-methylimidazole under solvent-free conditions to afford fused thiadiazole derivatives $\mathbf{4 0 8}$ in excellent yields. In this case, the aroyl isothiocyanate was in situ generated by reaction between aroyl chloride $\mathbf{4 0 9}$ and ammonium thiocyanate $\mathbf{4 1 0}$ and would be activated by $\mathbf{N}$-methylimidazole through intermediate $\mathbf{4 1 1}$ (Scheme 83). ${ }^{159}<$ Scheme 83 near here $>$

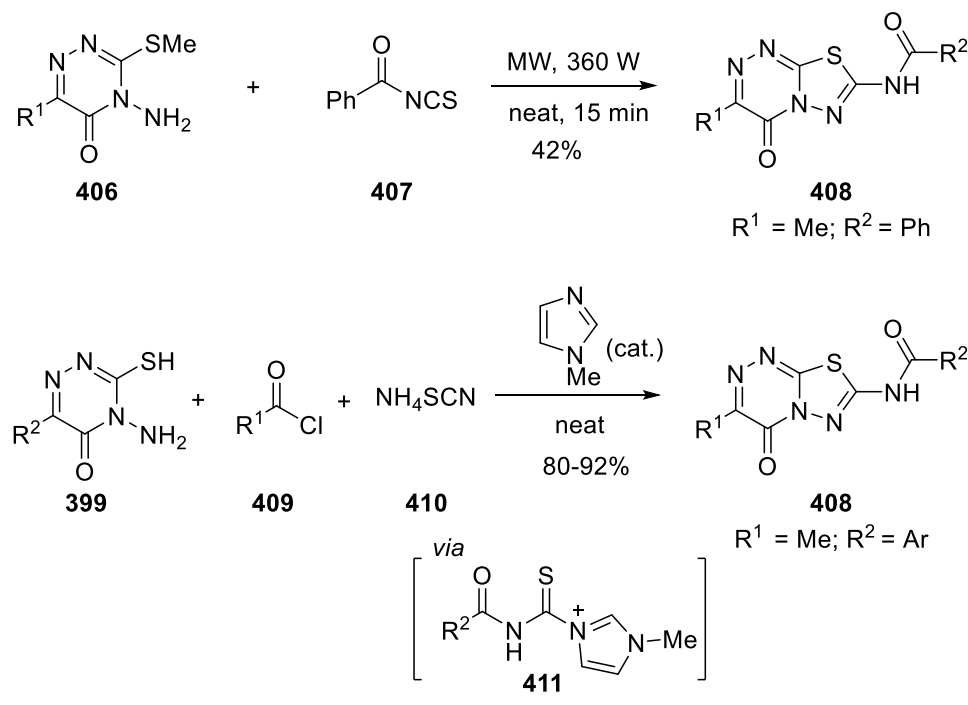

Scheme 83 
In a similar fashion, various $[1,3,4]$ thiadiazolo[2,3-c] $[1,2,4]$ triazines $413-415$ containing an indole moiety have been synthesized by cyclocondensation reaction of 4 -amino- $4 \mathrm{H}-[1,2,4]$ triazino[5,6b]indole-3-thiol 412 with triethyl orthoformate, ethyl chloroformate or carbone disulfide respectively (Scheme 84 ). ${ }^{160}<$ Scheme 84 near here>

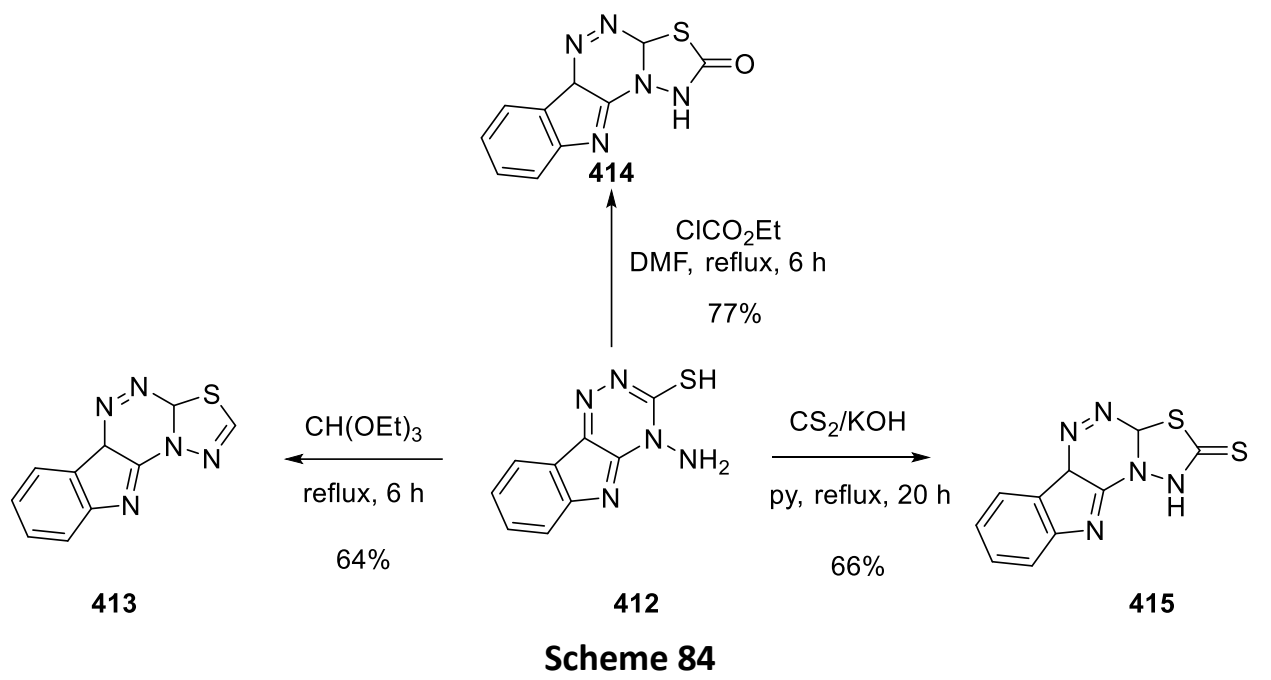

The oxidative cyclization of triazinylhydrazone derivatives has been used to access $[1,2,4]$ triazolo[3,4-c] $[1,2,4]$ triazines. As discussed above (see section 11.6.5.2(i)), such starting reagents have been also applied to the construction of 1,2,4-triazines with $b$ fusion. The comparative nucleophilicities of N2 or N4 in the 1,2,4-triazine ring might govern the course of orientation of the reaction and the substituents on the 1,2,4-triazine ring might play an important role. As shown in table 6, phenyliodine(III) diacetate, ${ }^{161}$ thionyl chloride ${ }^{140,162}$ and acetic anhydride ${ }^{163}$ have been employed to perform this oxidative transformation. It is worth pointing out that the cyclization of 368 with thionyl chloride gave rise to [1,2,4]triazolo[3,4-c]triazines 418 while $b$-fused 1,2,4-triazines were obtained when bromine in acetic acid was used as an oxidant highlighting the crucial role of the reaction conditions on the regioselectivity (Table 6, entry 2 vs Table 4, entry 6). <Table 6 near here> 
Table 6: Preparation of $[1,2,4]$ triazolo[3,4-c]triazines through oxidative cyclization of triazinylhydrazone derivatives.

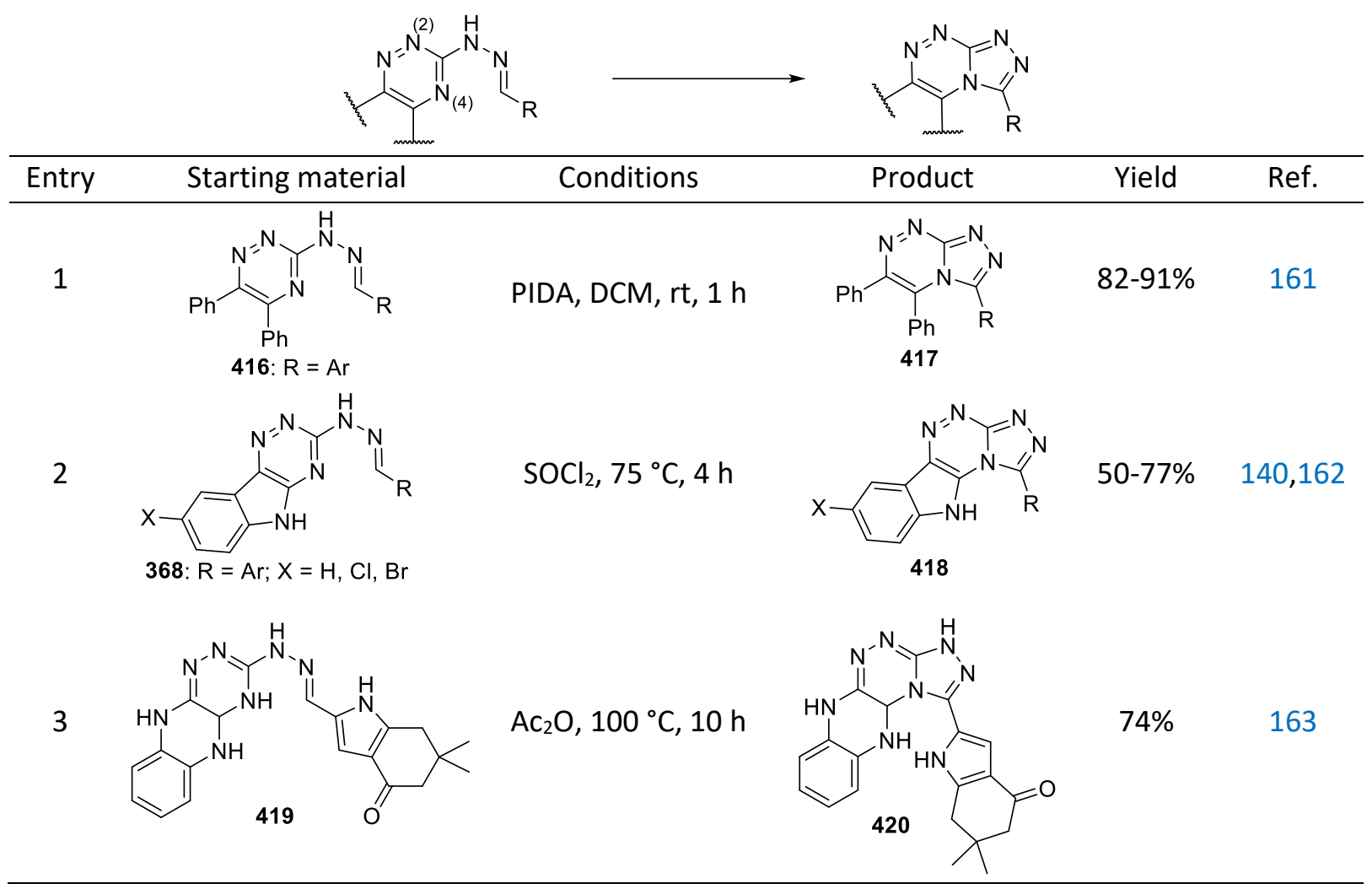

Heating hydrazines $\mathbf{4 2 1}$ in diethyl malonate afforded triazolotriazines $\mathbf{4 2 2}$ bearing an ester functional group (Scheme 85). ${ }^{163}<$ Scheme 85 near here $>$<smiles>NNc1nnc2c(n1)Nc1ccccc1N2</smiles>

421

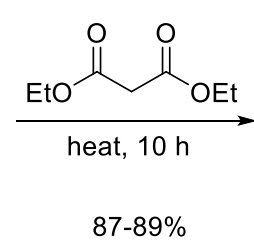

Scheme 85<smiles>CCOC(=O)Cc1nnc2n1C1=Nc3ccccc3NC1NN2</smiles>

422: $\mathrm{n}=0,1$

S-Alkylation of thiosemicarbazide $\mathbf{3 8 2}$ with dicyclohexylcarbodiimide in toluene under reflux afforded the triazolotriazine $\mathbf{4 2 3}$ via cyclization at the $\mathbf{N} 4$ position of the triazinone (Scheme 86). ${ }^{144}$ In contrast, as previously discussed (see section 11.6.5.2(i)), the use of methyl iodide as alkylating agent led to the $b$-fused 1,2,4-triazine. <Scheme 86 near here>

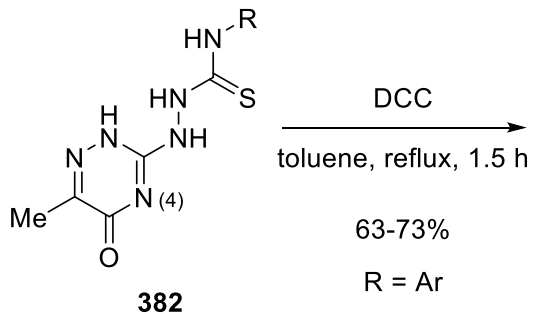<smiles>Cc1nnc2[nH]c(NP)nn2c1=O</smiles>

382

$\mathrm{R}=\mathrm{Ar}$

Scheme 86 


\subsubsection{3(ii) closure of the six-membered ring}

\subsubsection{3(ii)(a) $[1,3,4]$ thiadiazolo[2,3-c][1,2,4]triazines}

Two publications are related to the preparation of $[1,3,4]$ thiadiazolo[2,3-c] $[1,2,4]$ triazine derivatives through the ring closure of the six-membered ring. In both cases 5-hydrazino-1,3,4-thiadiazole derivatives $\mathbf{4 2 4}$ were used as starting reagents. Treatment with phenacyl bromides in refluxing ethanol furnished 4-aryl-2H-[1,3,4]thiadiazolo[2,3-c][1,2,4]triazine derivative $\mathbf{4 2 5}$ and 3-aryl-4H$[1,3,4]$ thiadiazolo[2,3-c][1,2,4]triazine $\mathbf{4 2 6}$ when the reaction was performed in the presence of potassium hydroxide. Different [1,3,4] thiadiazolo[2,3-c][1,2,4]triazin-4-one derivatives 427-431 have been obtained by using monochloroacetic acid, dichloroacetic acid, $\alpha$-ketoacids $\mathbf{4 3 2 - 4 3 3}$ or diketone 434. Finally, condensation with diethyl oxalate in THF afforded [1,3,4]thiadiazolo[2,3c] $[1,2,4]$ triazine-3,4-dione 435 (Scheme 87 ). ${ }^{164-165}<$ Scheme 87 near here>

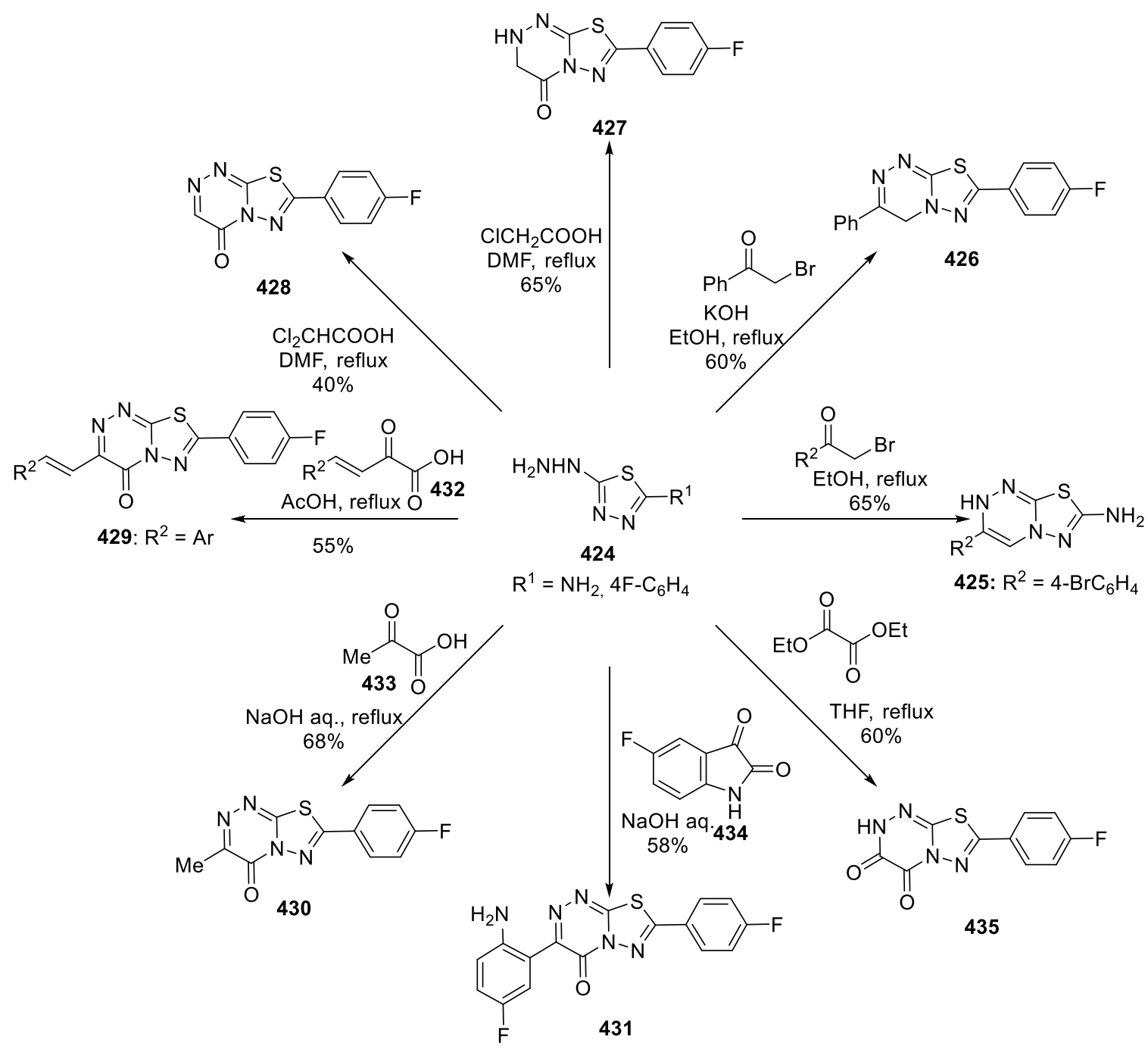

Scheme 87

11.6.5.3(ii)(b) $[1,2,4]$ triazolo[5,1- $d[1,2,4]$ triazines and $[1,2,3]$ triazolo[ $[5,1-c][1,2,4]$ triazines

From diazonium salts

As already mentioned in CHEC-III(2008), transformation of [1,2,4]triazole-3-diazonium salts 436, easily available by diazotation of aminotriazoles, is a very appealing approach for the synthesis of 
$[1,2,4]$ triazolo $[5,1-c][1,2,4]$ triazine derivatives (type 11). These starting materials already contain the five nitrogen atoms in the correct sequence and, thus, their reaction with proper reagents can give rise to the cyclized products in one single step. In the last period, it has been by far the most employed synthetic route. Reactions with enaminone derivatives $\mathbf{4 3 7}$ gave access to 3-benzoyl $[1,2,4]$ triazolo[3,2-c][1,2,4]triazine derivatives 439 after elimination of dimethylamine. ${ }^{166-178}$ Such transformations usually occurred in ethanol at low temperature in the presence of a base (pyridine or sodium acetate). Similar transformations have been also reported by using sodium salts $\mathbf{4 3 8}$ of $\mathbf{3 -}$ oxopropenolate derivatives yielding the corresponding acylated fused rings $\mathbf{4 3 9}$ after dehydration. 179-183 Very high yields were obtained in both procedures with diazenes $\mathbf{4 4 0}$ being the key intermediates (Scheme 88). <Scheme 88 near here>

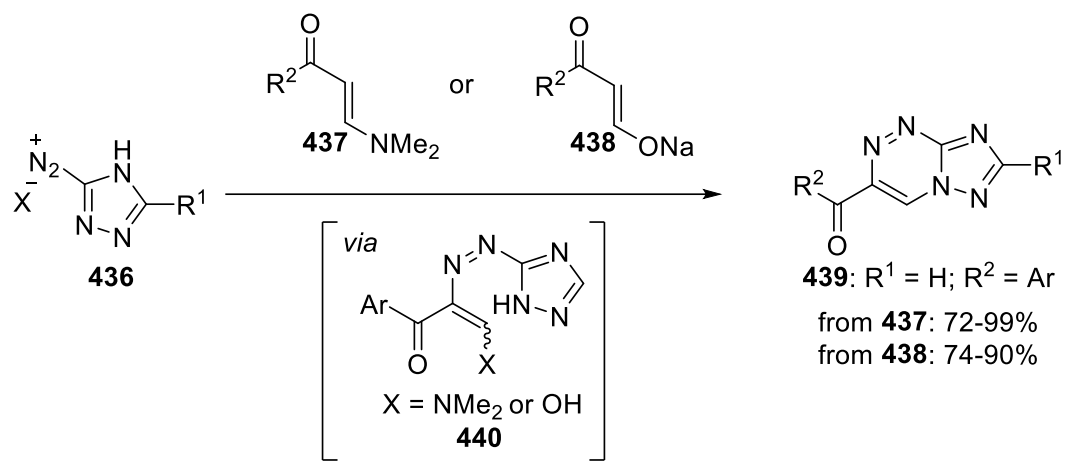

Scheme 88

Reaction of diazonium salts 436 with exocyclic enaminones 441 in pyridine at $0{ }^{\circ} \mathrm{C}$ furnished tetracyclic compound $\mathbf{4 4 2}$ in moderate to good yields (Scheme 89). ${ }^{125,184}<$ Scheme 89 near here><smiles>[R]c1nnc([N])[nH]1</smiles>

436

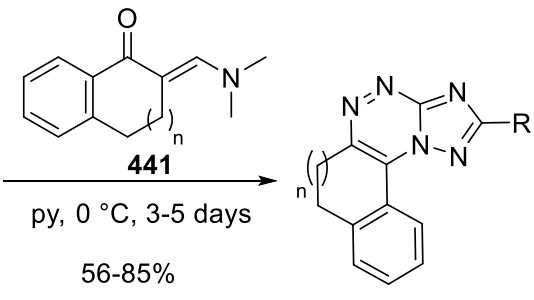

$$
442
$$$$
\mathrm{R}=\mathrm{H}, 4-\mathrm{ClC}_{6} \mathrm{H}_{4}
$$$$
n=1,2
$$

\section{Scheme 89}

Cyano compounds $\mathbf{4 4 3}$ bearing an $\alpha$-electron withdrawing group have been also widely used as reaction partners in the coupling reactions with diazonium salt $\mathbf{4 3 6}$ allowing the construction of $[1,2,4]$ triazolo[5,1-c] $[1,2,4]$ triazin-4-amine derivatives 444 with various substituents at C3 (i.e. nitro, ${ }^{185-186,58}$ aryloyls, ${ }^{187-190}$ carbamoyls, ${ }^{191-194}$ cinnamoyl, ${ }^{195}$ and cyano or ethyl carboxylate ${ }^{196}$ ). From a mechanistic point of view, reaction between $\mathbf{4 3 6}$ and $\mathbf{4 4 3}$ afforded hydrazones $\mathbf{4 4 5}$ which would undergo cyclization to generate fused systems $\mathbf{4 4 6}$. A subsequent tautomerization would form the desired triazolotriazolines $\mathbf{4 4 4}$. In some cases, the hydrazones $\mathbf{4 4 5}$ have been isolated. Usually, the reactions started at low temperature in ethanol in the presence of sodium acetate or in pyridine to get hydrazones $\mathbf{4 4 5}$ while the cyclization step might need to be performed under reflux (Scheme 90 ). $<$ Scheme 90 near here> 


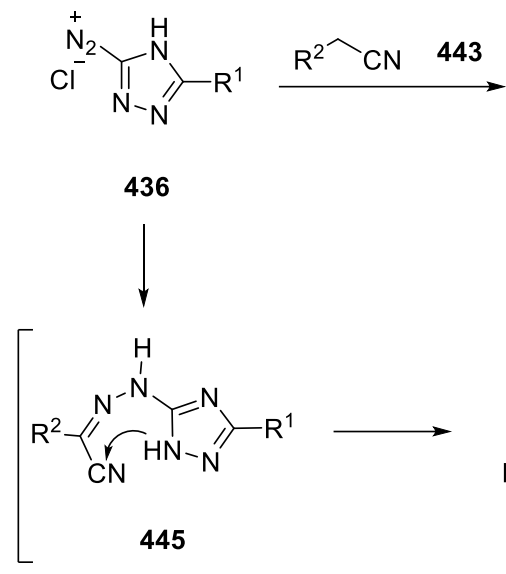<smiles>[R][R]1nnc2nc([R])nn2c1N</smiles>

444

$\mathrm{R}^{1}=\mathrm{H}, \mathrm{Me}, \mathrm{SMe}, \mathrm{Ar}, \mathrm{NO}_{2} ; \mathrm{R}^{2}=\mathrm{NO}_{2}, 42-78 \%$

$\mathrm{R}^{1}=\mathrm{H} ; \mathrm{R}^{2}=\mathrm{C}(\mathrm{O}) \mathrm{Ar}, 49-66 \%$

$\mathrm{R}^{1}=\mathrm{H} ; \mathrm{R}^{2}=\mathrm{C}(\mathrm{O}) \mathrm{NHAr}, 62-78 \%$

$\mathrm{R}^{1}=\mathrm{H} ; \mathrm{R}^{2}=\mathrm{CN}, 75 \%$

$\mathrm{R}^{1}=\mathrm{H} ; \mathrm{R}^{2}=\mathrm{CO}_{2} \mathrm{Et}, 62 \%$

$\mathrm{R}^{1}=\mathrm{H} ; \mathrm{R}^{2}=\mathrm{C}(\mathrm{O}) \mathrm{NH}_{2}, 43 \%$

$\underbrace{N-N}_{446}$

$\mathrm{R}^{1}=\mathrm{H} ; \mathrm{Ph}, \mathrm{R}^{2}=\mathrm{C}(\mathrm{O}) \mathrm{CH}=\mathrm{CHPh}, 35-50 \%$

Scheme 90

The access to 4-(phenylsulfonyl)-[1,2,4]triazolo[5,1-c][1,2,4]triazines 448 has been accomplished by treatment of diazos $\mathbf{4 3 6}$ with $\beta$-ketosulfones $\mathbf{4 4 7}$ in good yields. ${ }^{197-198}$ Reactions with dimethylacetylene dicarboxylate $\mathbf{4 4 9}$ or phenylacetylene $\mathbf{4 5 1}$ gave rise to the corresponding 3phenyl and 3,4-dimethyl dicarboxylate derivatives 450 and $\mathbf{4 5 2}$ respectively. ${ }^{125}$ Coupling with 1,3cyclohexadienones 453 furnished [1,2,4]triazolo[5,1-c][1,2,4] benzotriazin-6-ols 454 (Scheme 91). ${ }^{199}$ $<$ Scheme 91 near here>

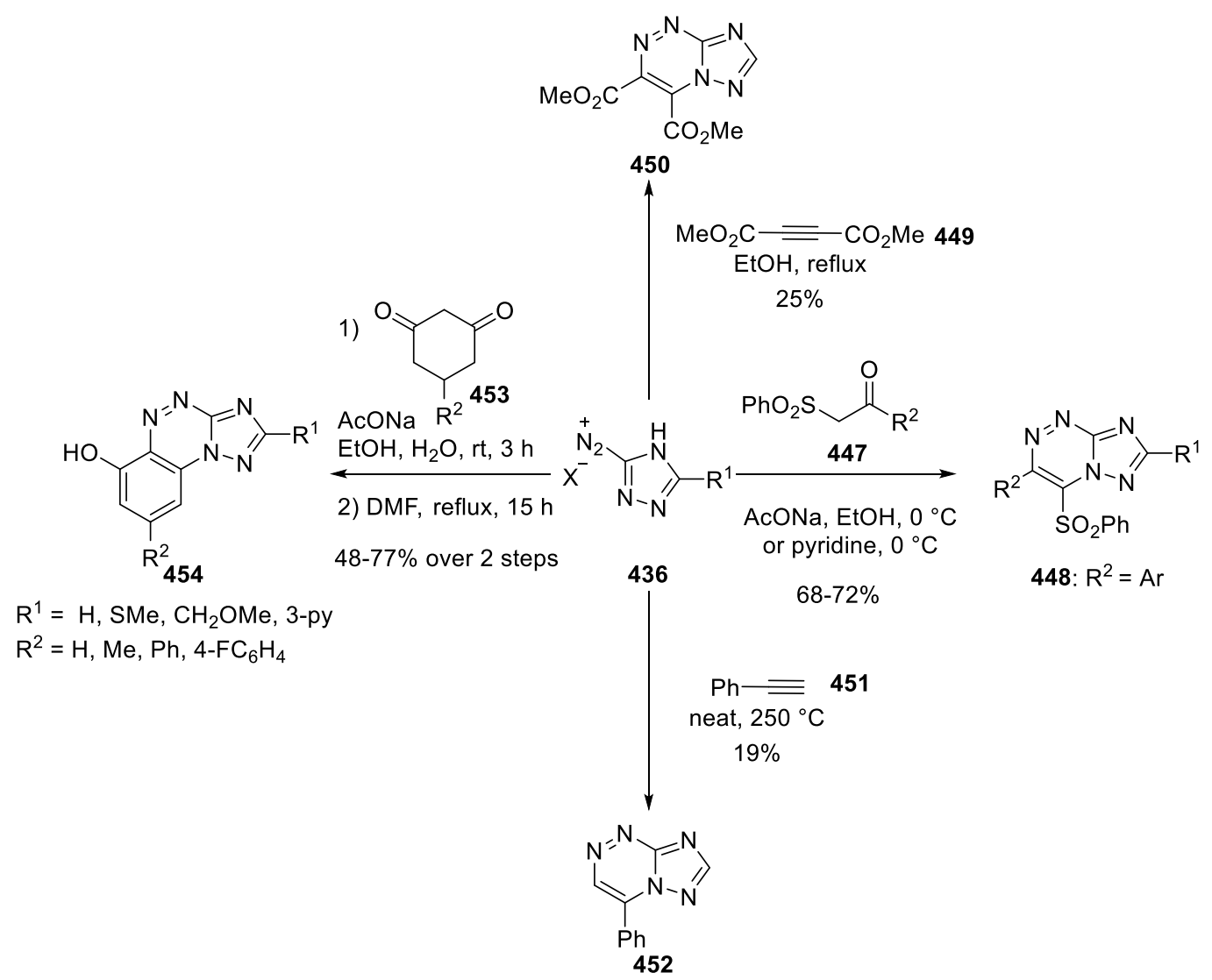

\section{Scheme 91}

Diazonium salts $\mathbf{4 3 6}$ have also been used for the synthesis of partially saturated fused systems by coupling with various $\beta$-ketoester or malonate derivatives. As shown in scheme 92, reaction with diethyl malonate $\mathbf{4 5 5}$ in the presence of sodium carbonate afforded triazolotriazinones $\mathbf{4 5 6}$ bearing 
an ethylcarboxylate substituent at C3. ${ }^{200}$ These compounds were isolated in the form of sodium salts to increase the water solubility and the bioavailability at the expense of the yields which were quite low. Treatment with ethyl 2-fluoroacetoacetate $\mathbf{4 5 7}$ in the presence of sodium acetate formed hydrazones 458 which were converted to fluorinated triazolotriazinones 459 upon heating in a solution of sodium acetate in ethanol. Interestingly, heating hydrazones $\mathbf{4 5 8}$ in pyridine furnished pyridinium 461. The latter could be also directly obtained by treating diazonium salts $\mathbf{4 3 6}$ with diethyl $\alpha$-pyridinium malonate 460 in pyridine under reflux. ${ }^{11}$ Polyfluoroalkyl-containing 1,3dicarbonyl reagents $\mathbf{4 6 2}$ have been used to access various 7-hydroxy-7-polyfluoroalkyl dihydrotriazolotriazines $\mathbf{4 6 3}$ in moderate to good yields (Scheme 92). ${ }^{201-203}<$ Scheme 92 near here><smiles></smiles>

456: $\mathrm{R}^{1}=\mathrm{H}, \mathrm{Me}, \mathrm{SMe}, \mathrm{SEt}, \mathrm{SPr}, \mathrm{S}^{\mathrm{i}}-\mathrm{Pr}, \mathrm{CO}_{2} \mathrm{Et}$

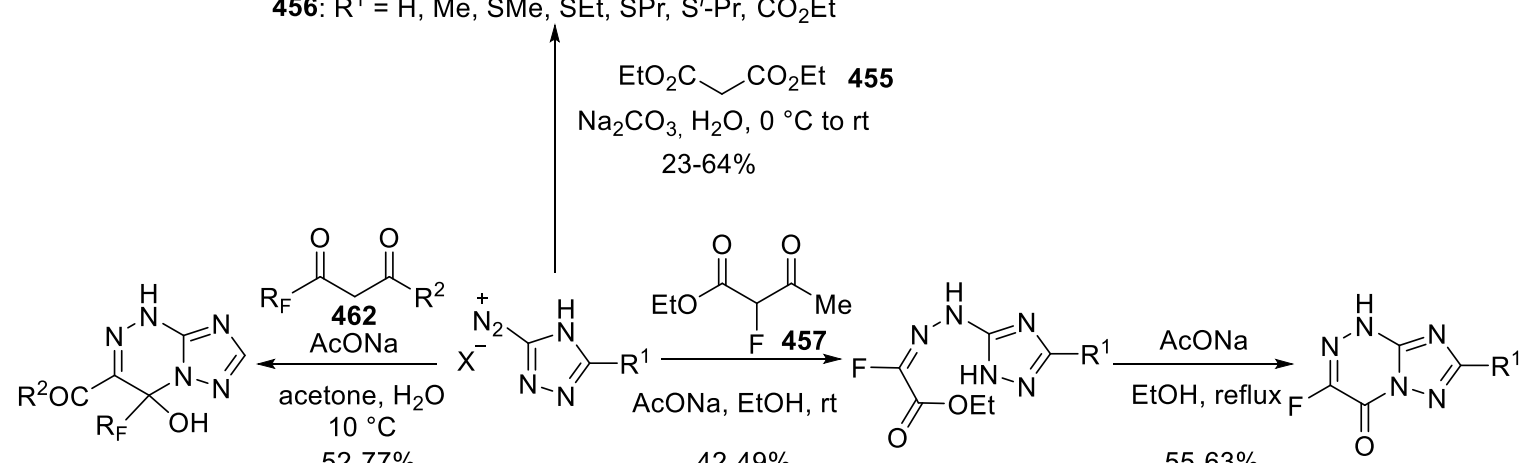

461: $\mathrm{R}^{1}=\mathrm{H}, \mathrm{SMe}$

Scheme 92

A convenient procedure for the in-situ generation of nitroacetaldehyde potassium salt 465 from 1morpholino-2-nitroethene $\mathbf{4 6 4}$ has allowed the preparation of 3-nitro-4-hydroxy-1,4dihydroazolo[5,1-c] $[1,2,4]$ triazines 466 in modest yields (Scheme 93). ${ }^{204}<$ Scheme 93 near here>

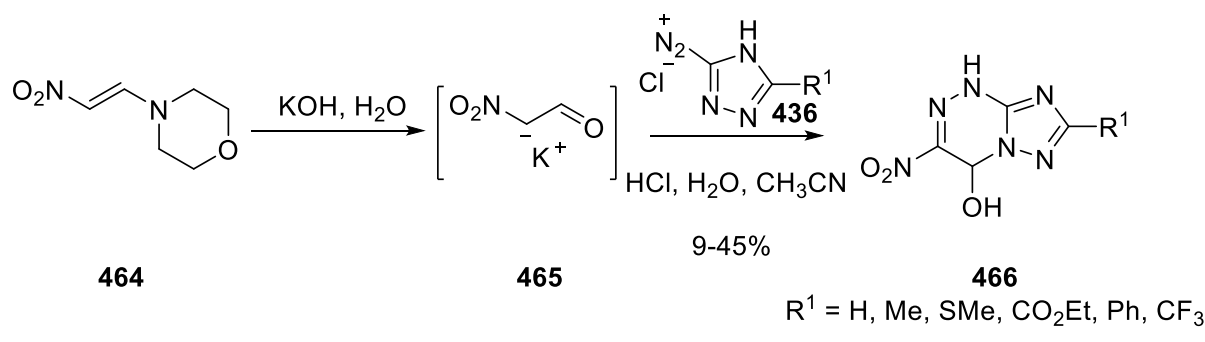


Labelled diazoniums salts 436 have been used for the synthesis of $\left[{ }^{15} \mathrm{~N}\right]$ and $\left[{ }^{2} \mathrm{H},{ }^{15} \mathrm{~N}\right]$-labelled 3nitrotriazolotriazinones 468 with ${ }^{15} \mathrm{~N}$ isotope in the triazole and/or triazine rings by treatment with (labelled) ethylnitroacetate 467. Similarly, $\left[{ }^{15} \mathrm{~N}\right]$-labelled triazolotriazin-4-amine $\mathbf{4 7 0}$ has been obtained from $\alpha$-phenyl- $\alpha$-formylacetonitrile $\mathbf{4 6 9}$ (Scheme 94). ${ }^{10,30,205}<$ Scheme 94 near here>
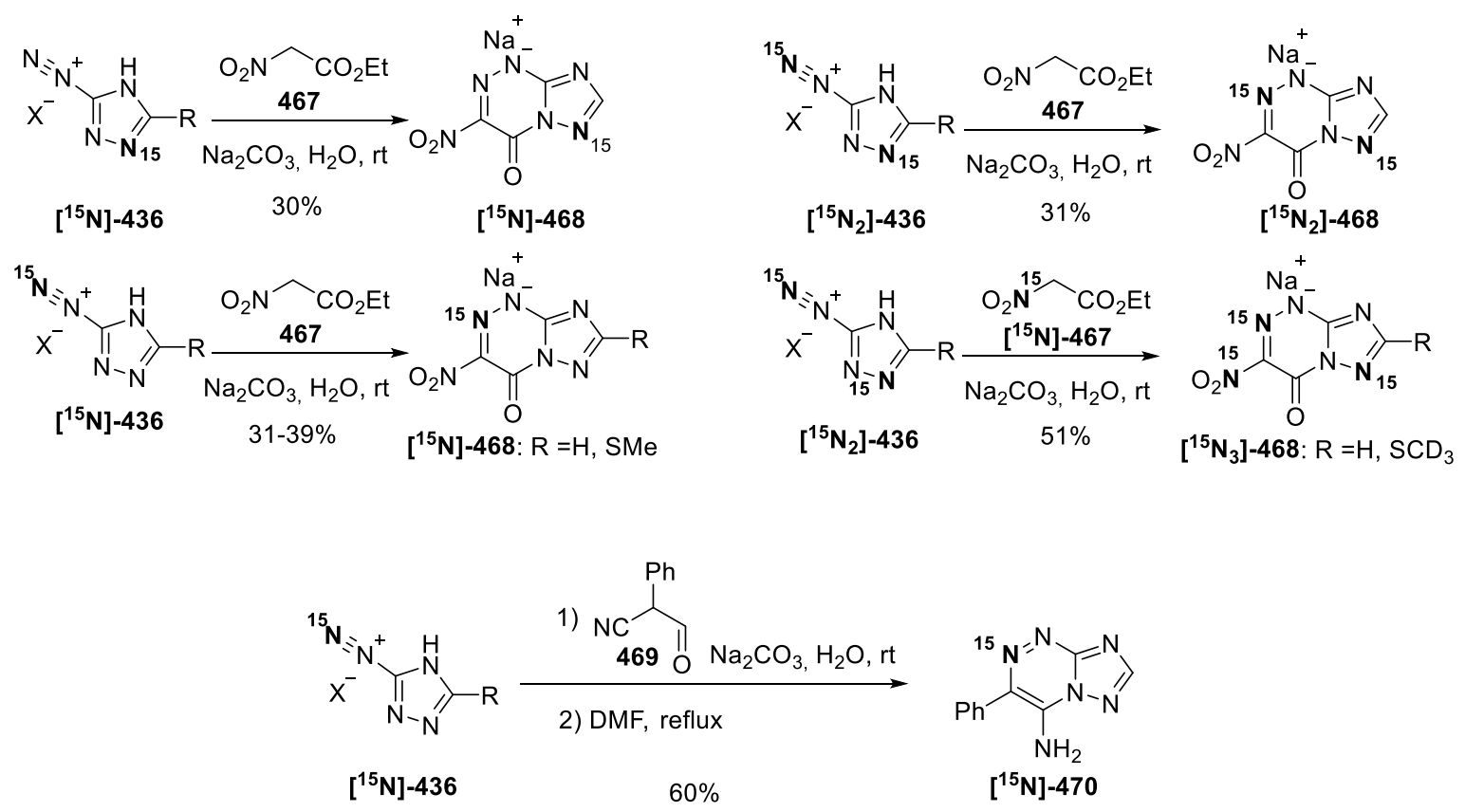

Scheme 94

By exploiting similar strategy, the use of $[1,2,3]$ triazole-5-diazonium salts can give rise to $[1,2,3]$ triazolo[5,1-c][1,2,4]triazines (structures 13). As such, coupling of diazo compound 471 with diethyl-2-oxopropane-1,3-dicarboxylate $\mathbf{4 7 2}$ delivered fused heterocycle $\mathbf{4 7 3}$ in modest yield (Scheme 95). ${ }^{33}<$ Scheme 95 near here>

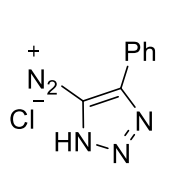

471

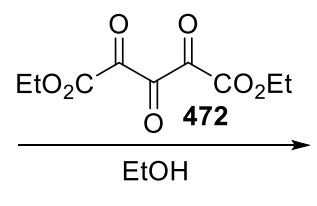

$33 \%$

Scheme 95<smiles>CCOc1nnc2c(-c3ccccc3)nnn2c1C[13C](=O)OCC</smiles>

473

Scheme 95

\section{$>$ Other routes}

A two steps procedure from 3,5-dibromo-1H-1,2,4-triazole $\mathbf{4 7 4}$ (easily prepared by bromination of 1,2,4-triazole) has been also published for the synthesis of $[1,2,4]$ triazolo[3,2-c][1,2,4]triazines. Nucleophilic substitution with bromomethyl aryl ketone 475 occurred at N1 delivering the corresponding $\mathrm{N}$-alkylated triazole $\mathbf{4 7 6}$ which was treated with hydrazine in methanol under reflux to build the fused triazine ring $\mathbf{4 7 7}$ (Scheme 96). $.^{15,25}<$ Scheme 96 near here> 


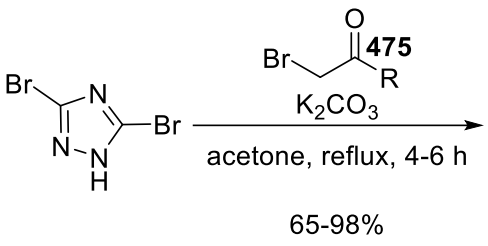

474<smiles>[R]C(=O)Cn1nc(Br)nc1Br</smiles>

476: $\mathrm{R}=\mathrm{Ar}$

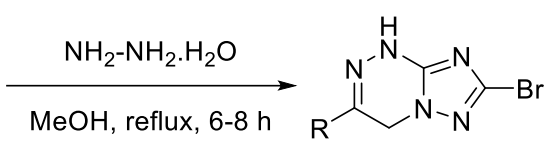

$60-78 \%$

477: $\mathrm{R}=\mathrm{Ar}$

Scheme 96

Hydrazinotriazoles $\mathbf{4 7 8}$ have been treated with formic acid or chloroacetic acid under reflux to furnish the corresponding dihydrotriazolotriazines $\mathbf{4 7 9}$ and dihydrotriazolotriazinols $\mathbf{4 8 0}$ respectively (Scheme 97). ${ }^{206}<$ Scheme 97 near here $>$

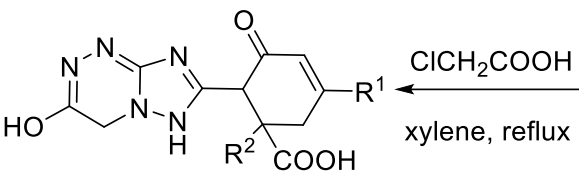

480: $R^{1}, R^{2}=A r$<smiles>[R]C1=CC(=O)C(c2nc(NN)n[nH]2)C([R])(C(=O)O)C1</smiles>

478<smiles>[R]C1=CC(=O)C(C2=NC3=NN=CCN3N2)C([R])(C(=O)O)C1</smiles>

479: $R^{1}, R^{2}=A r$

Scheme 97

Dong et al. have reported the building of the 1,2,4-triazine ring by transition or lanthanide metalpromoted intramolecular $\mathrm{C}-\mathrm{H}$ amination of (aryldiazenyl)triazoles 481 in water at $160{ }^{\circ} \mathrm{C}$ in an autoclave. When a transition metal was used as a promoter, the complex $\left[\mathrm{M}(\mathbf{4 8 2})_{2}\left(\mathrm{H}_{2} \mathrm{O}\right)_{4}\right] \cdot 2 \mathrm{H}_{2} \mathrm{O}$ was obtained. With lanthanide metals instead, the uncomplexed heterocycles $\mathbf{4 8 2}$ were directly isolated in good yields. In both cases, decarboxylation and deacetylation of the substituents on the phenyl rings occurred (Scheme 98). ${ }^{207}<$ Scheme 98 near here>

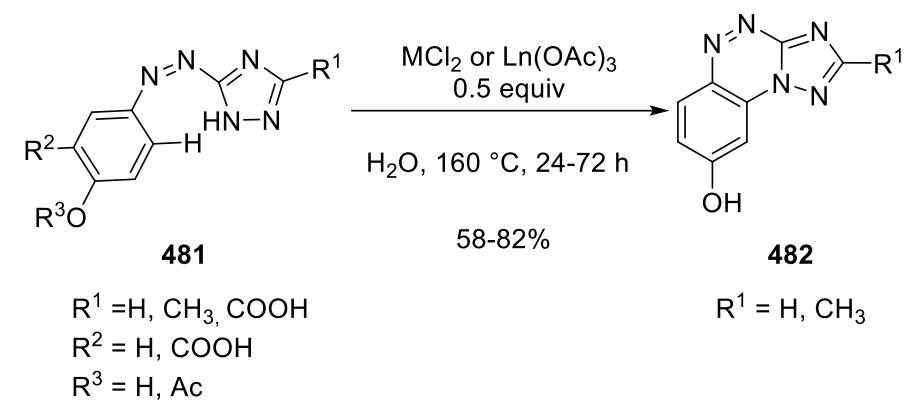

\section{Scheme 98}

\subsubsection{3(ii)(c) $[1,2,4]$ triazolo[3,4-c][1,2,4]triazines}

Three different approaches have been published for the synthesis of $[1,2,4]$ triazolo[3,4c] $[1,2,4]$ triazines (structures 12) since 2007 (Scheme 99). Shaaban has reported that trifluoromethylated diketone $\mathbf{4 8 3}$ reacted with diazonium salt $\mathbf{4 3 6}$ at low temperature to form hydrazone $\mathbf{4 8 4}$ which could cyclized under pressurized microwave irradiation to produce $\mathrm{CF}_{3}-$ containing triazolotriazine $\mathbf{4 8 5} .^{208}$ Treatment of 3-(triazolylhydrazinylidene)furan-2(3H)-ones $\mathbf{4 8 6}$ in ethanol under heating in the presence of triethylamine produced triazolotriazin-5-one derivatives 487 in high yields. ${ }^{209}$ The formation of triazolotriazin-6-one derivatives $\mathbf{4 8 9}$ has been described through the reaction between 5-hydrazinyl-3-phenyl-3H-[1,2,4]triazole 488 and chloroacetyl chloride in refluxing ethanol in the presence of piperidine. ${ }^{210}$ In these three procedures, it is the N4 atom of the triazole rings which would react. These results contrast with the examples reviewed in the 
previous section (11.6.5.3(II)(b), reactions at $\mathrm{N} 1)$. Unfortunately, there was no X-Ray analysis to ascertain the reported structures. <Schema 99 near here>
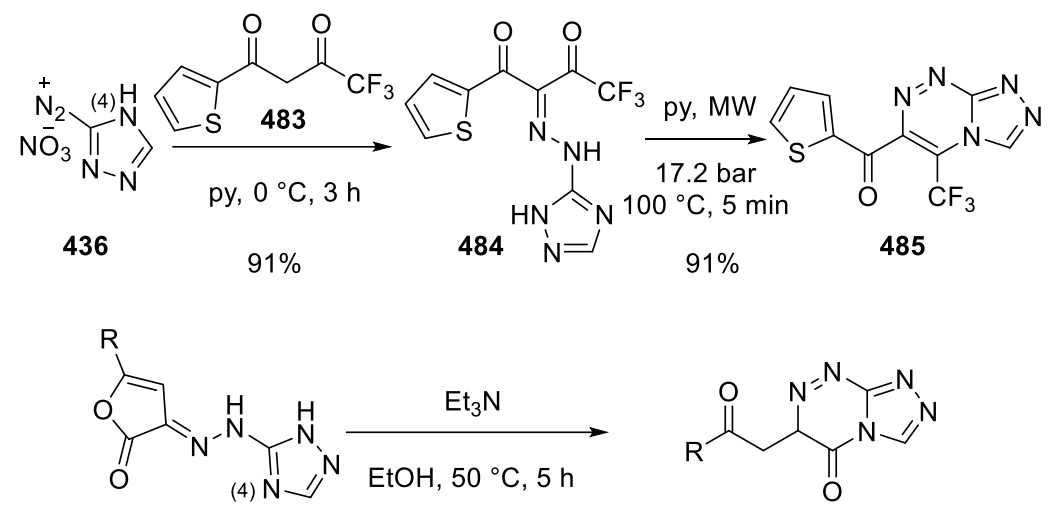

$86-87 \%$

486<smiles>NNc1nc(-c2ccccc2)n[nH]1</smiles>

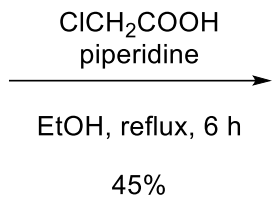

Schema 99
487: $\mathrm{R}=\mathrm{Ph}, 4-\mathrm{C}_{6} \mathrm{H}_{4}$<smiles>O=C1CN2C(=NN1)N=NC2c1ccccc1</smiles>

489

\subsection{Synthesis of $d$-fused [1,2,4]-triazines}

Starting from 5-cyano-1,2,4-triazines 490, two successive solvent-free reactions (i.e. ipsosubstitution of the cyano group by hydrazides $\mathbf{4 9 1}$ followed by dehydrative cyclization of $\mathbf{4 9 2}$ in phosphorus oxychloride) allowed the construction of $[1,2,4]$ triazolo[1,5- $d][1,2,4]$ triazine derivatives 493. It is worth mentioning that this sequence could be carried out in one-pot without isolation of 492 with slightly higher yields. From a mechanistic point of view, it was assumed that $\mathbf{4 9 3}$ was obtained via a Dimroth-type rearrangement of in-situ generated [1,2,4]triazolo[4,3-d][1,2,4]triazine 494. Indeed, ring opening of the triazine ring would lead to intermediate $\mathbf{4 9 5}$ under acid conditions. A rotation of 1,2,4-triazole ring around the $\mathrm{C}$ - $\mathrm{C}$ sigma bond would allow the ring closure of 1,2,4triazine to take place on intermediate $\mathbf{4 9 6}$ affording thermodynamically more stable product $\mathbf{4 9 3}$ (Scheme 100). ${ }^{3}<$ Scheme 100 near here $>$ 

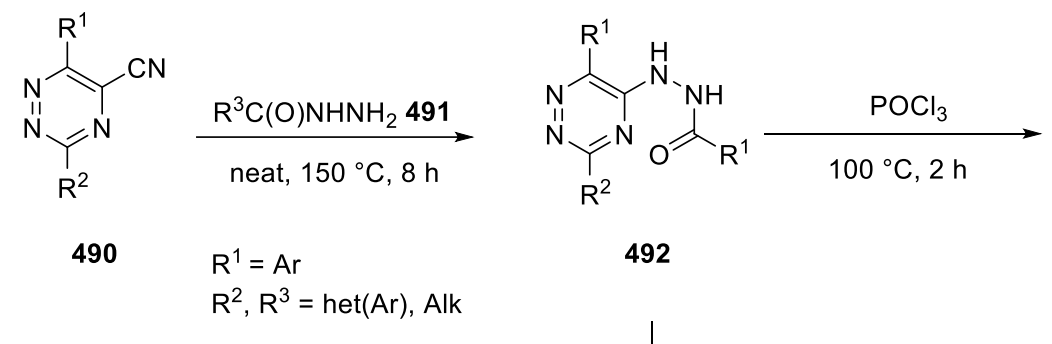<smiles>[R]c1nc2c([R])nnc([R])n2n1</smiles>

492

493

$19-70 \%$

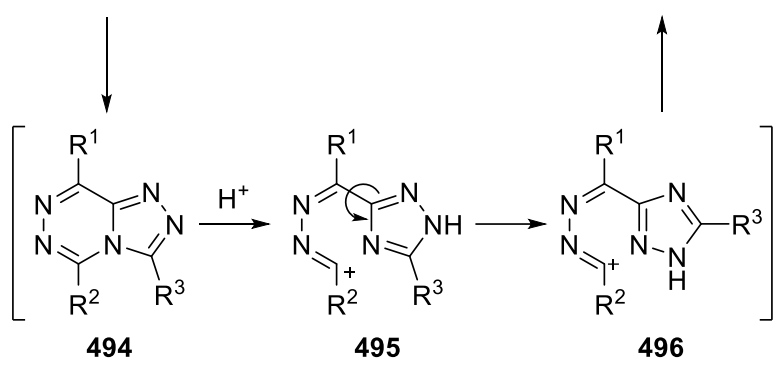

Scheme 100

Three synthetic routes have been described by El-Badry et al. for the construction of tetrazolo-fused $[1,2,4]$ triazolo[4,3-d] [1,2,4]triazine derivatives 505 (Scheme 101). Condensation of hydrazines 497 with equimolar amount of aromatic aldehydes 498 afforded the corresponding hydrazones 499 which was subjected to a dehydrogenative cyclization with bromine in acetic acid in the presence of sodium acetate or with an ethanolic iron(III) chloride solution. One pot cyclization of hydrazines $\mathbf{5 0 0}$ with aromatic acid chlorides $\mathbf{5 0 1}$ was also possible. Finally, an alternative route was proposed by reacting chloro derivative $\mathbf{5 0 2}$ with equimolar amount of aromatic hydrazides $\mathbf{5 0 3}$ followed by dehydrative cyclization in phosphorus oxychloride. Interestingly, by following the latter route, bistetrazolotriazolotriazine derivatives $\mathbf{5 0 8}$ could be obtained from two equivalents of $\mathbf{5 0 6}$ and one equivalent of oxalic, malonic, or succinic dihydrazide 507 (Scheme 101). ${ }^{211}<$ Scheme 101 near here $>$ 

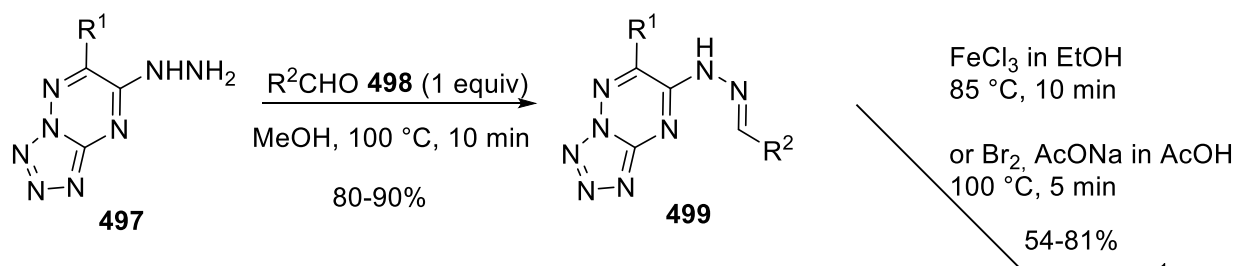<smiles>[R]c1nn2nnnc2nc1NN</smiles><smiles>[R]c1nn2nnnc2nc1Cl</smiles>

502
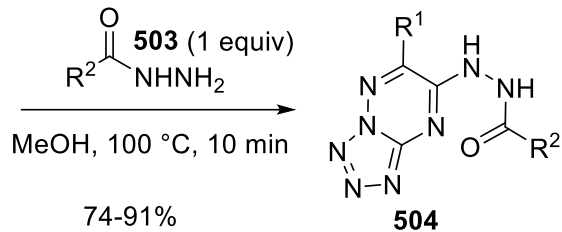

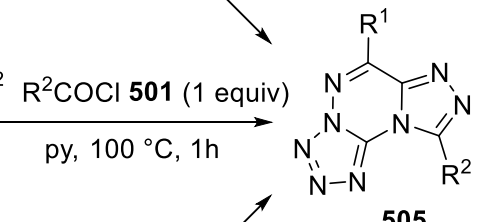

$\mathrm{R}^{1}=\mathrm{H}, \mathrm{Ph} ; \mathrm{R}^{2}=\mathrm{Ar}$

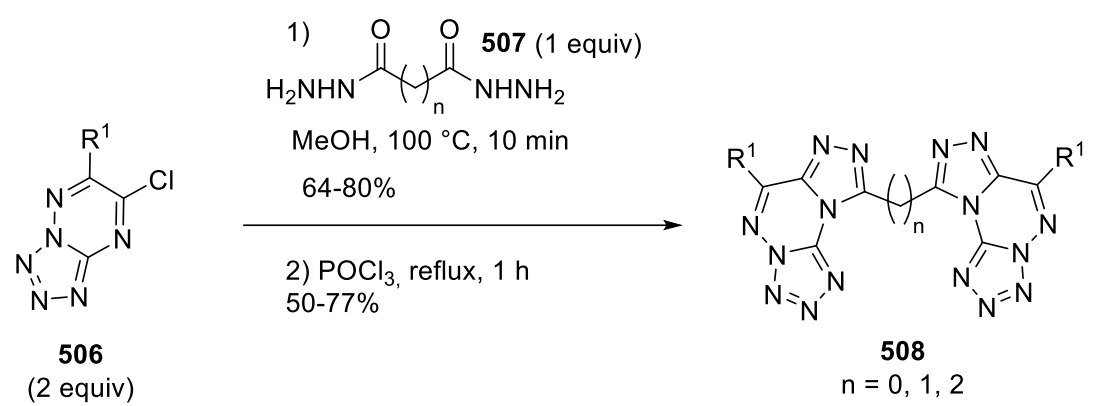

Scheme 101

\subsection{Synthesis of $f$-fused $[1,2,4]$-triazines}

\subsubsection{5(i) closure of the five-membered ring}

Only two publications relate to the synthesis of $[1,2,4]$ triazolo[3,4-f][1,2,4]triazine ring systems via cyclization of the five-membered ring. Treatment of hydrazinotriazine $\mathbf{5 0 9}$ with aromatic aldehydes $\mathbf{5 1 0}$ in the presence of potassium carbonate in dimethylformamide afforded bicyclic systems $\mathbf{5 1 1}$ in moderate yields. ${ }^{212}$ In a similar way, condensation of hydrazine derivatives $\mathbf{5 1 2}$ with formic acid or carbon disulfide gave rise to [1,2,4]triazolo[3,4-f][1,2,4]triazines 513 and $[1,2,4]$ triazolo[3,4$f][1,2,4]$ triazine-3(2H)-thiones 514 respectively. ${ }^{213}$ (Scheme 102) <Scheme 102 near here> 

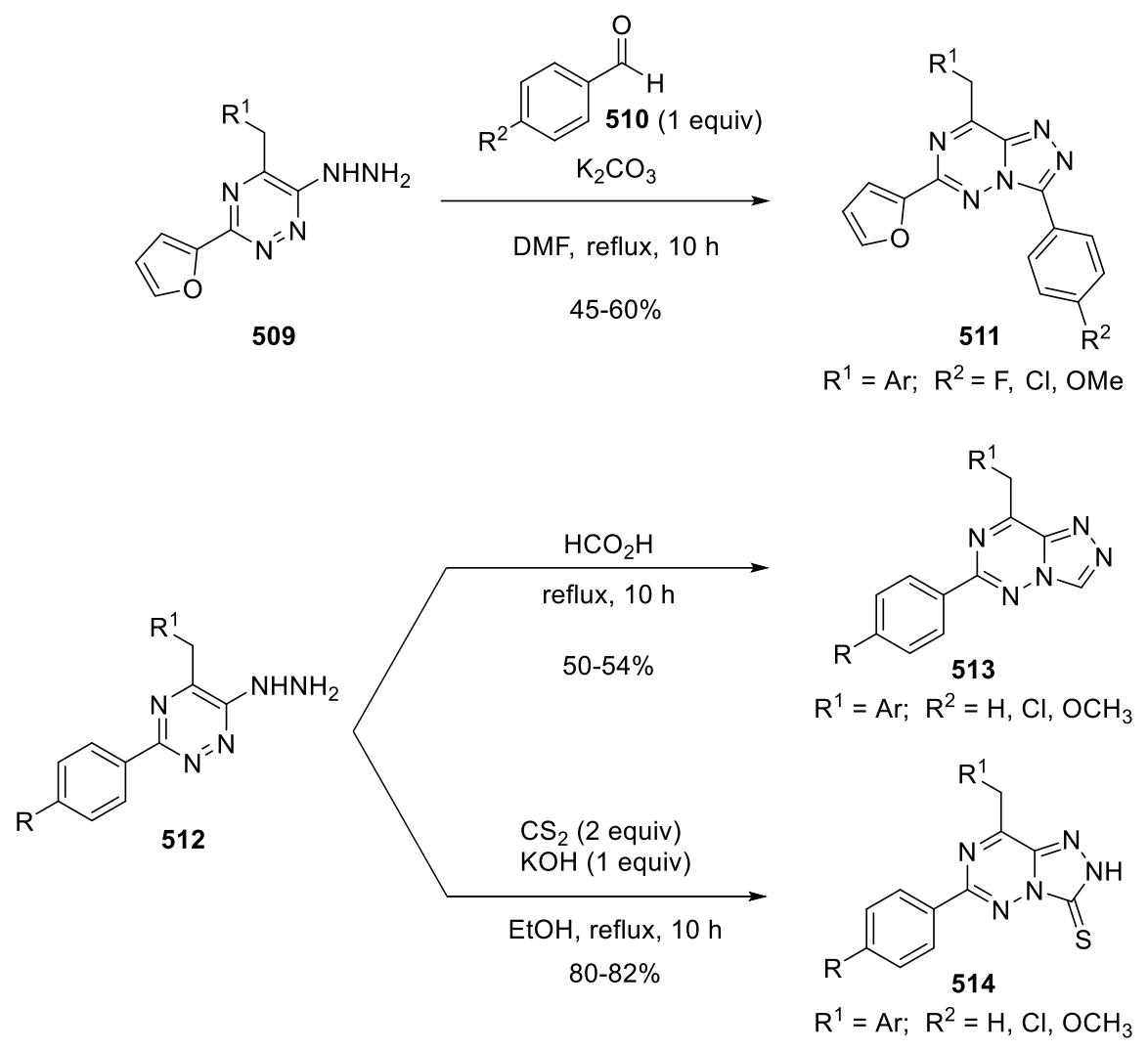

Scheme 102

11.6.5.5(ii) construction of both rings (closure of the six-membered ring at the last step)

The construction of $[1,2,4]$ triazolo[3,4-f][1,2,4]triazines by the ring closure of the triazine ring has been reviewed in CHEC-II(1996) and CHEC-III(2008). In 2010, Demirbas et al. have reported an original synthesis of this fused ring system by a cascade reaction involving construction of the $[1,2,4]$ triazole from oxadiazole $\mathbf{5 1 5}$ followed by ring closure of the triazine. As shown in Scheme 103, treatment of $\mathbf{5 1 5}$ with hydrazine hydrate led to 4-amino-1,2,4-triazine $\mathbf{5 1 6}$ which was not isolated and was directly converted to triazolotriazine $\mathbf{5 1 7}$ in good yield by intramolecular condensation with the closed carbonyl functional group. ${ }^{214}<$ Scheme 103 near here $>$

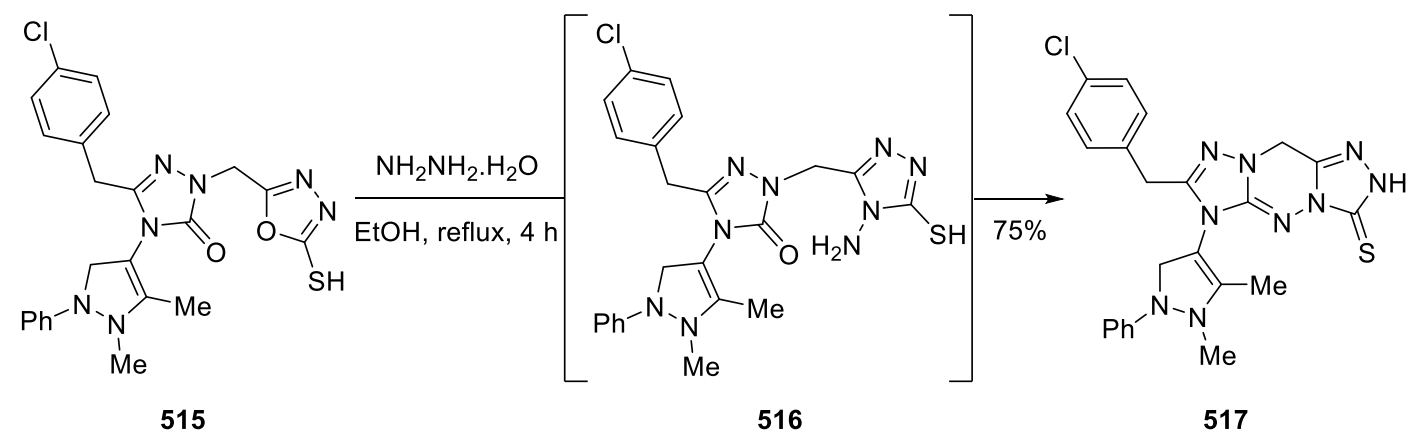

Scheme 103

\subsection{Synthesis of Fused [1,2,3]-triazines}

With the aim to synthesize variously substituted chromene systems, hydrazine derivative $\mathbf{5 1 8}$ has been engaged in different cyclizations with formic acid, acetic anhydride, benzoyl chloride and 
carbon disulfide affording the corresponding $[1,2,4]$ triazolo[4,3-c][1,2,3]triazine derivatives $\mathbf{5 1 9}$ in moderate yields (Scheme 104). ${ }^{215}<$ Scheme 104 near here>

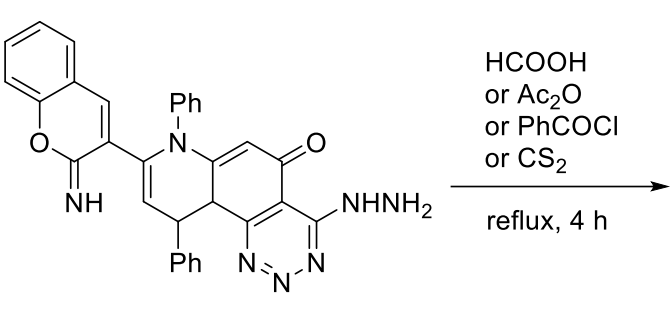

518

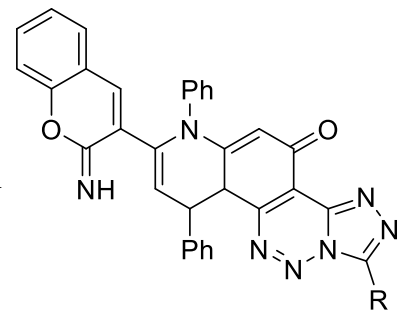

519

with $\mathrm{HCOOH}, \mathrm{R}=\mathrm{H}, 55 \%$ with $\mathrm{Ac}_{2} \mathrm{O}, \mathrm{R}=\mathrm{Me}, 60 \%$ with $\mathrm{PhCOCl}, \mathrm{R}=\mathrm{Ph}, 62 \%$ with $\mathrm{CS}_{2}, \mathrm{R}=\mathrm{SH}, 55 \%$

Scheme 104

\subsubsection{Ring Synthesis by Transformations of Another Bicyclic system}

Staninets et al. have found that $[1,2,4]$ triazolo[3,4-c][1,2,4]triazine $\mathbf{5 2 0}$ could isomerize to $[1,2,4]$ triazolo[1,5-c][1,2,4]triazine $\mathbf{5 2 1}$ upon heating in refluxing ethanol in the presence of sodium acetate in very good yield (Dimroth rearrangement). Also of note, the same transformation could be carried out quantitatively by simply heating 520 at $270{ }^{\circ} \mathrm{C}$ in a sand bath under neat conditions (Scheme 105). ${ }^{144}<$ Scheme 105 near here><smiles>[R]Nc1n[nH]c2nnc(C)c(=O)n12</smiles>

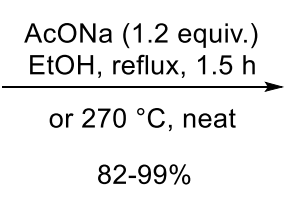

Scheme 105<smiles>[R]Nc1nn2c(=O)c(C)nnc2[nH]1</smiles>

521: $\mathrm{R}=\mathrm{Ar}$

\subsubsection{Important Compounds and Applications}

\subsubsection{Biological and agrochemical applications}

The main purpose of designing new derivatives of the ring systems belonging to this chapter was to evaluate their biological properties. Some of them have shown valuable biological activities and have been patented.

\subsubsection{1(i) $[1,2,4]$ triazolo[3,4-b][1,3,4]thiadiazines}

$\mathbf{5 2 2}^{216}$ and $\mathbf{5 2 3}^{217}$ are activators of caspases and inducers of apoptosis. $\mathbf{5 2 3}$ is also an antineoplastic compound with activity against MES-SA and P388 and their multi-drug resistant cells. $\mathbf{5 2 4}$ exhibits anti-tuberculosis activity. ${ }^{218} \mathbf{5 2 5}$ is able to selectively inhibit STAT3 in the presence of STAT1. ${ }^{219}$ $\mathbf{5 2 6}^{220}$ and $\mathbf{5 2 7}^{221}$ are inhibitors of phosphodiesterase 4 and UDP-galactopyranose mutase respectively (Figure 8 ). <Figure 8 near here> 
<smiles>COc1ccc(C2=Nn3c(nnc3-c3ccc(Cl)cc3OC)SC2)cc1N</smiles>

522<smiles>COc1ccc(C2=Nn3c(nnc3-c3[nH]cc4c3CCC4)SC2C)cc1</smiles>

525<smiles>COc1ccc(-c2nnc3n2N=C(c2ccc(C)cc2)CS3)c(OC)c1</smiles>

523<smiles>COc1ccc(OC)c(-c2nnc3n2N=C(c2ccc(OC)c(OC4CCOC4)c2)CS3)c1</smiles>

526<smiles>FC(F)(F)C1=Nn2c(nnc2-c2ccc(Br)cc2)SC1</smiles>

524<smiles>O=C(O)CC1Sc2nnc(Cc3ccc(Br)cc3)n2N=C1c1ccc(-c2ccccc2)cc1</smiles>

527

Figure 8

\subsubsection{1(ii) $[1,2,4]$ triazolo[1,5-a][1,3,5]triazines}

The synthesis of heterobivalent ligand $\mathbf{5 2 8}$ was based on the chemical structure of the dopamine receptor $D_{2} R$ agonist ropinirole and the adenosine receptor $\left(A_{2 A} R\right)$ antagonist $Z M 241385$. This ligand maintained the potency of the original pharmacophores and could therefore be tested as a potential treatment of Parkinson disease. ${ }^{44}$ The antagonist ZM241385 has been also used as a starting point to design irreversibly binding human $A_{2 A} R$ ligand 529. The latter features an electrophilic fluorosulfonyl moiety to covalently bind to the receptor and a terminal alkyne as a probe. Click ligation with a sulfonated cyanine-3 fluorophore allows visualization of the receptor on SDS-PAGE (Figure 9). ${ }^{41}$ $<$ figure 9 near here>

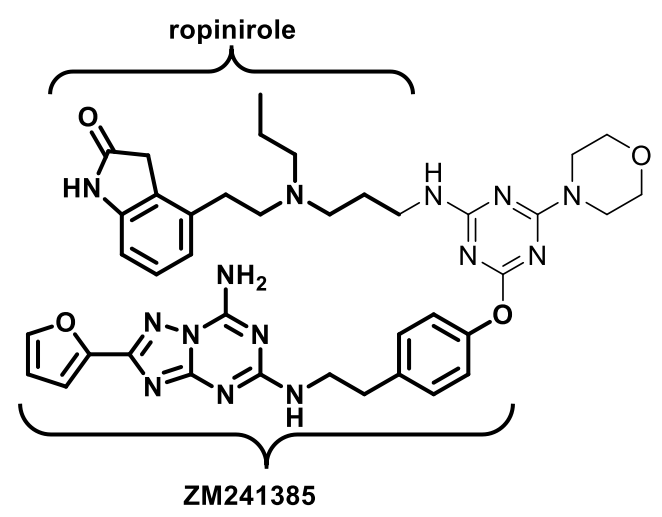

heterobivalent ligand $\mathbf{5 2 8}$<smiles>C[14C]N(CCc1ccc(O)cc1)c1nc(N)n2nc(-c3ccco3)nc2n1</smiles><smiles>C#CCN(CCCCCNc1nc(N)n2nc(-c3ccco3)nc2n1)C(=O)c1ccc(S(=O)(=O)F)cc1</smiles>

529

Figure 9 
$\mathbf{5 3 0 ^ { 2 2 2 }}$ and $\mathbf{5 3 1}^{223}$ are inhibitors of kinases such as c-Met. Triazolotriazinone $\mathbf{5 3 2}$ is a potent herbicide (Figure 10). ${ }^{224}<$ Figure 10 near here>

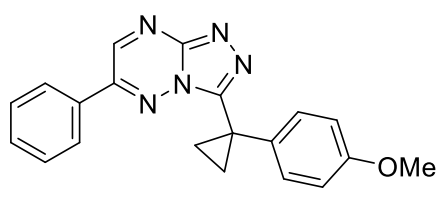

530<smiles>c1ccc(Cn2cc(-c3cnc4nnc(Cc5ccc6ncccc6c5)n4n3)cn2)cc1</smiles>

531<smiles>CCCn1nnnc1NC(=O)c1nn2cnn(-c3ccc(F)cc3)c2nc1=O</smiles>

532

Figure 10

\subsubsection{1(iv) $[1,2,4]$ triazolo $[5,1-c][1,2,4]$ triazines}

Triazavirine ${ }^{\circledR}$ is an inhibitor of Influenza A and B virus replication. ${ }^{225}$ L-argininium salt $\mathbf{5 3 3}$ exhibits increased antiviral activity with better oral bioavailability compared to the sodium salt Triazavirine ${ }^{\circledR} .{ }^{226}$ Cysteine-containing Triazavirine ${ }^{\circledR} \mathbf{5 3 4}$ displays numerous antiviral activities against for example Influenza $A\left(H_{x} N_{y}\right)$ and $B$, West Nile virus, coronaviruses, yellow fever virus... ${ }^{227}$ (Figure 11). <Figure 11 near here><smiles>Cc1nc2n([14CH3])nc([N+](=O)[O-])c(=O)n2n1</smiles>

Triazavirine $\AA$<smiles>NC(N)=[NH+]CCC[C@H](N)C(=O)[O-]</smiles><smiles></smiles>

533<smiles>CSc1nc2n(COC(=O)C(C)(C)C)nc(SCC(N)C(=O)O[Na])c(=O)n2n1</smiles>

534

Figure 11

\subsubsection{Other applications}

Triazolotriazines 535-537 are promising candidates as high-energy and insensitive explosives (Figure 12). ${ }^{53,185,228}<$ figure 12 near here>

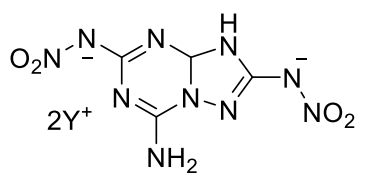

535: $\mathrm{Y}^{+}=\mathrm{N}_{2} \mathrm{H}_{5}{ }^{+}, \mathrm{NH}_{3} \mathrm{OH}^{+}$<smiles>Nc1c([N+](=O)[O-])nnc2nc([N+](=O)[O-])nn12</smiles>

536<smiles>Nc1c([N+](=O)[O-])nnc2nc([N+](=O)[O-])nn12</smiles>

537

Figure 12

A fluorescent triazolothiadiazine sensor $\mathbf{5 3 8}$ immobilized on polyvinyl chloride membrane has been developed for sensitive detection of $\mathrm{Pb}$ (II) ions. In addition to high reproducibility and reversibility of the fluorescence signal, the sensor also exhibits good selectivity over common metal ions (Figure 13). ${ }^{229}<$ figure 13 near here> 


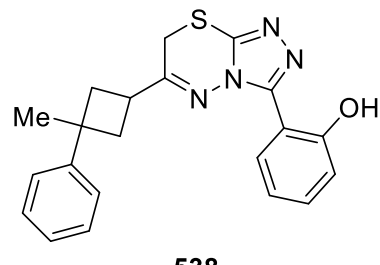

538

Figure 13

\section{Acknowledgement}

The author thanks CNRS for financial support.

\section{References}

(1) Hajós, G. In Comprehensive Heterocyclic Chemistry, 2nd ed. Elsevier Science Ltd., 1996; pp 479-491.

(2) Hajós, G.; Riedl, Z. In Comprehensive Heterocyclic Chemistry, 3rd ed. Elsevier Science Ltd., 2008; pp 847-893.

(3) Krinochkin, A. P.; Kopchuk, D. S.; Giri, K.; Shtaitz, Y. K.; Starnovskaya, E. S.; Khalymbadzha, I. A.; Drokin, R. A.; Ulomsky, E. N.; Santra, S.; Zyryanov, G. V.; Rusinov, V. L.; Chupakhin, O. N. ChemistrySelect 2018, 3, 8202-8206.

(4) Ul'yankina, I. V.; Zavodskaya, A. V.; Parfenov, V. E.; Gidaspov, A. A.; Shiryaev, A. K.; Selezneva, E. V.; Bakharev, V. V. Chem. Heterocyclic Comp. 2016, 52(12), 1054-1060.

(5) Batova, M.; Klobucnikova, V.; Oblasova, Z.; Gregan, J.; Zahradnik, P.; Hapala, I.; Subik, J.; Schuller, C. BMC Genomics 2010, 11, 153-170.

(6) Fusco, S.; Maglione, C.; Velardo, A.; Piccialli, V.; Liguori, R.; Peluso, A.; Rubino, A.; Centore, R. Eur. J. Org. Chem. 2016, 1772-1780.

(7) Aggarwal, N.; Kumar, R.; Dureja, P.; Khurana, J. M. Eur. J. Med. Chem. 2011, 46, 4089-4099.

(8) Bjorgaard, J. A.; Sifain, A. E.; Nelson, T.; Myers, T. W.; Veauthier, J. M.; Chavez, D. E.; Scharff, R. J.; Tretiak, S. J. Phys. Chem. A 2016, 120, 4455-4464.

(9) Sifain, A. E.; Tadesse, L. F.; Bjorgaard, J. A.; Chavez, D. E.; Prezhdo, O. V.; Scharff, R. J.; Tretiak, S. J. Chem. Phys. 2017, 146, 114308-114315.

(10) Shestakova, T. S.; Khalymbadzha, I. A.; Deev, S. L.; Eltsov, O. S.; Rusinov, V. L.; Shenkarev, Z. O.; Arseniev, A. S.; Chupakhin, O. N. Russ. Chem. Bull. 2011, 60, 729-732.

(11) Ulomskiy, E. N.; Medvedeva, N. R.; Shchepochkin, A. V.; Eltsov, O. S.; Rusinov, V. L.; Chupakhin, O. N.; Deeva, E. G.; Kiselev, O. I. Chem. Heterocyclic Comp. 2011, 47(9), 1164-1169.

(12) Sert-Ozgur, S.; Tel, B. C.; Somuncuoglu, E. I.; Kazkayasi, I.; Ertan, M.; Tozkoparan, B. Arch. Pharm. Chem. Life Sci. 2017, 350(7), e1700052.

(13) Iradyan, M. A.; Iradyan, N. S.; Minasyan, N. S.; Paronikyan, R. V.; Stepanyan, G. M. Pharm. Chem. J. 2016, 50, 10-15.

(14) Laus, G.; Wurst, K.; Schottenberger, H. Crystals 2014, 4, 509-515.

(15) Patel, B. D.; Bhadada, S. V.; Ghate, M. D. Bioorg. Chem. 2017, 72, 345-358.

(16) Ding, Q.; Zhang, L.; Zhang, H. Phosphorus Sulfur 2010, 185, 567-572.

(17) Aytac, S. P.; Tozkoparan, B.; Kaynak, F. B.; Aktay, G.; Goektas, O.; Uenuevar, S. Eur. J. Med. Chem. 2009, 44, 4528-4538.

(18) Kaynak, F. B.; Aytac, S. P.; Tozkoparan, B. Struct. Chem. 2010, 21, 795-802.

(19) Guendogdu, G.; Aytac, S. P.; Mueller, M.; Tozkoparan, B.; Kaynak, F. B. Powder Diffr. 2017, 32, 271-278.

(20) Mohamed, G. G.; Badawy, M. A.; Omar, M. M.; Nassar, M. M.; Kamel, A. B. Spectrochim. Acta, Part A 2010, 77, 773781.

(21) El-Barbary, A. A.; Hafiz, Y. A.; Abdel-Wahed, M. S. Nucleosides Nucleotides Nucleic acids 2010, 29, 55-71.

(22) LaPorte, M. G.; Wang, Z.; Colombo, R.; Garzan, A.; Peshkov, V. A.; Liang, M.; Johnston, P. A.; Schurdak, M. E.; Sen, M.; Camarco, D. P.; Hua, Y.; Pollock, N. I.; Lazo, J.S.; Grandis, J. R.; Wipf, P.; Huryn, D. M. Bioorg. Med. Chem. Lett. 2016, 26, 3581-3585.

(23) Dabholkar, V. V.; Parab, S. D. Organic Chemistry: an Indian Journal 2013, 9(10), 318-328.

(24) Gorbunov, E. B.; Ulomsky, E. N.; Voinkov, E. K.; Drokin, R. A.; Lyapustin, D. N.; Rusinov, G. L.; Rusinov, V. L.; Charushin, V. N.; Chupakhin, O. N. Synthesis 2018, 50, 4889-4896.

(25) Aiwale, S. T.; Dallavalle, S. Synthesis 2012, 44, 3055-3058.

(26) Deev, S. L.; Yasko, M. V.; Karpenko, I. L.; Korovina, A. N.; Khandazhinskaya, A. L.; Andronova, V. L.; Galegov, G. A.; Shestakova, T. S.; Ulomskii, E. N.; Rusinov, V. L.; Chupakhina, O. N. ; Kukhanovac, M. K. Bioorg. Chem. 2010, 38, 265-270. 
(27) Shestakova, T. S.; Luk'yanova, L. S.; Tseitler, T. A.; Deev, S. L.; Ulomskii, E. N.; Rusinov, V. L.; Kodess, M. I.; Chupakhina, O. N. Russ. Chem. Bull. 2008, 57, 2423-2430.

(28) Rusinov, V. L.; Chupakhin, O. N.; Deev, S. L.; Shestakova, T. S.; Ulomskii, E. N.; Rusinova, L. I.; Kiselev, O. I.; Deeva, E. G. Russ. Chem. Bull. Int. Ed. 2010, 59, 136-143.

(29) Deev, S. L.; Shestakova, T. S.; Rusinov, V. L.; Chupakhin, O. N.; Shashkov, A. S. Arkivoc 2008, 6, 196-207.

(30) Deev, S. L.; Paramonov, A. S.; Shestakova, T. S.; Khalymbadzha, I. A.; Chupakhin, O. N.; Subbotina, J. O.; Eltsov, O. S.; Slepukhin, P. A.; Rusinov, V. L.; Arseniev, A. S.; Shenkarev, Z. O. Beilstein J. Org. Chem. 2017, 13, 2535-2548.

(31) Bakherad, M.; Keley, V.; Amin, A. H. J. Chem. Res. 2008, 11, 633-634.

(32) Montazeri, N.; Heravi, M. M.; Tajfirooz, F.; Nazari, N. Monatsh. Chem. 2017, 148, 691-694.

(33) Ezema, B. E.; Akpanisi, L. E. S.; Ezema, C. G.; Onoabedje, A. E. J. Heterocyclic Chem. 2015, 52, 1411-1414.

(34) Dabholkar, V. V.; Naik, P.; Karekar, A.; Shinde, N. Der Pharma Chem. 2013, 5, 161-165.

(35) Deohate, P. P. Der Pharma Chem. 2012, 4, 2042-2046.

(36) Gomha, S. M.; Riyadh, S. M. Arkivoc 2009, 11, 58-68

(37) Abou-Elregal, M. K.; Mohamed, A. T. A.; Youssef, A. S. A.; Hemdan, M. M.; Samir, S. S.; Abou-Elmagd, W. S. I. Synthetic commun. 2018, 48, 2347-2357.

(38) Pastorin, G.; Federico, S.; Paoletta, S.; Corradino, M.; Cateni, F.; Cacciari, B.; Klotz, K.-N.; Gao, Z.-G.; Jacobson, K. A.; Spalluto, G.; Moro, S. Bioorg. Med. Chem. 2010, 18, 2524-2536.

(39) Federico, S.; Paoletta, S.; Cheong, S.-L.; Pastorin, G.; Cacciari, B.; Stragliotto, S.; Klotz, K. N.; Siegel, J.; Gao, Z.-G.; Jacobson, K. A.; Moro, S.; Spalluto, G. J. Med. Chem. 2011, 54, 877-889.

(40) Federico, S.; Ciancetta, A.; Porta, N.; Redenti, S.; Pastorin, G.; Cacciari, B.; Klotz, K. N.; Moro, S.; Spalluto, G. Eur. J. Med. Chem. 2016, 108, 529-541.

(41) Yang, X.; Michiels, T. J. M.; De Jong, C.; Soethoudt, M.; Dekker, N.; Gordon, E.; Van der Stelt, M.; Heitman, L. H.; Van der Es, D.; IJzerman, A. P. J. Med. Chem. 2018, 61, 7892-7901.

(42) Yang, X.; Dong, G.; Michiels, T. J. M.; Lenselink, E. B.; Heitman, L.; Louvel, J.; IJzerman, A. P. Purinergic Signalling 2017, $13,191-201$.

(43) Guo, D.; Xia, L.; Van Veldhoven, J. P. D.; Hazeu, M.; Mocking, T.; Brussee, J.; Ijzerman, A. P.; Heitman, L. H. ChemMedChem 2014, 9, 752-761

(44) Jorg, M.; May, L. T.; Mak, F. S.; Lee, K. C. K.; Miller, N. D.; Scammells, P. J.; Capuano, B. J. Med. Chem. 2015, 58, 718738.

(45) Jorg, M.; Shonberg, J.; Mak, F. S.; Miller, N. D.; Yuriev, E.; Scammells, P. J.; Capuano, B. Bioorg. Med. Chem. Lett. 2013, 23, 3427-3433.

(46) Dolzhenko, A. V.; Tan, B. J.; Chiu, G. N. C.; Chui, W. Keung; Dolzhenko, A. V. J. Fluorine Chem. 2015, 175, 68-72.

(47) Dolzhenko, A. V.; Pastorin, G.; Dolzhenko, A. V.; Chui, W. K. Tetrahedron Lett. 2008, 49, 7180-7183.

(48) Junaid, A.; Lim, F. P. L.; Zhou, Y. P.; Chui, W. K.; Dolzhenko, A. V. Molecules 2019, 24, 1453-1467.

(49) Ulomskiy, E. N.; Lyapustin, D. N.; Mukhin, E. M.; Voinkov, E. K.; Fedotov, V. V.; Savateev,

K. V.; Eltsov, O. S.; Gorbunov, E. B.; Drokin, R. A.; Rusinov, V. L.; Chupakhin, O. N. Chem. Heterocyclic Comp. 2018, 54, 6369.

(50) Rusinov, V. L.; Sapozhnikova, I. M.; Ulomskii, E. N.; Medvedeva, N. R.; Egorov, V. V.; Kiselev, O. I.; Deeva, E. G.; Vasin, A. V.; Chupakhin, O. N. Chem. Heterocyclic Comp. 2015, 51, 275-280.

(51) Nagarajan, G.; Anush, K. V. S.; Mahesh, A.; Spandana, B. L. V. M.; Saminathan, K.; Balasubramaniam, V.; Manjunath, K. S. Orient. J. Chem. 2008, 24, 1053-1055.

(52) Nagarajan, G.; Sriram, R.; Swathi, V.; Keerthi, V.; DineshKumar, L.; Saminathan, K.; Balasubramaniam, V.; Manjunath, K. S. Rasayan J. Chem. 2008, 1, 911-913.

(53) Ma, J.; Cheng, G.; Ju, X.; Yi, Z.; Zhu, S.; Zhang, Z.; Yang, H. Dalton Trans. 2018, 47, 14483-14490.

(54) El-Sayed, W. A.; Nassar, I. F.; Abdel-Rahman, A. A.-H. J. Heterocyclic. Chem. 2010, 48, 135-143.

(55) Bera, H.; Lee, M. H.; Sun, L.; Dolzhenko, A. V.; Chui, W. K. Bioorg. Chem. 2013, 50, 34-40.

(56) Bera, H.; Dolzhenko, A. V.; Sun, L.; Dutta Gupta, S.; Chui, W.-K. Chem. Biol. Drug Des. 2013, 82, 351-360.

(57) El-Wakil, M. H.; El-Yazbi, A. F.; Ashour, H. M. A.; Khalil, M. A.; Ismail, K. A.; Labouta, I. M. Bioorg. Chem. 2019, 90, $103089-103102$.

(58) Voinkov, E. K.; Ulomskiy, E. N.; Rusinov, V. L.; Chupakhin, O. N.; Gorbunov, E. B.; Drokin, R. A.; Fedotov, V. V. Chem. Heterocycl. Compd. 2015, 51, 1057-1060.

(59) El Hefny, E. A.; Elhag, F. A.; Swelam, S. A.; El Rashedy, A. A.; Soliman, A. E. M. J. Pharm. Res. 2014, 3, 79-87.

(60) Makki, M. S. T.; Rahman, R. M. A.; Ali, O. A. A. Int. J. Org. Chem. 2015, 5, 153-165.

(61) Al-Soud, Y. A.; Al-Masoudi, N. A.; Schuppler, T.; De Clercq, E.; Pannecouque, C. Nucleosides Nucleotides Nucleic Acids 2008, 27, 469-483. 
(62) Hu, G. Q.; Hou, L. L.; Yang, Y.; Yi, L.; Xie, S. Q.; Wang, G. Q.; Duan, N. N.; Chao, T. Y.; Wen, X. Y.; Huang, W. L. Chinese Chem. Lett. 2011, 22, 804-806.

(63) Ibrahim, Y. A.; Al-Awadi, N. A.; John, E. Tetrahedron 2008, 64, 10365-10374.

(64) Al-Etaibi, A.; John, E.; Ibrahim, M. R.; Al-Awadi, N. A.; Ibrahim, Y. A. Tetrahedron 2011, 67, 6259-6274.

(65) Hajri, A.; Marzouki, L. Russ. J. Org. Chem. 2019, 55, 1580-1583.

(66) Kulikov, A. S.; Epishina, M. A.; Fershtat, L. L.; Makhova, N. N. Chem. Heterocyclic Comp. 2018, 54, 669-672.

(67) Prakash, O.; Aneja, D. K.; Wadhwa, D.; Kumar, R.; Arora, S. J. Heterocyclic Chem. 2012, 49, 566-570.

(68) Jakhar, A.; Makrandi, J. K. J. Chem. Res. 2010, 34, 238-240.

(69) Jakhar, A.; Makrandi, J. K. Indian J. Chem. B. 2012, 51B, 313-317.

(70) Aggarwal, R.; Sharma, S.; Hooda, M.; Sanz, D.; Claramunt, R. M.; Twamley, B.; Rozas, I. Tetrahedron 2019, 75, 130728130739.

(71) Taha, M. A. M. Phosphorus Sulfur 2008, 183, 2525-2533.

(72) Karthikeyan, M. S.; Holla, B. S.; Shenoy, S. Monatsh. Chem. 2008, 139, 707-716.

(73) El Shehry, M. F.; Swellem, R. H.; Abu-Bakr, Sh. M.; El-Telbani, E. M. Eur. J. Med. Chem. 2010, 45, 4783-4787.

(74) Chidananda, N.; Poojary, B.; Sumangala, V.; Lobo, P. L. J. Applicable Chem. 2013, 2, 1080-1101.

(75) Prakash, O.; Sharma, N. Arkivoc 2007, 16, 65-72.

(76) El-Sherief, H. A. H.; Hozien, Z. A.; El-Mahdy, A. F. M.; Sarhan, A. A. O. Synthesis 2010, 15, 2636-2642.

(77) Harisha, R. S.; Hosamani, K. M.; Keri, R. S. Arch. Pharm. 2009, 342, 412-419.

(78) Almajan, G. L.; Barbuceanu, S.-F.; Saramet, I.; Draghici, C. Eur. J. Med. Chem. 2010, 45, 3191-3195.

(79) Al-Soud, Y. A.; Al-Masoudi, N. A.; Loddo, R.; La Colla, P. Arch. Pharm. 2008, 341, 365-369.

(80) Dabholkar, V. V.; Parab, S. D. Indian J. Pharm. Sci. 2011, 73, 199-207.

(81) Nami, N.; Hosseinzadeh, M.; Rahimi, E. Phosphorus Sulfur 2008, 183, 2438-2442.

(82) Shah, T. A.; Ahmad, Z.; Mir, N. A.; Muneer, M.; Rath, N. P.; Ahmad, M. RSC Adv. 2015, 5, 107931-107937.

(83) Dabholkar, V. V.; Patil, S. R.; Pandey, R. V. J. Heterocyclic Chem. 2013, 50, 403-407.

(84) Srinivas, V.; Rao, V. R. J. Sulfur Chem. 2011, 32, 99-104.

(85) Dabholkar, V. V.; Parab, S. D. Indian J. Chem. B 2007, 46B, 344-348.

(86) Raeiat, S. H.; Tahghighi, A. Chem. Sci. Trans. 2014, 3, 1043-1046,

(87) Shiradkar, M. R.; Padhalingappa, M. B.; Bhetalabhotala, S.; Akula, K. C.; Tupe, D. A.; Pinninti, R. R.; Thummanagoti, S. Bioorg. Med. Chem. 2007, 15, 6397-6406.

(88) Hassan, A. Y.; Sarg, M. T.; El Deeb, M. A.; Bayoumi, A. H.; El Rabeb, S. I. J. Heterocyclic Chem. 2018, 55, 1426-1443.

(89) Srivastava, V.; Singh, P. K.; Singh, P. P. Chem. Heterocyclic Comp. 2014, 50, 573-578.

(90) Shiradkar, M. R.; Padhalingappa, M. B.; Bhetalabhotala, S.; Akula, K. C.; Tupe, D. A.; Pinninti, R. R.; Thummanagoti, S. Bioorg. Med. Chem. 2007, 15, 6397-6406.

(91) Kidwai, M.; Mothsra, P. J. Sulfur Chem. 2007, 28, 149-153.

(92) Karthikeyan, M. S.; Holla, B. S.; Kumari, N. S. Eur. J. Med. Chem. 2008, 43, 309-314.

(93) Khalafy, J.; Mohammadlou, M.; Mahmoody, M.; Salami, F.; Poursattar Marjani, A. Tetrahedron Lett. 2015, 56, 15281530.

(94) Motamedi, R.; Heravi, M. M.; Bamoharram, F. F.; Haeri, A. J. Heterocyclic Chem. 2008, 45, 1211-1214.

(95) Asghari, T.; Bakavoli, M.; Rahimizadeh, M.; Eshghi, H.; Saberi, S.; Karimian, A.; Hadizadeh, F.; Ghandadi, M. Chem. Biol. Drug Des. 2015, 85, 216-224.

(96) Asghari, T.; Bakavoli, M.; Eshghi, H.; Saberi, S.; Ebrahimpour, Z. J. Heterocyclic Chem. 2016, 53, 403-407.

(97) Afrough, T.; Bakavoli, M.; Eshghi, H. J. Chem. Res. 2017, 41, 376-379.

(98) Ebrahimpour, Z.; Shiri, A.; Bakavoli, M.; Seyedi, S. M.; Asghari, T.; Mague, J. J. Heterocyclic Chem. 2017, 54, $235-241$.

(99) Mekky, A. E. M.; Elwahy, A. H. M. J. Heterocyclic Chem. 2014, 51, E34-E41.

(100) Abdou, W. M.; Ganoub, N. A.; Sabry, E. Acta Pharmaceutica 2014, 64, 267-284.

(101) Dabholkar, V. V.; Ansari, F. Y. Phosphorus Sulfur 2010, 185, 298-305.

(102) Vaarla, K.; Pavurala, S.; Arandkar, V.; Vedula, R. R.; Toopurani, M. K. ChemistrySelect 2019, 4, 5828-5834.

(103) Chunduru, V. S. R.; Rajeswar Rao, V. J. Heterocyclic Chem. 2013, 50, 159-163.

(104) Koksal, M.; Ozkan, I.; Yarim, M.; Bilge, S. S.; Bozkurt, A.; Erol, D. D. Rev. Chim. (Bucharest, Rom.) 2011, 62, $1069-1072$.

(105) Patrao, P.; Khader, A. M. A.; Kalluraya, B.; Vinayachandra J. Chem. Pharm. Res. 2013, 5, 326-334.

(106) Abd El-Salam, O. I.; Amr, A. E.; Abu-Bakr, S. M.; Bassyouni, F. A.; Abdullah, M. Org. Chem. Ind. J. 2013, 9, 385-396.

(107) Halawa, A. H.; Abd El-Hameed Hassan, A.; El-Nassag, M. A.; Abd El-All, M. M.; Abd El-Jaleel, G. A. E.-R.; Eliwa, E. M.; Bedair, A. H. Eur. J. Chem. 2014, 5, 111-121.

(108) Khalil, N. A.; Kamal, A. M.; Emam, S. H. Biol. Pharm. Bull. 2015, 38, 763-773. 
(109) Redenti, S.; Marcovich, I.; De Vita, T.; Perez, C.; De Zorzi, R.; Demitri, N.; Perez, D. I.; Bottegoni, G.; Bisignano, P.; Bissaro, M.; Moro, S.; Martinez, A.; Storici, P.; Spalluto, G.; Cavalli, A.; Federico, S. ChemMedChem 2019, 14, 310-314.

(110) Zhang, L.-Y.; Zhang, C.; Wang, T.; Shi, Y.-L.; Ban, M.-T.; Cui, D.-M. J. Org. Chem. 2019, 84, 536-543.

(111) Bakharev, V. V.; Parfenov, V. E.; Ul'yankina, I. V.; Zavodskaya, A. V.; Selezneva, E. V.; Gidaspov, A. A.; Eltsov, O. S.; Slepukhin, P. A. Tetrahedron 2014, 70, 6825-6830.

(112) Bakharev, V. V.; Parfenov, V. E.; Ul'yankina, I. V.; Zavodskaya, A. V.; Gidaspov, A. A.; Slepukhin, P. A. Chem. Heterocycl. Compd. 2015, 51, 1014-1018.

(113) Zavodskaya, A. V.; Bakharev, V. V.; Parfenov, V. E.; Gidaspov, A. A.; Slepukhin, P. A.; Isenov, M. L.; Eltsov, O. S. Tetrahedron Lett. 2015, 56, 1103-1106.

(114) Golovina, O. V.; Bakharev, V. V.; Golovin, E. V.; Parfenov, V. E.; Slepukhin, P. A. Tetrahedron Lett. 2013, 54, 38583861.

(115) Mishra, A. R.; Rai, P. K.; Singh, C. R. J. Ultra Chem. 2012, 8, 211-217.

(116) Anekal, D. P.; Biradar, J. S. J. Chem. Pharm. Res. 2013, 5, 75-85.

(117) Basedia, D. K.; Shrivastava, B.; Dubey, B. K.; Sharma, P. Int. J. Drug Deliv. 2013, 5, 379-388.

(118) Basedia, D. K.; Shrivastava, B.; Dubey, B. K.; Sharma, P. Int. J. Biomed. Res. 2014, 5, 13-18.

(119) Moradivalikboni, R.; Heidarnezhad, Z.; Hozhiboev, Y.; Rahmanov, R.; Rahmatuloeva, O. Chem. Sci. Trans. 2014, 3, 1019-1022.

(120) Kalinin, D. V.; Kalinina, S. A.; Dolzhenko, A. V. Heterocycles 2013, 87, 147-154.

(121) Dolzhenko, A. V.; Kalinina, S. A.; Kalinin, D. V. RSC Adv. 2013, 3, 15850-15855.

(122) Kalinina, S. A.; Kalinin, D. V.; Dolzhenko, A. V. Tetrahedron Lett. 2013, 54, 5537-5540.

(123) Jorg, M.; Agostino, M.; Yuriev, E.; Mak, F. S.; Miller, N. D.; White, J. M.; Scammells, P. J.; Capuano, B. Struct. Chem. 2013, 24, 1241-1251.

(124) Dolzhenko, A. V.; Tan, B. J.; Dolzhenko, A. V.; Chiu, G. N. C.; Chui, W. K. J. Fluorine Chem. 2008, 129, 429-434.

(125) Hassan, A. Y.; Sarg, M. T.; Bayoumi, A. H.; El-Deeb, M. A. J. Heterocyclic Chem. 2018, 55, 1450-1478.

(126) Dolzhenko, A. V.; Dolzhenko, A. V.; Chui, W.-K. Heterocycles 2007, 71, 429-436.

(127) Demidchuk, B. A.; Brovarets, V. S.; Chernega, A. N.; Howard, J. A. K.; Vasilenko, A. N.; Turov, A. V.; Drach, B. S. Russ. J. Org. Chem. 2007, 77, 474-481.

(128) Kalinin, D. V.; Kalinina, S. A.; Dolzhenko, A. V. Heterocycles 2012, 85, 2515-2522.

(129) Wang, M.; Meng, Y.; Wei, W.; Wu, J.; Yu, W.; Chang, J. Adv. Synth. Catal. 2018, 360, 86-92.

(130) Hoang, G. L.; Soeholm Halskov, K.; Ellman, J. J. Org. Chem. 2018, 83, 9522-9529.

(131) Zamigailo, L. L.; Petrova, O. N.; Shirobokova, M. G.; Lipson, V. V. Russ. J. Org. Chem. 2013, 49, 288-293.

(132) Khankischpur, M.; Hansen, F. K.; Geffken, D. Synthesis 2010, 10, 1645-1648.

(133) Bera, H.; Tan, Bee J.; Sun, L.; Dolzhenko, A. V.; Chui, W.-K.; Chiu, G. N. C. Eur. J. Med. Chem. 2013, 67, 325-334.

(134) Bera, H.; Chui, W.-K.; Dutta Gup, S.; Dolzhenko, A. V.; Sun, L. Med. Chem. Res. 2013, 22, 6010-6021.

(135) Hajri, A.; Marzouki, L. Russ. J. Org. Chem. 2019, 55, 1394-1398.

(136) Abdel-Rahman, R. M.; Abdel-Monem, W. R. Indian J. Chem. B 2007, 46B, 838-846.

(137) Hassanin, H. M.; El-Edfawy, S. M. Heterocycles 2012, 85, 2421-2436.

(138) Zhan, Z.; Peng, X.; Liu, Q.; Chen, F.; Ji, Y.; Yao, S.; Xi, Y.; Lin, Y.; Chen,T.; Xu, Y.; Ai, J.; Geng, M.; Duan, W. Eur. J. Med. Chem. 2016, 116, 239-251.

(139) Chen, F.; Wang, Y.; Ai, J.; Zhan, Z.; Lv, Y.; Liang, Z.; Luo, C.; Mei, D.; Geng, M.; Duan, W. ChemMedChem 2012, 7, $1276-$ 1285.

(140) Misra, A. R.; Tripathi, M. M.; Shahma, A. Orient. J. Chem. 2011, 27, 783-788.

(141) Mironovich, L. M.; Ivanov, M. A. Russ. J. Org. Chem. 2010, 46, 1750-1751.

(142) Hamama, W. S.; El-Bana, G. G.; Shaaban, S.; Zoorob, H. H. J. Heterocyclic Chem. 2018, 55, 971-982.

(143) El Massry, A. M.; Asal, A. M.; Khattab, S. N.; Haiba, N. S.; Awney, H. A.; Helmy, M.; Langer, V.; Amer, A. Bioorg. Med. Chem. 2012, 20, 2624-2637.

(144) Vas'kevich, R. I.; Savitskii, P. V.; Rusanov, E. B.; Staninets, V. I. Russ. J. Org. Chem. 2010, 46, 1682-1686

(145) Nami, N.; Hosseinzadeh, M.; Nami, N.; Haghdadi, M. Phosphorus Sulfur 2009, 184, 2846-2855.

(146) Pundeer, R.; Kiran, V. Organic Chemistry: an Indian Journal 2016, 12(5), 106-114.

(147) Azimi, S.; Soheilizad, M.; Zonouzi, A.; Mahdavib, M. Arkivoc 2017, 5, 293-300.

(148) Hamama, W. S.; El-Bana, G. G.; Mostafa, M. El-H.; Zoorob, H. H. J. Heterocyclic Chem. 2019, 56, 239-250.

(149) Hamama, W. S.; El-Bana, G. G.; Shaaban, S.; Habib, O. M. O.; Zoorob, H. H. J. Heterocyclic Chem. 2017, 54, 422-428.

(150) Saad, H. A.; Moustafa, A. H. Molecules 2011, 16, 5682-5700.

(151) Castelino, P. A.; Naik, P.; Dasappa, J. P.; Sujayraj, R. S.; Sharath Chandra, K.; Chaluvaiah, K.; Nair, R.; Sandya Kumari, M. V.; Kalthur, G.; Adiga, S. K. Eur. J. Med. Chem. 2014, 84, 194-199. 
(152) Gurbuz, D.; Tanyolac, S. J. Serb. Chem. Soc. 2012, 77, 867-871.

(153) El-Barbary, A. A.; Hafiz, Y. A.; Abdel-Wahed, M. S. J. Heterocyclic Chem. 2011, 48, 639-644.

(154) El-Barbary, A. A.; El-Shehawy, A. A.; Abdo, N. I. Phosphorus Sulfur 2014, 189, 400-409.

(155) Ashok, M.; Holla, B. S. Phosphorus Sulfur 2007, 182, 981-991.

(156) El-Telbani, E. M.; Swellem, R. H.; Nawwar, G. A. M. Russ. J. Org. Chem. 2007, 43, 1815-1820.

(157) Saad, H. A.; Youssef, M. M.; Mosselhi, M. A. Molecules 2011, 16, 4937-4957.

(158) Adhami, F.; Nabilzadeh, N.; Emmerling, F.; Ghiasi, M.; Heravi, M. M. J. Serb. Chem. Soc. 2012, 77, 1211-1222.

(159) Mohebat, R.; Tabatabaee, M.; Bafghi, M. A. J. Sulfur Chem. 2013, 34, 377-382.

(160) Amin, M. A.; Saad, H. A. Curr. Org. Synth. 2016, 13, 116-125.

(161) Kumar, M.; Kumar, V.; Beniwal, V. Int. J. Pharm. Pharm. Sci. 2014, 6, 376-383.

(162) Upadhyay, K.; Manvar, A.; Loddo, R.; La Colla, P.; Virsodiya, V.; Trivedi, J.; Chaniyara, R.; Shah, A. Med. Chem. Res. 2013, 22, 3675-3686.

(163) Hassan, S. Y. Molecules 2013, 18, 2683-2711.

(164) Salih, N. A. Turk. J. Chem. 2008, 32, 229-235.

(165) Makki, M. S. T.; Rahman, R. M. A.; Ali, O. A. A. Journal of Chemistry and Chemical Engineering 2015, 9, $162-175$.

(166) Mabkhot, Y. N.; Kaal, Nahed A.; Alterary, S.; Al-Showiman, S. S.; Farghaly,T. A.; Mubarak, M. S. Chemistry Central Journal 2017, 11, 75-86.

(167) Abdelhamid, A. O.; Fahmi, A. A.; Baaiu, B. S. J. Heterocyclic Chem. 2016, 53, 1917-1927.

(168) Shawali, A. S.; Haboub, A. J. M. J. Chem. Res. 2011, 35, 341-345.

(169) Shaaban, M. R.; Saleh, T. S.; Farag, A. M. Heterocycles 2009, 78, 699-706.

(170) Abdel-Aziz, H. A.; Hamdy, N.I A.; Farag, A. M.; Fakhr, I. M. I. J. Heterocyclic Chem. 2008, 45, 1033-1037.

(171) Sanad, S. M. H.; Mekky, A. E. M. J. Heterocyclic Chem. 2018, 55, 836-843.

(172) Mabkhot, Y. N.; Alatibi, F.; El-Sayed, N. N. E.; Kheder, N. A.; Al-Showiman, S. S. Molecules 2016, 21, 1036-1036.

(173) Abdelhamid, A. O.; Fahmi, A. A.; Halim, K. N. M. Synthetic Commun. 2013, 43, 1101-1126.

(174) Abdelhamid, A. O.; Fahmi, A. A.; Al-Bahlol Ali, A. Int. J. Adv. Res. 2013, 1, 627-644.

(175) Abdelhamid, A. O.; Shokry, S. A.; Tawfiek, S. M. J. Heterocyclic Chem. 2012, 49, 116-124.

(176) Riyadh, S. M. Molecules 2011, 16, 1834-1853.

(177) Shawali, A. S.; Farghaly, T. A.; Aldahshoury, A. I. R. Arkivoc 2010, 9, 19-30.

(178) Abbas, E. M. H.; Farghaly, T. A. Monatsh. Chem. 2010, 141, 661-667.

(179) Abdelhamid, A. O.; Gomha, S. M.; El-Enany, W. A. M. A. J. Heterocyclic Chem. 2019, 56, 426-433.

(180) Mohamed, Mahmoud A. J. Heterocycl. Chem. 2010, 47, 517-523.

(181) Khalil, M. A.; Raslan, M. A.; Sayed, S. M. J. Heterocyclic Chem. 2017, 54, 1845-1853.

(182) Gomha, S. M.; Shawali, A. S.; Abdelhamid, A. O. Turk. J. Chem. 2014, 38, 865-879.

(183) Abdelhamid, A. O.; Fahmi, A. A.; Alsheflo, A. A. M. Eur. J. Chem. 2012, 3, 129-137.

(184) Farghaly, T. A.; Abdalla, M. M. Bioorg. Med. Chem. 2009, 17, 8012-8019.

(185) Kumar, D.; Imler, G. H.; Parrish, D. A.; Shreeve, J. M. Chem. Eur. J. 2017, 23, 1743-1747.

(186) Piercey, D. G.; Chavez, D. E.; Scott, B. L.; Imler, G. H.; Parrish, D. A. Angew. Chem. Int. Ed. 2016, 55, 15315-15318.

(187) Raslan, M. A.; Omran, O. A. J. Heterocyclic Chem. 2016, 53, 1121-1128.

(188) Gomha, S. M.; Khalil, K. D.; El-Zanaty, A. M.; Riyadh, S. M. Heterocycles 2013, 87, 1109-1120.

(189) Khalil, M. A.; Sayed, S. M.; Raslan, M. A. J. Korean Chem. Soc. 2013, 57, 612-617.

(190) Gomha, S. M.; Abdel-Aziz, H. A. B. Korean Chem. Soc. 2012, 33, 2985-2990.

(191) Fadda, A. A.; Abd El Salam, M.; Tawfik, E. H.; Anwar, E. M.; Etman, H. A. RSC Adv. 2017, 7, 39773-39785.

(192) Farag, A. M.; Kheder, N. A.; Dawood, K. M. Int. J. Modern Org. Chem. 2013, 2, 26-39.

(193) Riyadh, S. M.; Kheder, N. A.; Asiry, A. M. Monatsh. Chem. 2013, 144, 1559-1567.

(194) Abdelall, M. M. Phosphorus Sulfur 2009, 184, 2208-2226.

(195) Dawood, Kamal M.; Moghazy, Salwa M.; Farag, Ahmad M. Arab. J. Chem. 2017, 10, S2782-S2789.

(196) El Hefny, E. A.; Elhag, F. A.; Swelam, S. A.; El Rashedy, A. A.; Soliman, A. E. M. Journal of Pharma Research 2014, 3, 7987.

(197) Darweesh, A. F.; Mekky, A. E. M.; Salman, A. A.; Farag, A. M. Heterocycles 2014, 89, 113-125.

(198) Tao, Z.; Gomha, S. M.; Badrey, M. G.; El-Idreesy, T. T.; Eldebss, T. M. A. J. Heterocyclic Chem. 2018, 55, 2408-2416.

(199) Mawlood, M. N.; Potapov, A. Y.; Vandyshev, D. Y.; Shikhaliev, K. S.; Potapov, M., A.; Ledenyova, I. V.; Kosheleva, E. A. Chem. Heterocycl. Comp. 2019, 55, 1075-1079.

(200) Rusinov, V. L.; Sapozhnikova, I. M.; Bliznik, A. M.; Chupakhin, O. N.; Charushin, V. N.; Spasov, A. A.; Vassiliev, P. M.; Kuznetsova, V. A.; Rashchenko, A. I.; Babkov, D. A. Arch. Pharm. Chem. Life Sci. 2017, 350, e1600361-e1600376.

(201) Shchegol'kov, E. V.; Makhaeva, G. F.; Boltneva, N. P.; Lushchekina, S. V.; Serebryakova, O. G.; Rudakova, E. V.; Kovaleva, N. V.; Burgart, Y. V.; Saloutin, V. I.; Chupakhin, O. N.; Bachurin, S. O.; Richardson, R. J. Bioorg. Med. Chem. 2017, 25, 3997-4007. 
(202) Shchegol'kov, E. V.; Khudina, O. G.; Ivanova, A. E.; Burgart, Y. V.; Sadchikova, E. V.; Kravchenko, M. A.; Saloutin, V. I. Pharm. Chem. J. 2014, 48, 383-386.

(203) Shchegol'kov, E. V.; Sadchikova, E. V.; Burgart, Y. V.; Saloutin, V. I. Russ. Chem. Bull. 2008, 57, 612-616.

(204) Voinkov, E. K.; Ulomskiy, E. N.; Rusinov, V. L.; Drokin, R. A.; Fedotov, V. V.; Gorbunov, E. B. Mendeleev Commun. 2017, $27,285-286$.

(205) Shestakova, T. S.; Deev, S. L.; Ulomskii, E. N.; Rusinov, V. L.; Kodess, M. I.; Chupakhin, O. N. Arkivoc 2008, 4, 69-78.

(206) Abd Elal, S. N. J. Chem. Pharm. Res. 2013, 5(6), 168-177.

(207) Chen, W.-B.; Li, Z.-X.; Yu, X.-W.; Yang, M.; Qiu, Y.-X.; Dong, W. New J. Chem. 2015, 39, 1222-1227.

(208) Shaaban, M. R. J. Fluorine Chem. 2008, 129, 1156-1161.

(209) Maksimov, E. A.; Mayorova, O. A.; Yegorova, A. Y. Russ. J. Org. Chem. 2015, 51, 1305-1307.

(210) El Rady, E. A. J. Heterocyclic Chem. 2013, 50, E228-E233.

(211) Taha, M. A. M.; El-Badry, S. M. Monatsh. Chem. 2008, 139, 1261-1267.

(212) Khalifa, M. M. A. Orient. J. Chem. 2008, 24, 825-830.

(213) Kadry, A. M.; Al-Mahmoudy, A. M. Chemistry \& Biology Interface 2011, 1, 44-58.

(214) Bayrak, H.; Demirbas, A.; Demirbas, N.; Karaoglu, S. A. Eur. J. Med. Chem. 2010, 45, 4726-4732.

(215) El Azab, I. H.; El Rady, E. A. J. Heterocyclic Chem. 2012, 49, 135-148.

(216) Cai, S. X.; Zhang, H.-Z.; Kemnitzer, W. E.; Drewe, J. A.; Sirisoma, N. S. PCT Int. Appl. WO2009094205 A2, 2009.

(217) Cai, S. X.; Drewe, J. A.; Zhang, H.-Z.; Kasibhatla, S.; Claassen, G.; Sirisoma, N. S.; Kemnitzer, W. E. PCT Int. Appl. WO 2008011045 A2, 2008.

(218) Xiao, C.; Wang, Y.; Li, Z.; Deng, Q.; Liu, Y.; Guan, Y.; Meng, J.; Wang, J.; Zhang, G.; Zhu, M.; Wang, B. Faming Zhuanli Shenqing CN 109293681 A, 2019.

(219) Huryn, D. M.; Wipf, P.; Grandis, J. R.; Laporte, M. G.; Johnston, P. A.; Schurdak, M. E.; Colombo, R. PCT Int. Appl. WO 2016115455 A2, 2016.

(220) Thomas, C. J.; Xia, M.; Skoumbourdis, A. P.; Leclair, C. A.; Huang, R.; Walsh, M. J. U.S. Pat. Appl. Publ. US 20110112079 A1, 2011.

(221) Kiessling, L. L.; Winton, V. J.; Justen, A. M. U.S. Pat. Appl. Publ. US 20170258805 A1, 2017.

(222) Zhuo, J.; Zhang, C.; Xu, M.; Qian, D.-Q.; Yao, W.; Jalluri, R. K. U.S. Pat. Appl. Publ. US 20080039457 A1, 2008.

(223) Duan, W.; Geng, M.; Chen, F.; Ai, J.; Chen, Y.; Zhan, Z.; Lv, Y.; Wang, Y.; Ding, J. PCT Int. Appl. WO 2012075683 A1, 2012.

(224) Mitchell, G.; Curley, L. H. PCT Int. Appl. WO 2016135196 A1, 2016.

(225) Karpenko, I.; Deev, S.; Kiselev, O.; Charushin, V.; Rusinov, V.; Ulomsky, E.; Deeva, E.; Yanvarev, D.; Ivanov, A.; Smirnova, O.; Kochetkov, S.; Chupakhin, O.; Kukhanova, M. Antimicrob. Agents Chemother. 2010, 54, 2017-2022.

(226) Chupakhin, O. N.; Rusinov, V. L.; Ulomskii, E. N.; Savateev, K. V.; Borisov, S. S.; Novikova, N. A.; Loginova, S. Y.; Borisevich, S. V.; Sorokin, P. V. Russ. RU 2536874 C1, 2014.

(227) Kiselev, O. I.; Rusinov, V.; Ulomsky, E.; Medvedeva, N.; Sapozhnikova, I.; Charushin, V.; Chupakhin, O.; Danilenko, D.; Deeva, E. PCT Int. Appl. WO 2018035509 A2, 2018.

(228) Klenov, M. S.; Anikin, O. V.; Leonov, N. E.; Churakov, A. M.; Tartakovskii, V. A. Russ. RU 2697843 C1, 2019.

(229) Aksuner, N. Sens. Actuators B Chem. 2011, 157, 162-168.

\section{Change History}

June 2020. A. Claraz uptaded the abstract, Figure 1, the entire text of this chapter, the references section and added Figures 2-13, Schemes 1-105 and Tables 1-6. 